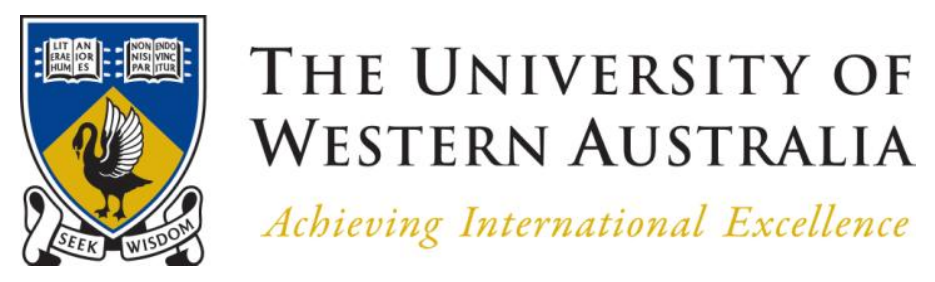

\title{
The Determinants of Effectiveness of Sporting Associations in Singapore
}

\author{
Angela Koh-Tan \\ BA Hons (English), Grad Dip (Communication Studies), \\ M Sc (International Marketing), M Sc (Recreation Management), \\ Master of Management Research
}

This thesis is presented for the degree of Doctor of Business Administration of The University of Western Australia

Business School

December 2008 


\begin{abstract}
This study explores the different perceptions of effectiveness among four constituent groups of stakeholders in Singapore national sports associations. The four groups are athletes, board members, coaches, and secretariat staff. The study applies a qualitative research methodology. It uses a focus group and semi-structured interviews across 25 national sports associations. The qualitative data is analysed using NVivo software to organise the data into general themes and as an aid in breaking the data into sub-themes.
\end{abstract}

The four constituent groups discuss multi-faceted perceptions of effectiveness by providing varying interpretations, meanings, inferences, and relational issues depending on the roles they hold. While confirming multi-dimensional perceptions of effectiveness, the study uncovers three determinants of effectiveness that are not cited directly in the literature: communication, athlete management, and commitment and organisation of the management committee.

The study suggests major tensions in terms of organisational and personal athlete outcomes. It also highlights the paramount importance of funding, both for sports development and the organisation's personnel staffing and systems.

There is a symbiotic relationship between internal and external perceptions of influences on effective performance. The findings suggest constituent groups' perceptions of the Singapore Sports Council influence their perceptions of effectiveness within their own associations. In turn, SSC's policy making and organisational behaviour are perceived to affect how the effectiveness of constituent groups is evaluated as well as their scope for action within their organisations.

The implications for sports administrators and policy makers include the need for better communications between and within constituent groups, quality leadership (with decisions based on sports management and sports science knowledge), a more equitable distribution of funds, an internal environment of trust and empowerment balanced by objectivism, and an external environment of realism balanced by recognition of the need for continual performance improvement.

The Determinants of Effectiveness of Sporting Associations in Singapore 


\section{Table of Contents}

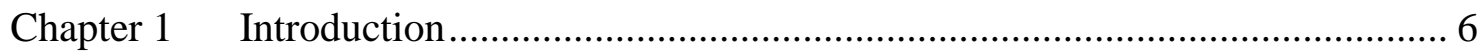

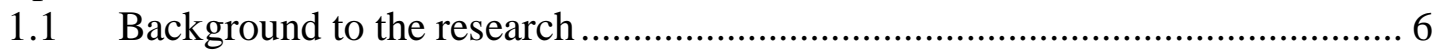

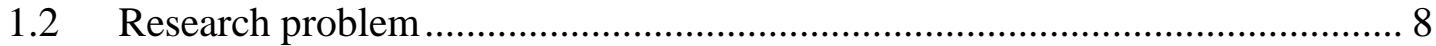

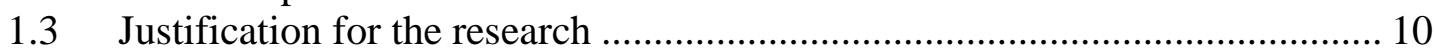

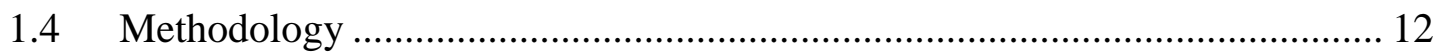

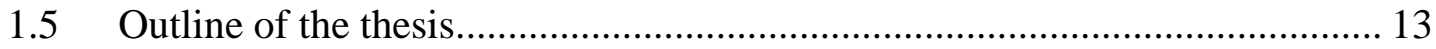

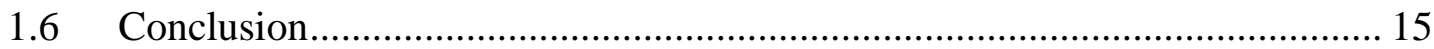

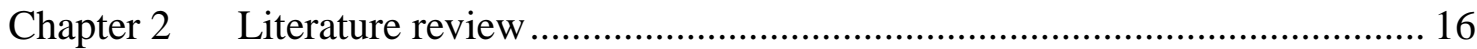

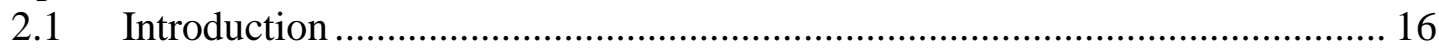

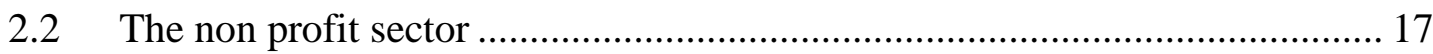

2.3 Institutional governance in the non profit sector........................................... 25

2.4 Defining and measuring effectiveness in non profit organisations .................. 31

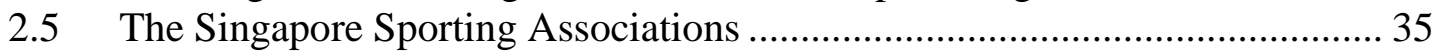

2.6 Theoretical frameworks of organisational effectiveness.................................. 40

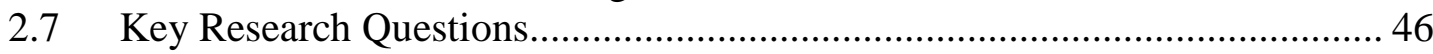

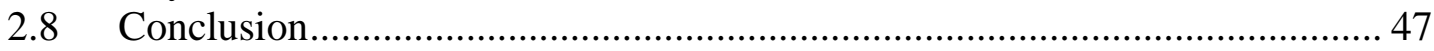

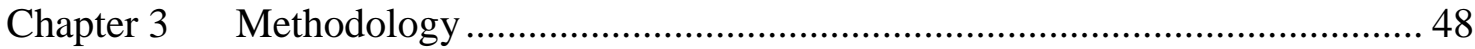

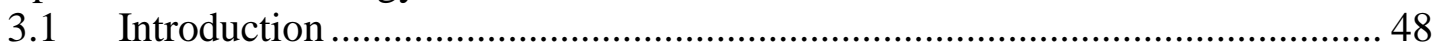

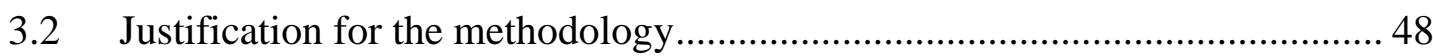

3.3 The unit of analysis and subjects or sources of data …….............................. 51

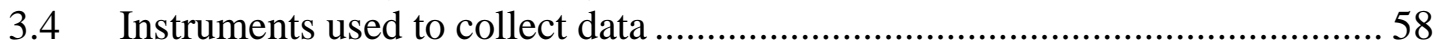

3.5 Administration of instruments or procedures................................................. 73

3.6 Limitations of the methodology ………………....................................... 74

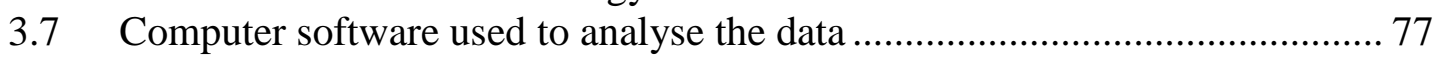

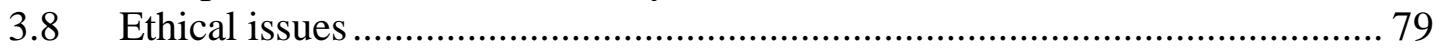

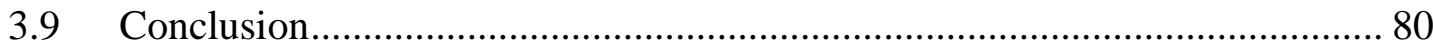

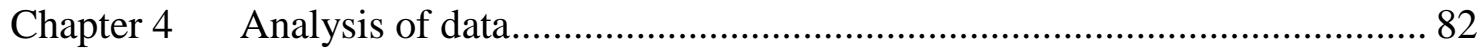

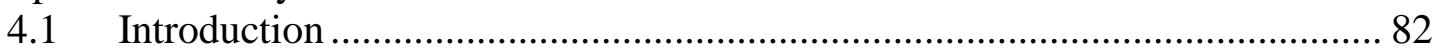

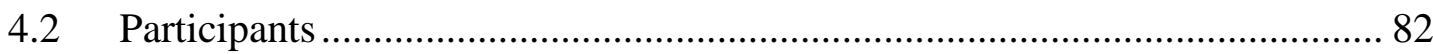

4.3 Patterns of data for each key research question ........................................... 87

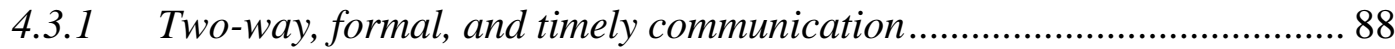

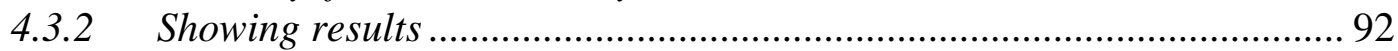

4.3.3 Good financial management practices …………................................ 96

4.3.4 Athlete management .............................................................................98

4.3.5 Organisational processes and procedures............................................ 100

4.3.6 Commitment and organisation of the management committee ............... 104

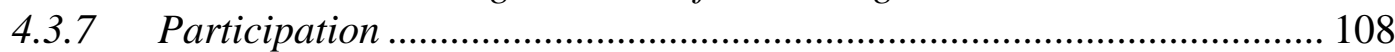

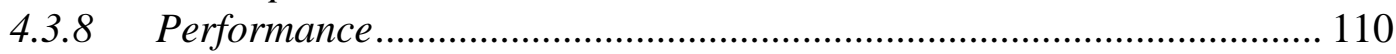

4.3.9 Balancing outcomes with continual process indicators......................... 112

4.3.10 Development of athletes' potential ................................................... 115

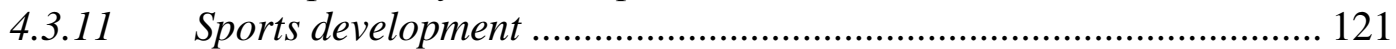

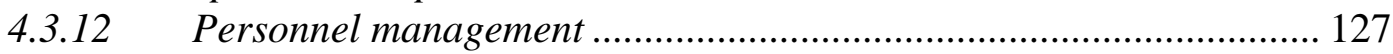

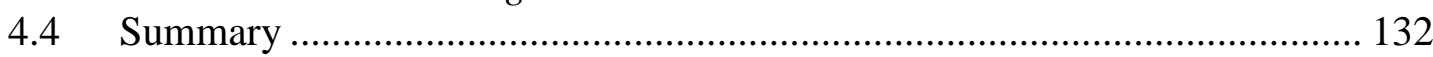

Chapter 5 Discussion and Conclusion ................................................................. 133

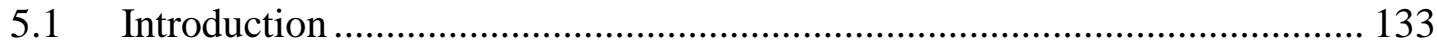

The Determinants of Effectiveness of Sporting Associations in Singapore 3 of 204 


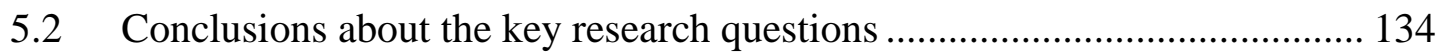

5.2.1 Conclusions from the findings on perceptions of effectiveness ............. 134

5.2.2 Conclusions from the findings on criteria of effectiveness ..................... 143

5.2.3 Conclusions from the findings on funding, outcomes and effectiveness 147

5.3 Conclusions about the research problem..................................................... 150

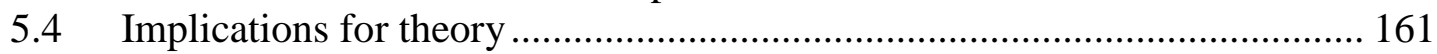

5.5 Implications for policy and sports management practice ............................... 164

5.5.1 Implications for constituent groups …………...................................... 164

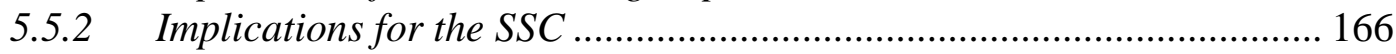

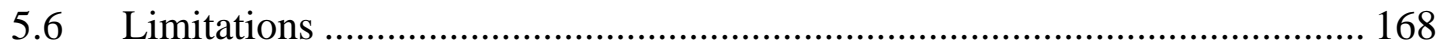

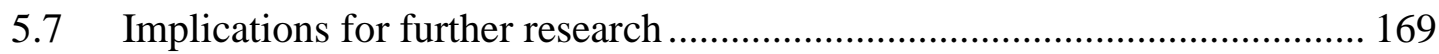

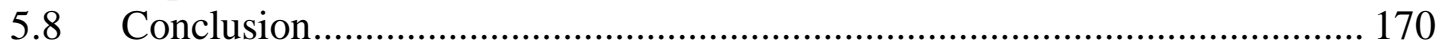

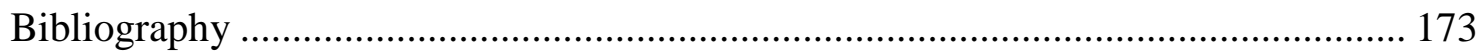

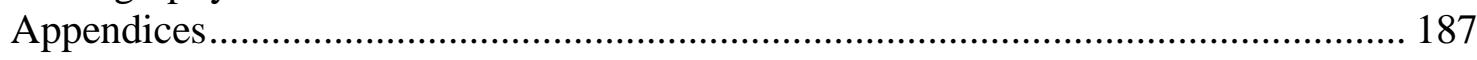




\section{Acknowledgements}

I thank God who answers in His own way, and makes everything possible.

Next, I want to thank my loved ones who have been totally supportive of my academic endeavours throughout the years: my husband, Stephen, who has taken care of the family and their needs to leave me time for my research; my mother, Patricia, who has lent unstinting and unspoken assistance through her actions; and my three children, Amanda Fay, Elliot Noah, and Ethan Neal who are the prime motivations for my perseverance.

I have been fortunate too, to have Professor David Plowman as my supervisor. He has been most patient and helpful at the various stages of a long but rewarding research study. His guidance and invaluable advice have been timely and his feedback is always prompt.

I owe most to my respondents for this research. The study was possible because athletes, coaches, secretariat staff, and board members took time off from training, coaching, work, and family, to meet up with me willingly. It is never easy to trust an interviewer who is a total stranger much less to share one's thoughts truthfully. For the respondents who overcame that and provided invaluable qualitative data to me, I am indebted and grateful.

Inspired by the human spirit in every individual met personally, spoken to on the phone, or communicated via email, I would have liked to thank and acknowledge each one of them here, if it were not for confidentiality reasons. These diverse individuals share a common denominator, a personal story behind their involvement in sport. Their openness encouraged me greatly during the journey and compelled me to represent their views fairly and objectively.

Last, but not least, I would like to acknowledge my classmates from the DBA Singapore class of January 2004, Simon, Santi, Sharon, Gan, and other friends made along the quest, Raymond and Stefano, for their kind encouragement at crucial points of the undertaking. To all others who have provided moral support through words or deeds during the exploration, I am deeply appreciative and will continue to pass it forward. 


\section{Chapter 1 Introduction}

\subsection{Background to the research}

This chapter provides a background to this study. It outlines Singapore's approach to encouraging international sporting success and then the thesis' research problem in that context. This exploratory research study is an attempt to uncover perceptions of effectiveness among the major stakeholders of national sports associations in Singapore. A national sports association, being the sanctioning body of the sport in Singapore, has obligations to its various publics - athletes, coaches, board, paid professional staff, members, sponsors, and government. As such the association may need to provide a host of services to satisfy multiple stakeholders. Also, as government funding increases, there have been changes in the management of amateur sport. Those who hold the purse strings want an increased level of professionalism to bring in results tied to funding levels. More professional staff have been recruited by volunteer boards as mandated. Professionalisation has an impact on both the structure of national sports organisations. It also impacts on the behaviour of volunteers and paid staff as it challenges the culture and voluntary ethos of amateur sports organisations. Further, the level of professionalism highlights the varying degree of volunteerism in the running of these organisations. Thus, the study has taken place in the context of a sporting transition in Singapore from an amateur culture to a professional culture. Different sporting bodies have adjusted more easily and more quickly to this cultural change.

After the landmark Committee of Sporting Singapore Report in 2001, a blueprint that serves to take Singapore into the top ten sporting nations in Asia by 2010, the government promised S\$500 million dollar funding for sport over five years from 2001 to 2005 . Another $\mathrm{S} \$ 300$ million was thereafter agreed to for a further three years from 2006 to 2010 (Tan 2006a). The Code of Governance (COG) introduced on 15 February 2003 was another significant milestone in Singapore sport. The purpose is to nurture effective national sports associations and enhance Singapore's sports delivery system. The COG is a set of good governance guidelines for national sports associations to be 
more effective and improve upon their relationships with stakeholders. One of the requirements for additional grant aid is the recruitment of professional staff in the national sports associations. In addition, when the Singapore Sports Council released news of an outcome-based funding model for national sports associations on 10 March 2006 detailing that national sports associations would be getting an increase in annual grants, it stated clearly that the funding would be based on their plans and programmes to develop their athletes and sport towards excellence (high performance thrust); get more people to take part in their sport (high participation thrust); and grow the sports industry (industry develop thrust). ${ }^{1} \quad$ From an observer's point of view, the funding criteria may appear skewed towards quantitative goals and measurable outcomes.

The academic study of effectiveness, be it in sport or other industries, has a history of being defined as outcomes or goals (Komarovsky 1946; Gordon and Babchuck 1950; Dotson 1953; Gallagher 1957; Scott Jr. 1957; Wright and Hyman 1958; Warriner and Prather 1965; Booth, Babchuk and Knox 1968; Bratton 1971; Ross 1972; Tomeh 1973; Dauriac 1980; Williams and Jackson 1981; Slack 1981; Beamish 1985; Malenfant 1987; Slack and Hinings 1987; Whitson and Macintosh 1988; Roberts-Du Bord 1989; Wood 1989; Auld 1994; Cuskelly 1995; Green and Chalip 1998; Watt 2003). While little consensus has been reached about the operationalisation of the terms, the agreement has been on its multi-dimensionality. Since organisations, non profit and for profit, are continually being evaluated on how effective they are, it is non profit organisations that have a more difficult task due to multiple social, economic and political goals, and the lack of a clear common denominator of profits as the basis of assessing performance.

However, non profit sport organisations are here to stay. Each year, more than 50 national sports associations get public funding from Singapore Sports Council. S\$24 million was disbursed in 2002. In the past, when the national sports associations were categorised as 'Core', 'Merit' and 'Other', the Core sports could receive up to S\$3 million each while Merit sports could receive up to $\mathrm{S} \$ 2$ million each and Other sports

\footnotetext{
${ }^{1}$ http://www.ssc.gov.sg/SportsWeb/media_release.jsp?artid=5891 accessed 25 July 2006
} 
up to $\mathrm{S} \$ 500,000$ (Peh 2004). All national sports associations are required to submit quarterly reports of their accounts to SSC for random checking and auditing. Thus, selfgovernance and financial control, other than sport development, are also key issues in the management of sport organisations.

Despite the de-classification of categories of sports from 2006 with the introduction of the outcome based funding model, there will be continued, if not increased pressure, for the national sports associations to be more business-like. Funding bodies, both public and private, will want more accountability for grants and resources utilised by the associations, even more so in the light of financial and governance debacles among Singapore Rugby Union and Singapore Tenpin Bowling Congress (The Straits Times, 13 November 2005 and 15 April 2007), Singapore Swimming (The Straits Times, 15 April 2007), and Cuesports (Today, 6 March 2006; The Straits Times, 30 July 2006 and 19 October 2007). These associations were under investigation for misappropriating large sums of money. Singapore Tenpin Bowling Congress (STBC), who was given one of the largest financial aid packages under SSC's Co-operative Agreement previously, was probed by the Commercial Affairs Department over missing money at its 2002 congress. Both the Commercial Affairs Department and Singapore Sports Council (SSC) were investigating the former President in that regard.

This study aims not only to contribute to the sparse sports association management literature in Singapore but also to advance the understanding of organisational effectiveness in national sports associations by providing a starting point for other researchers interested in investigating management issues and organisational phenomena of the non profit sport sector.

\subsection{Research problem}

Most of the research conducted on voluntary sport organisations has been quantitative and focuses on membership, participation, motivations, gender issues and organisational design. To the researcher's knowledge, there has only been one specific study comprising a qualitative component on the effectiveness of national sports 
organisations (Papadimitriou 1994), and one current quantitative study applying the competing values approach (CVA) of organisational effectiveness to a sample of non profit Australian national Olympic sporting organisations (NOSOs) (Shilbury and Moore 2006). Papadimitriou (1994) has studied Greek national sports associations.

Most researchers have defined and measured effectiveness from the goals or outcome perspective. Each researcher employs different sets of criteria and there has been little consistency on the operational definition and measurement of effectiveness, other than to agree on its multi-dimensionality (Frisby 1986, Cameron 1978, Chelladurai and Haggerty 1991). There is no consensus on the criteria to be employed for identifying effectiveness.

As individual and organisational perceptions of effectiveness differ, there have also been few attempts to understand similarities or differences among groups or individuals' perceptions of effectiveness. This research is aiming to explore whether the different stakeholders in national sports associations in Singapore determine effectiveness in the same way, or whether, and if so why, they have dissimilar perceptions. In addition, the research will examine the criteria used to determine effectiveness, identify whether effectiveness is affected by funding, and whether the organisational outcomes correspond with the funding received.

Thus, the broad purpose of this research is to explore organisational effectiveness in Singapore national sports associations. Special attention is given to four constituent groups - board or executive committee members, secretariat staff, athletes, and coaches - to draw out their perceptions and determinants of effectiveness, and the connection to outcomes desired of the associations. In so doing, the exploratory study proposes to find out:

1a) Do different groups of stakeholders have different perceptions of effectiveness of Singapore national sporting associations?

1b) If so why? 
2) What are the criteria used by the different stakeholders to determine effectiveness of national sporting associations in Singapore?

3a) How are the determinants of effectiveness affected by funding?

3b) Are the outcomes commensurate with the funding received?

\subsection{Justification for the research}

The aim of the study is to provide a starting point for work on the determinants of effectiveness among the key stakeholder groups in Singapore sports, in light of the government's new emphasis on building a sports culture. Increased funding has been provided to facilitate sports and recreation, to help associations organise international events, and to nurture potential Olympic champions (Lim 2006a, 2006b; Low 2007; Prentice 2006; Singapore Sports Council 2006; Tan 2006a, 2006b, 2006c, 2006d; Wang 2007; Wee 2007). As these long-term national goals require a fresh and continual injection of public money, there have been stringent requirements for more accountability of the enlarged funds and greater responsibility towards the three pillars - mass participation, sports excellence, and an improved sports industry - as outlined in the recommendations of the CoSS report.

Most previous research on the non profit sport sector in various parts of the world has been quantitative and concentrated on volunteerism; association memberships (demographic characteristics); motivations for participation; types of voluntary associations (typologies); the alignment of goals, functions, and its contribution to the social structure and changes in centralisation; specialisation and formalisation in organisational structures and design upon the introduction of professionals (Komarovsky 1946; Gordon and Babchuck 1950; Dotson 1953; Gallagher 1957; Scott Jr. 1957; Wright and Hyman 1958; Warriner and Prather 1965; Booth, Babchuk and Knox 1968; Bratton 1971; Ross 1972; Tomeh 1973; Dauriac 1980; Williams and Jackson 1981; Slack 1981; Beamish 1985; Malenfant 1987; Slack and Hinings 1987; Whitson and Macintosh 1988; Roberts-Du Bord 1989; Wood 1989; Auld 1994; 
Cuskelly 1995; Green and Chalip 1998; Watt 2003). If organisational effectiveness as a construct has been the centre of their research, it has been from the perspective of goal and systems models (Frisby 1986; Cameron 1978; Chelladurai and Haggerty 1991).

As there have been few qualitative studies, the researcher hopes the proposed inductive approach will draw out the cognitive perspectives and affective responses from the multiple informants, and derive some understanding of how the four key groups of stakeholders perceive and determine effectiveness. The affective dimension is important because discussions on sports inevitably bring out a vicissitude of emotions in people who engage or hold related positions. Also, as there are multiple stakeholders, the grounded theory approach incorporates the 'human status' of subjects studied, who will have 'perspectives on and interpretations of their own and other actors' actions' (Strauss and Corbin 1994: 280). With the intended conceptual flexibility and theoretical sensitivity, the study will also allow for a different way of making sense of the qualitative data within each constituent group, across constituent groups, and in the political, economic, and social context of Singapore. The study will examine the period from 2000 .

The study hopes to complement the work of Papadimitriou (1994) who had included a qualitative element in a dissertation on effectiveness of Greek national sports organisations. In her investigation, semi-structured interviews were used to explore effectiveness-related perceptions of the constituent groups selected. The reason was that Greek national sport organisations were under-researched with little empirical findings in any organisation theory-related area. The semi-structured interviewing was used to distinguish both subtle and specific attributes of the effectiveness construct across the constituent groups (Papadimitriou 1994: 115-116).

In the same way, the researcher hopes that the usefulness of the findings will assist governing bodies and associations to better understand how effectiveness can be perceived and determined. Further, the comparative information from the study can assist stakeholders to make better decisions, and be more aware of their own multi- 
faceted roles in sport development, as they continue to serve in the various important positions.

\subsection{Methodology}

This thesis adopts a qualitative approach and uses NVivo to analyse the data. The research employs two methods: focus group discussion and semi-structured interviewing. The sample consists of four major constituent groups of stakeholders in the national sports associations, namely national athletes, national coaches, secretariat staff, and board members.

Since Papadimitriou's (1994) semi-structured questionnaire was adopted, the objective of the focus group discussion and the pilot interviews was to test the instrument. As a result, modifications were made to the research design and two more questions were added to the ten questions in the original instrument.

The focus group discussion was planned so that the participants could build on the responses and ideas of others, thus increasing the richness of the information gained (Langford and McDonagh, ed, 2003:2). Less typical in the management of a focus group discussion, is the strategy employed by the researcher to get the participants to focus on the construct effectiveness even before the discussion began. Each participant was asked to complete the sentence 'Effectiveness is ...' on an A4-sized paper individually. Taking about five minutes to pen the statement and their thoughts, this tactic helped in organising their views, leading to a highly substantive discussion during the one and a half hours.

The semi-structured interviewing (also known as depth, exploratory, or personal interviewing) aims to understand perceptions, perspectives and meanings attached to situations and contexts important to the respondents. As affirmed by Edwards et al. (2001:158), one-to-one interviewing generates outcomes 'with greater emphasis on the issues which are most pertinent or sensitive to the individual concerned'. Since establishing a relationship that met the trust and confidence of the informants in the 
researcher is paramount in this study for quality data collection, all possible means to identify concerns and to address barriers of communication were used before the focus group discussion and interviewing. Some of these tactics included reiterating the confidentiality of the respondent's name, and confirming that the respondent could withdraw at any point in time. The respondent could also choose not to answer any question, and request to vet the transcript, all of which ensured a high level of honesty in the data provided by the informants.

The researcher used memos and journals to ensure observations, thoughts, and ideas during the entire research process over the twelve months were recorded. These were stored in NVivo, a software programme used to contain and analyse qualitative data, as well as physical notebooks. In NVivo, attributes were created in a casebook to capture the demographic information of the informants in both the focus group and the interviews. Open coding or broad-brush coding in NVivo was used as a first step to 'break open' the data and the concepts in them (Bazeley and Richards, 2005:54-55), allowing themes or categories to emerge by using the eight observational techniques: repetition; indigenous typologies or categories; metaphors and analogies; transitions; similarities and differences; linguistic connectors; missing data; and theory-related material (Ryan and Bernard 2003:89-94).

\subsection{Outline of the thesis}

To achieve its objectives, the thesis is broken into five chapters according to Perry's (1994) suggested structure:

Chapter 1 Introduction - In Chapter one, the broad field of study and the focus of the research problem was outlined. As the exploratory research study is an attempt to uncover perceptions of effectiveness among the major stakeholders of national sports associations in Singapore, this section prepares the foundation for the study. It gives a background to the research by stating some milestones in Singapore sport, and briefly reviews the relatively scarce sport management literature in Singapore. 
Chapter 2 Literature Review - Chapter two reviews the general literature on the non profit sports sector. The first section introduces the definitions and characteristics of the non profit sector which sports associations are part of, identifies reasons for the growth of the sector. It also attempts to show how researchers have debated and described how the sector is comprised, and the role it plays in society. The second section focuses on research conducted on institutional governance in the non profit sector in general, since much of this research is relevant to non profit sports organisations. The third section addresses the difficulties in operationalising effectiveness and measures of organisational effectiveness which are increasingly important in light of more government funding to non profit organisations. The fourth section provides a background of Singapore sport, especially the major blueprint to take Singapore to the top ten sporting nations in Asia by 2010. The fifth section examines the definitions of effectiveness and traces the theoretical frameworks of organisational effectiveness developed up to 2006. Lastly, the final and sixth section states the key research questions of the study suggested by the literature.

Chapter 3 Methodology - Chapter three covers the research methodology in seven sections: justification for the methodology; the unit of analysis and subjects or sources of data; instruments used to collect data; administration of instruments or procedures; limitations of the methodology; computer software used to analyse the data; and lastly, ethical issues.

Chapter 4 Analysis of data - In Chapter four, the research findings are presented by first describing the subjects of the study; secondly by describing the coding process; thirdly by showing patterns of data for each key research question; and finally summing up of the key points with a conclusion.

Chapter 5 Discussion and Conclusion - In the final chapter of the thesis, the discussion and conclusion are presented. The chapter synthesises the conclusions in order to answer the research questions. In addition, it suggests the implications of the findings for theory, policy, and practice. It also suggests areas for further research. 


\subsection{Conclusion}

This study examines the determinants of effectiveness of sporting associations in Singapore. Through the reciprocal shaping of the experiences of the multiple stakeholders and the researcher, the study provides an insight into how the different constituent groups determine effectiveness, the criteria used, and the effect of funding on outcomes. The study is located in the context of the government's emphasis on establishing a sporting culture, improving the quality of the sports industry, supporting sports excellence, enhancing professionalisation, achieving greater financial accountability, and facilitating more effective governance by associations. To this end, the qualitative study will also add to the sparse literature on national sports associations, and contribute to the knowledge of those in policy making, leadership and governance roles in sport.

This chapter has laid the foundations for the study. The next chapter examines the relevant literature.

\section{END OF CHAPTER ONE INTRODUCTION.}




\section{Chapter 2 Literature review}

\subsection{Introduction}

The previous chapter has developed the focus of this thesis, namely to examine perceptions of effectiveness among the major stakeholders of national sports associations in Singapore. The study takes account of the increased government funding for sport (Report of the Committee on Sporting Singapore 2001; The Straits Times 2003a, 2003b; Singapore Sports Council 2006; Lim 2006b; Tan 2006) and mandatory changes in the management of amateur sport, particularly towards more professionalism (Ministry of Community Development and Sports and Singapore Sports Council 2003; Low 2003a, 2003b; Fang 2005; Tay 2006). This chapter reviews the salient literature to 2006. In doing so, the chapter is organised into six sections: (a) The non profit sector; (b) Institutional governance in the non profit sector; (c) Defining and measuring effectiveness in non profit organisations; (d) The Singapore Sporting Associations; (e) Theoretical frameworks of organisational effectiveness; and (f) Key Research Questions.

Sporting associations form a part of the non profit sector. Thus, this study is informed by the general literature on this sector. This is undertaken in the first section which will introduce the definitions and characteristics of the non profit sector; identify reasons for the growth of the sector; and attempt to show how researchers have debated and described how the sector is comprised and the role it plays in society.

Section 2.3 on Institutional governance in the non profit sector will focus on research conducted on governance in the non profit sector in general, since much of this research is relevant to non profit sports organisations. This section will reveal how managing non profit organisations can be quite different from private or public sectors for different reasons. Some of the differences are the various perspectives of what constitute effectiveness and accountability; the management of a mix of volunteer and 
paid human resources; the structure of organisations; and the diverse missions of non profit organisations.

The next section (2.4) is concerned with defining and measuring effectiveness in non profit organisations and will address the difficulties in operationalising effectiveness and measures of organisational effectiveness. From early attempts to measure effectiveness solely through organisational goals, the review reveals new criteria such as efficiency, productivity, and growth.

Section 2.5 on The Singapore Sporting Associations will provide a background of Singapore sport by examining the sport delivery system and important milestones, especially the major blueprint to take Singapore to the top ten sporting nations in Asia by 2010. Section 2.6 on Theoretical frameworks of organisational effectiveness examines the definitions of effectiveness and traces the theoretical frameworks of organisational effectiveness developed up to 2006. Lastly, Section 2.7 states the key research questions of the study suggested by the literature.

\subsection{The non profit sector}

Historically, the three main reasons for the rise of the non profit sector globally were pressures from individual citizens (or grassroots), outside institutions (or public and private institutions), and governments (or government policies) (Salamon 1994:110, 112).

Non profit organisations were commonly known as the 'third sector', with the public and corporate sectors named as 'first' and 'second' sectors respectively. While reviewing the literature on definitions of the non profit sector, Salamon, who termed the non profit sector explicitly as 'the third sector', defined it as 'self-governing private organisations, not dedicated to distributing profits to shareholders or directors, pursuing public purposes outside the formal apparatus of the state' (Salamon 1994:109). 
Most of Singapore national sports associations, particularly those that are members of International Federations (IFs), meet Salamon's definition of non profits. They establish the rules of their respective sports, and make decisions on competitions, training, and selection. Singapore national sports associations obtain government grants but also generate revenue through membership fees, competitions, fund-raising, and sponsorship.

Because of increasing concerns about effective management among the non profit sector and a popular belief that business management concepts can be readily applied to not-for-profit enterprises, Newman and Wallender (1978) conducted a pilot study of 22 not-for-profit enterprises. The not-for-profit enterprises were defined as selfadministered, self-contained organisations that generated and delivered a complete service. Their research showed that the not-for-profit classification was too broad to be useful in management analysis. It also showed that though profit-seeking and not-forprofit enterprises were rather similar in their operations, the term 'profit maximisation' was abstract and less useful. In addition, the researchers also found several constraining characteristics in not-for-profit enterprises, which, though not confined to the not-forprofit sector, affected the management of non profit organisations with specific impacts on planning, organising, motivation, and control.

According to Newman and Wallender (1978), the several characteristics that constrained planning in not-for-profit enterprises are as follows. Firstly, while for profit organisations can use profits as a criterion in conflict resolution and decision making, in not-for-profit enterprises, divergent goals (for example, economic, political, and social) interfered with planning. Secondly, as payments by customers were secondary sources of funding in that payments were usually less than service costs, the weak customer influence permitted divergent values in the non profit organisation where the producer was presumed to know best. Thirdly, many non profit organisations were led by charismatic leaders who had personal convictions and values that were useful in decision making. However, the leaders also dictated the character and values accepted by others who were expected to follow. Fourthly, the focus of planning tended to shift 
from results to resources as not-for-profit enterprises provided services that were difficult to measure, intangible and subsidised, and planning had to deal with the next best activities that produced quantifiable results. As an example, if an educational institution could not measure the learning that took place among students, the next best operating objectives would be in terms of the number of classes, student contact hours or student feedback, the assumption being that assigned resources would be used for activities that could produce the desired results. Fifthly, ambiguous operating objectives created opportunities for internal politics resulting in abuse and political manoeuvring for personal ends. Sixthly, when professionals held positions in not-for-profit enterprises, they tended to dictate how the enterprises were being managed by their professions rather than by enterprise management. This produced rigidity in responding to new needs.

Just as there were a number of characteristics of not-for-profit enterprises that constrained planning, Newman and Wallender (1978) state that there are several characteristics that limit the organising functions. Firstly, there is less delegation than in a for profit enterprise. This is because services are intangible and difficult to measure, resulting in managers having difficulties in communicating objectives. The second reason is that because managers cannot use performance rewards due to the subjectivity about performance, they are reluctant to delegate to subordinates. Secondly, the dependence of not-for-profit enterprises on government and donors for funds and resources leads to 'defensive centralization' as managers keep decision making to themselves. This helps avoid actions which outside interest groups might find objectionable as the government and donors impose conditions. Also, the important task of connecting both inside and outside groups to agree on actions undertaken is particularly difficult in the face of multiple and shifting objectives. Thirdly, as not-for-profit enterprises often have traditions in organising transferred from the government, there is a hindrance to promotion from within. This contrasts with the for profit sector. So, though internal labour markets are a feature of the for profit sector, this is less so in the not-for-profit sector. 
Moving on to the characteristics that affect the management functions of motivation and control, Newman and Wallender's (1978) research shows that the first characteristic that constrains motivation and control is the ambiguity of desired results. Feedback cannot be objective, permitting subjective interpretations of success with attention given to only measurable activities even though they may not present the total picture. Since measurement difficulties in assessing performance are prevalent, rewards and penalties are not related to individual performance, making a centrally administered control system ineffective. Limitations on output controls cause not-for-profit enterprises to depend on control over inputs (such as expenditure and human resources) and over volume of activities. As such, employees are not motivated as there is little incentive to meet standards (Newman and Wallender 1978:24-31).

In the context of American society, Rosenbaum (1984:3-4) suggests that non profit organisations evolve through four stages:

1. Voluntary/civic model - the original model for non profit organisations sprung out of community necessity when government were not able and commercial firms did not exist to meet the needs, characterised by homogeneous interests, shared personal philosophies, and low economic welfare.

2. Philanthropic patronage - as American philanthropy matured, it was noted that wealthy families were setting up foundations, playing a major role in funding non profit organisations, and influencing national agenda especially in healthcare, education, politics and the environment.

3. Rights and entitlements - characterised by government-funded programmes and services with groups stating their entitlement for government funding to support their social causes.

4. Competitive market stage - marked by entrepreneurial style and structure, operating in a competitive environment, and characterised by a reduction in reliance on individuals and the government for funding but a turn to the private sector for support. 
Rosenbaum (1984:4) predicted that most agencies would either shift to the new entrepreneurial mode or move back to the voluntary model as government funding gradually decreased.

Since the competitive market stage phase is the most common in developing countries, non profits have to become more marketing aware. They have diversified their roles to boost income and are increasingly commercialised. This leads Hall (1998:24) to question whether non profits, because of their dependence on direct and indirect government support, can be called the 'independent sector', be donor supported, stay voluntary, and remain true to their mission and public interest.

Salamon and Anheir (1992:125, 128-129) argue that the inattention to the third sector in the past was the outcome of the lack of meaningful concepts used to describe it. While trying to make sense of the terminology used on a range of institutions in the non profit sector, they show how the terminology can be misleading. Their findings are summarised below:

Table 2.1: How the various terms used in the third sector can be misleading

\begin{tabular}{|l|l|}
\hline Term used & How the term can be misleading \\
\hline Charitable sector & $\begin{array}{l}\text { Emphasises the support from private and charitable donations } \\
\text { but the donations do not constitute the only, or major, source of } \\
\text { revenue for these organisations. }\end{array}$ \\
\hline Independent sector & $\begin{array}{l}\text { Emphasises the role of these organisations as a 'third force' } \\
\text { outside government and private businesses but they depend } \\
\text { heavily on both the government and private businesses } \\
\text { financially. }\end{array}$ \\
\hline Voluntary sector & $\begin{array}{l}\text { Emphasises the significant input of volunteers in management } \\
\text { and operations but many activities in these organisations are } \\
\text { carried out by paid staff. }\end{array}$ \\
\hline Tax-exempt sector & $\begin{array}{l}\text { Emphasises the fact that the organisations are exempted from } \\
\text { taxation but begs the question of what characteristics qualify }\end{array}$ \\
\hline
\end{tabular}




\begin{tabular}{|l|l|}
\hline & $\begin{array}{l}\text { organisations for this treatment, and not helpful in comparative } \\
\text { research as tax systems of countries differ. }\end{array}$ \\
\hline $\begin{array}{l}\text { NGO (non- } \\
\text { organisation) }\end{array}$ & $\begin{array}{l}\text { Depicts organisations in the developing world but tends to refer } \\
\text { to those engaged in the promotion of economic and social } \\
\text { development at the grassroots level. }\end{array}$ \\
\hline Economic sociale & $\begin{array}{l}\text { Depicts a range of NGOs in France and Belgium and the } \\
\text { European Community but embraces a variety of business-like } \\
\text { organisations such as mutual insurance companies, savings } \\
\text { banks, cooperatives and agricultural marketing organisations } \\
\text { which would be considered the business sector. }\end{array}$ \\
\hline Non profit & $\begin{array}{l}\text { Emphasises that these organisations do not exist primarily to } \\
\text { generate profits but they do earn profits by generating more } \\
\text { revenues than they spend in a given year. }\end{array}$ \\
\hline
\end{tabular}

Source: Salamon and Anheir (1992:128-9)

Salamon and Anheir suggest that there are the four ways in which the non profit sector can be defined: the legal definition (defining the non profit sector as provided in a country's law); the economic/financial definition (emphasising the source of its income); the functional definition (emphasising the functions or purposes that organisations carry out); and the structural/operational definition (emphasising the basic structure and operation). They conclude that the most useful definition is the 'structural/operational' definition which includes the five characteristics shared by non profit organisations - formal, private, non profit-distributing, self-governing and voluntary (Salamon and Anheir 1992:132-136). A description of the five characteristics is summarised below.

Table 2.2: A description of the five characteristics shared by non profit organisations

\begin{tabular}{|l|l|}
\hline $\begin{array}{l}\text { Five characteristics of the third sector } \\
\text { which are a collection of organisations }\end{array}$ & $\begin{array}{l}\text { Thus, to be part of the non profit sector } \\
\text { that are: }\end{array}$ \\
& $\begin{array}{l}\text { under the structural/operational } \\
\text { five of the criteria in varying degrees }\end{array}$ \\
\hline
\end{tabular}




\begin{tabular}{|l|l|}
\hline 1. Formal & $\begin{array}{l}\text { Institutionalised to some extent e.g. formal } \\
\text { charter of incorporation. }\end{array}$ \\
\hline 2. Private & $\begin{array}{l}\text { Institutionally separate from government, } \\
\text { may receive government support, and have } \\
\text { government officials sit on their boards, } \\
\text { but they are fundamentally private } \\
\text { institutions in basic structure. }\end{array}$ \\
\hline 3. Non profit-distributing & $\begin{array}{l}\text { Not returning profits to owners or } \\
\text { directors but profits are ploughed back } \\
\text { into the basic mission of the agency. }\end{array}$ \\
\hline 4. Self-governing & $\begin{array}{l}\text { Equipped to control their own activities; } \\
\text { have internal procedures for governance; } \\
\text { and not controlled by outside entities. }\end{array}$ \\
\hline 5. Voluntary & $\begin{array}{l}\text { Involving some degree of voluntary } \\
\text { participation either in the conduct of its } \\
\text { activities or in the management of its } \\
\text { affairs e.g. a voluntary board. }\end{array}$ \\
\hline
\end{tabular}

Source: Salamon and Anheir (1992:132-136)

On the other hand, Morris (2000:26-28) argues that the structural/operational definition excludes many non-statutory and non profit maximising providers, especially mutual aid organisations recognised for the development of civil society. Morris considers these to be key components of the sector. Morris thus makes a distinction between the third sector and the non profit sector. She recommends the term 'non profit sector' to be reserved for the sector as defined by the earlier structural/operational definition, while organisations that are neither statutory nor profit maximizing to be referred to as third sector organisations. The latter have the following characteristics - producing public goods for society, providing services for consumers who are at a disadvantage financially, personally, or socially; and fostering social capital which promotes economic growth and contributes to democracy. 
Comparing non profit organisations with the government service in the United States, Staats (1998:601) states that non profit organisations display 'the same attributes of dedication, probity, imagination, loyalty, and commitment to the welfare of their fellow citizens as those who were employed by government'. Without them, the government will have to assume many of their activities. According to Staats, the non profit sector is also known as 'the independent sector'.

Salamon and Sokolwoski (2001) have examined the non profit sector with regard to volunteering across 24 countries. Their cross-national findings on this sector are particularly significant in the following areas:

- State of volunteering - 'citizen participation in the form of volunteering is alive and well and volunteering represents the equivalent of 4.5 million FTE jobs in Western Europe and nearly 5 million FTE jobs in the U.S.'

- Correlation between government spending and volunteering - their findings contradicts a myth that government provision of social welfare and reliance on paid employment results in less volunteer participation. Instead, it was found that 'larger government social welfare spending was associated with larger amounts of volunteering.'

- Distribution of volunteer input - volunteering is found in two different activity areas. One area represents the expressive role of the non profit sector and is in culture, recreation, advocacy, and occupational interests. The other represents the service role of the non profit sector and encompasses education, health, social services, and economic development.

- Affect by social and institutional forces - volunteering is not just about individual choice and altruism. Rather it was found that 'countries with more developed non profit organisational structures tended to have a higher volume of volunteer activity because such structures are instrumental in recruiting and maintaining volunteer participation.'

- Volunteering was purposive - it 'can be used to accomplish varied social goals from self-actualization, expression of value, and enhancement of the quality of life, to the production and delivery of public goods which are affected by 
political cultures and development paths'. Thus, there is a need to pay special attention to the non profit sector in terms of its relationship to social and political institutions. (Salamon and Sokolwoski 2001:20-22).

The problems with analysing non profit organisations across countries include several factors namely: the diverse and lack of systematic data, varying terminology, widely divergent functions of the sector, the varied treatment of these organisations in national legal structures, incomplete official listings, imperfect treatment in national economic statistics and 'ideological blinders' (Salamon 1994:110). In spite of these problems, he suggests the dispelling of these three myths about the non profit organisations. Firstly, the 'myth of pure virtue', that non profit organisations are the vehicles for selfexpression, self-help, participation, and mutual aid. Rather they are prone to bureaucracy; tensions between flexibility and effectiveness; and grassroots control and administrative accountability. Second is the 'myth of voluntarism' implying that non profit organisations that rely primarily on voluntary action and private philanthropy. In fact, the government has become a major source of financial support. Thirdly, the 'myth of immaculate conception', that non profit organisations are new in most places. Instead they have roots and traditions in institutional settings (Salamon 1994:118-121).

Salamon (1994:121-122) advises emerging third sector organisations to take themselves seriously by being sensitive to the trade-offs that exist between voluntarism and professionalism, giving more attention to training and technical assistance, and forging a relationship with government. Increasingly, this approach is seen in Singapore as the Code of Governance and the outcome funding model instituted by the Singapore Sports Council (with the backing of the Ministry of Community, Development, Youth and Sports), is aimed at making national sports associations more effective, underpinned by increased accountability through better governance.

\subsection{Institutional governance in the non profit sector}

As there is little research on governance in the non profit sports sector specifically, the literature review here attempts to draw on research done on institutional governance in 
the non profit sector in general. This covers charitable organisations, church organisations, welfare, nursing, education, healthcare and community services. Increasingly, more attention is being paid to management concerns because of the complex and uncertain resource environment that these organisations operate in. The organisations are exhorted to undertake strategic planning, quality assurances, and to streamline their budgeting practices the same way as public and private sector organisations. Yet many people in third sector organisations do not have the necessary background and skills to enable them to effectively carry out these tasks (Lewis, French, and Steane 1997).

From a management perspective, and a review of literature on culture and conflict in non profit organisations in Australia, Lewis, French, and Steane (1997) propose that managing non profit organisations is different from private or public sectors primarily due to three factors. Firstly, the management process itself: it is difficult to define specific priorities, measurement criteria and allocation of resources. When the organisation is not able to do so, and when accountability to stakeholders (that include funding bodies, volunteers, service users, members, staff, and donors) is high, the organisation can be in a state of stagnation or chaos.

Secondly, the human component of the organisation: non profit organisations comprise people brought together by altruistic motives. However, voluntary boards, voluntary labour, paid staff and donors would have personal motives and expect to be part of the decision making process and have their opinions listened to and their values cherished. Without competent conflict management strategies, division and fragmentation results in either excessive rigidity or a lack of innovation.

Thirdly, the size and structure of the organisation: as non profit organisations grow, hierarchical structures are adopted which can increase conflict due to formality and bureaucracy that override the flexibility and informality that are valued in non profit organisations, especially by volunteer staff. The researchers conclude that the challenge 
is for non profit organisations to define an organisational culture that respects differences.

In Australia, Steane (2001:15) argues that it is incorrect to expect organisations across sectors to be homogeneous in their governance practices, and particularly for non profit boards to behave like corporate sector boards. Divergent practices, rather than convergent expectations, are manifest in non profit governance in non profit boards in Australia. This is because research into non profit boards reveals two dimensions that differentiate them from corporate sector boards. One is that greater diversity of members in non profit boards allows greater involvement and a broader and more diffused base of skills to tap into funding, lobbying, or to monitor management. The other is the value or ideological foundation of non profit organisations, also termed as 'commitment' that underlies strategic decision making at the senior management and board levels. Thus, the link between structure and mission in non profit governance is its membership (Steane 2001:15).

From an assets perspective, Connelly (2004), in the United States of America, notes that the non profit sector has increased in size and complexity in terms of assets since the 1980s. Connelly's work showed that by 1998, 1.27 million non profits in the USA (not including churches) contributed to $9 \%$ of gross domestic product. There have been phenomenal changes in the non profit sector. Firstly there are the financial measures of success versus need for measures of mission success. While profit organisations can measure success by profit, share prices and market share, non profit organisations need to generate their own measures of success to evaluate the achievement of their mission. In the past, most non profit organisations depended on donations for their revenue but today many market their services to increase their financial viability. The present challenge is for these non profit organisations to continue preserving their identities while balancing their sales efforts (where success is easily measured), and their social mission efforts (which is less easily measured). 
The second phenomenal change in the non profit sector is the hybrid legal structure. Adding to the identity crisis is the fact that non profit organisations have characteristics of both the government and for profit sectors. In a for profit organisation, assets (stocks) are privately owned and decisions are made privately. In a government organisation, assets are owned by taxpayers and decisions are made public. In a non profit organisation, assets are to benefit the community that it serves, and decisions on the usage of assets are privately made by the board within the context of its legal purpose, be it arts, education, or healthcare.

The third change in the non profit sector is that board members need to understand the tensions involved. While most board members start being involved in a non profit organisation because of interest in its social mission, they find that they have to address complex business challenges to balance mission and financial margin. A balance has to be struck between board members who see their roles as solely fundraisers and those who see the non profit organisation as 'any other business', ignoring the organisation's mission (Connelly 2004:7-8).

The result is increased expectations about governance. From his experience as the chief executive officer of Catholic Healthcare Partners (CHP), a health system with $\$ 4$ billion in assets and 35,000 employees across five states in the USA, Connelly summarises five critical success factors for CHP's governance makeover in the light of dynamic changes in the assets environment. These are: explicitly defining and measuring strategic success with regard to mission; defining board responsibilities and committing to board development; committing to board diversity; committing to developing board culture and independent oversight; and preparing focused and well-organised board meetings (Connelly 2004:10).

In the light of the corporate and accounting scandals such as Enron, Worldcom and Arthur Anderson, and the increasing interest in governance issues in many countries, corporations, self-regulatory bodies, and professional associations have suggested a myriad of proposals to improve corporate responsibility and governance. In conjunction 
with the massive changes taking place in the non profit sector, Peregrine's (2004) white paper, 'Best practices: non profit corporate governance', provides a set of guidelines for non profit organisations to respond to the 'corporate responsibility' environment. Peregrine (2004:1) begins by setting three qualifications in order: (a) that best practice guidelines are aspirational goals and not legal requirements; (b) one size does not fit all, and (c) relevant public policy should not be undermined in situations where a board chooses to consolidate individual best-practice guidelines to meet the particular characteristics of its institution. This means that the policy of enhanced corporate governance should not be compromised by variances from these guidelines, for example, requiring only a majority, as opposed to complete, control of key committees in 'independent' directors. Peregrine outlines guidelines under the following sub sections: Consistency with charitable mission and vision; Relationship of board and senior management team; Fulfillment of the board's oversight obligations; Duty of loyalty compliance; Financial accountability and transparency; The governance/nominating committee; The audit committee; The executive compensation committee; Corporate ethics/corporate compliance; Relationship between the board, senior management and general counsel; Board deliberative processes; Fund-raising accountability; and finally Reviewing transactions with disqualified persons (Peregrine 2004:4-13). The goal of Peregrine's paper is to provide the guidelines as useful resources for an evaluation of how best to govern a non profit organisation while preserving effective stewardship of their charitable assets.

In Western Europe, Anheier, Toepler and Sokolowski (1997:190) note that researchers have cited a 'neo corporatist' pattern while examining the relationship between the state and non profit organisations. This stems from the observation that non profit organisations have become more bureaucratic when they adopt public sector policies and state accounting and reporting procedures. These are the result of dependency on government funds. Their quantitative study involving correspondence analysis suggests that the difference between predominant public sector funding and majority private sector funding is a most important distinction in understanding how organisational orientations differ. Those that are dependent on public funds (either grants or third 
party payments) are more state-oriented than organisations which rely for more than 50 per cent of their revenue on donations or other forms of private income. The latter are more market-oriented (Anheier, Toepler and Sokolowski 1977:211-212).

A similar observation is made by Kawashima (1998) in his study of the emerging voluntary sector in Japan. Kawashima points out that as governments supervise voluntary organisations more closely, there is a concern that the organisations could be 'colonised', lose their original characteristics and become institutionalised to form an implicit public sector (Kawashima 1998:40).

In Singapore, the 2003 Code of Governance for National Sports Associations (COG) is a significant milestone in Singapore sports. The purpose is to nurture effective national sports associations and enhance Singapore's sports delivery system. With S\$500 million dollar funding promised over five years from 2001 and a further $\mathrm{S} \$ 300$ million from 2006 to 2010, the COG is a set of good governance guidelines for national sports associations to improve upon their relationships with stakeholders - athletes, governing councils, management committees, secretariat staff, members, coaches and volunteers (Tan 2006a). The COG aims to enable NSAs to shape up by complying with the 10 stipulated conditions of:

1. Well-defined mission and programmes

2. Responsible and prudent governing councils

3. Effective and accountable leadership

4. Democratic and fair elections and appointments

5. Proper management of conflict of interest

6. Enlightened staff and volunteer management

7. Sound financial and legal management

8. Transparent actions

9. Ethical fundraising and use of funds

10. Responsive public relations and corporate communication 
Compliance with the COG is supposed to have, as one of the desired outcomes, national sports associations being run like professional outfits with strategic planning, functional departments, professional staff, leadership renewal and high performance athlete management. However, a national sports association in Singapore is constituted as an independent body registered under the Registry of Societies and distinct from a private entity in its legal status and objectives. Transposing the findings from the literature review on governance to the Singapore context, it could be hypothesised that the core and merit national sports associations who are heavily dependent on public funds would take on a form of state orientation and lose some of their self-governance and independence from government. Thus, political and institutional constraints that beset non profit organisations have made the measurement of performance and effectiveness in national sports associations more complex than in the private sector. There exists difficulty in tracing factors directly influencing the outputs of sport development programmes, a key mission of most sport organisations.

\subsection{Defining and measuring effectiveness in non profit organisations}

Research on effectiveness of non profit sports organisations has specifically analysed the relationship between the goal and systems models of organisational effectiveness. Frisby (1986) studied Canadian National Sport Governing Bodies, Cameron (1978), and Chelladurai and Haggerty (1991) looked at the multiple constituent aspects of organisational effectiveness while Papadimitriou (1994) explored the effectiveness of Greek national sports organisations using an empirical application of the multiple constituency approach. More current research has applied the competing values approach (CVA) of organisational effectiveness to a sample of non profit Australian national Olympic sporting organisations (NOSOs) (Shilbury and Moore 2006).

Baruch and Ramalho (2006), in a recent analysis of 'Communalities and distinctions in the measurement of organisational performance and effectiveness across for profit and non profit sectors', looked at research papers in ABI/Inform from 1992 to 2003. They discovered a set of common issues across both sectors, namely efficiency and/or 
productivity, growth and/or market share, customer orientation, quality, and public image and/or reputation, social performance. Particular to the non profit sector, the following criteria were considered salient in measuring organisational performance and effectiveness: efficiency and/or productivity, customer orientation, financial success, quality (and/or product - service quality), employee satisfaction (morale, commitment, and participation), sales and/or resource acquisition, public image and/or reputation (or goodwill), and social performance (Baruch and Ramalho 2006:56). Thus Baruch and Ramalho demonstrate that the body of knowledge on non profit organisational effectiveness has become more sophisticated than merely attempting to measure effectiveness solely through organisational goals.

Herman and Renz (1999:121-123) propose six theses about non profit organisational effectiveness despite the sparse literature on the subject due to two main reasons: the criterion problem of defining and measuring NPO effectiveness; and the general theoretical problem of multiple models of effectiveness. Although the academic study of business effectiveness is more extensive than non profit organisational effectiveness, and many think that business effectiveness can be applied to non profit organisations, the researchers state that the research on business effectiveness is inconclusive. Instead, they recommend the development of a measure of responsiveness to the needs and expectations of stakeholders as an indicator of effectiveness. The six theses have since been enlarged to nine theses by further extensive research to include the following:

- Non profit organisational effectiveness is always a matter of comparison.

- Non profit organisational effectiveness is multidimensional and will never be reducible to a single measure.

- Governing boards make a difference in non profit organisational effectiveness, but how they do so is unclear.

- Non profit organisational effectiveness is a social construction.

- Programme outcome indicators as measures of NPO effectiveness are limited and can be dangerous.

- Effective non profits are more likely to use good management practices.

- The promise of 'best practices' should be viewed with skepticism. 
- The concept of responsiveness may offer a solution to the problem of differing judgments of effectiveness by different stakeholder groups.

- Since many NPOs operate as part of a network of service delivery, there is a need to think more in terms of network effectiveness rather than to assess individual NPO effectiveness.

The Singapore Sports Council's approach does not appear to measure responsiveness or place strategic importance on the concept as proposed by Herman and Renz (1999). In March 2000, the Council released news of an outcome-based funding model for national sports associations. This is reaffirmed in 'Singapore Sports Council launches new funding model for national sports associations' (2006), where national sports associations would receive an increase from $\$ 28.3$ million to $\$ 31.1$ million in annual grants for 2006. The increase would be based on their plans and programmes to (a) develop their athletes and sport towards excellence (high performance thrust), (b) get more people to take part in their sport (high participation thrust), and (c) grow the sports industry (industry develop thrust).

It will be seen that this approach runs counter to Herman and Renz's (1999) dictum that 'programme outcome indicators as measures of NPO effectiveness are limited and can be dangerous'. According to Herman and Renz, the idea behind outcomes assessment is that programme outcomes are specific and measurable and that these indicators of outcomes are consistently tracked. However there are limitations. As long as outcome assessments are believed to establish causality, they are dangerous in both positive and negative outcome situations. In a positive situation, an NPO may take credit for the outcome for which it is slightly (if at all) responsible. In a negative situation the inference may be that the programme is a failure. Another danger is the use of data regularly collected to measure some intended outcome, when such data may not be the most appropriate measure nor an indicator of the examined outcome. The demands for assessments of outcomes may result in unintended or inappropriate consequences. As an example, a job training evaluation that is appraised in relation to outcomes led to 'creaming' where those most ready for the service and least likely to need it are 
selected and served by the programme. Also when outcome reports are used for comparison between NPOs without controlling for differences in client characteristics, the judgements on effectiveness may be inappropriate and the error compounded if such judgements are to become the basis for future funding decisions (Herman and Renz 1999:119-121).

In the Singapore Sports Council's new outcome-based approach, national sports associations can pursue one, two, or all three thrusts, and submit programmes based on their focus. The rationale for the use of the outcome-based approach is that it was 'well proven in the commercial and non profit sector and would help the entire sports sector make every dollar work harder for results' (Singapore Sports Council 2006). Strong governance is cited as vital for several reasons. Firstly, governance is necessary for sports to be credible and to attract investments. Secondly, governance is important for national sports associations to perform their public role as the governing body of the sport, and assume the accountability which they have towards Singapore and the public. Over time, it is hoped that national sports associations would be more professionally run. In the evaluations, Singapore Sports Council will consider the sport's past achievements and projected outcomes towards 2010, as well as the state of organisational excellence of the association (Singapore Sports Council 2006).

Herman and Renz (1999:123) conclude that the most important challenge faced by those determining NPO effectiveness will be that of the criteria, for 'indicators such as size (measured by total revenues) and growth are limited in their bias toward what is popular with constituencies that possess substantial income and wealth.' Thus, they suggest that what is required to advance research on NPO effectiveness is 'the development of a measure of responsiveness as an indicator of effectiveness.'

The measurement of organisational effectiveness in non profits is a complicated task. Some academics believe that NPO effectiveness is similar to business effectiveness (Herman and Renz 1999:121). In 1973, when Drucker (1973:45-46) examined the management of the public service institutions, he dispelled three popular explanations 
for their failure to perform - that their managers were not 'businesslike', the need for 'better men', and that their objectives and results were 'intangible'. Drucker noted that judging performance and measuring effectiveness in non profit organisations are particularly challenging because of intangible social and psychological goals compounded by measurement difficulties. He provided six requirements for successful performance and measurement. To perform, the non profit organisation will need a system to:

a) know 'what is our business and what should it be?' - that is, their specific function, purpose and mission;

b) derive clear objectives and goals from their function and mission - from not 'better people', but effective people who focused the organisation on performance and results;

c) think through priorities to enable setting of targets, standards of accomplishment and performance, deadlines and accountability;

d) define measurements of performance;

e) use the measurements to 'feedback' on efforts and build self control from results into their system; and

f) organise an audit of objectives and results to identify objectives that were no longer relevant or unattainable rather than wasting money and energies where results were not (Drucker 1973:58-59).

\subsection{The Singapore Sporting Associations}

As national sports associations in Singapore fall under the non profit sector, it is useful to examine some of the definitions and characteristics of non profit organisations in general. The spelling and usage of the word 'non profit' appears in various forms such as, 'non-profit' or 'not-for-profit', and have not been consistent across literature. For the purpose of this study, 'non profit' will be used. The term 'non profit' sector has been debated by academics and researchers concerning its composition and its role in public life. The word 'non profit' had also been used synonymously with terms such as 'voluntary', 'independent', and 'third' adding to the confusion (Hall 1998:13). 
Internationally, national sports associations are also known as 'national sport organisations', or 'national governing bodies'. Depending on the country they are constituted in, they are usually categorised as voluntary or non profit organisations, distinct from private and public sector organisations. In Singapore, the definition of a non profit organisation or NPO is one which is not operating for the profit of its individual members. Any profit made by the organisation goes back into the operation of the organisation to carry out its purposes. Charities and institutions of a public character or IPCs are referred to generally as non profit organisations (Directory of non profit organisations n.d.). While a Singapore national sports association is constituted as a 'society', not every association has a registered IPC status, but all national sports association are listed in the Singapore Directory of Non profit Organisations residing in the National Volunteer and Philanthropy Centre (NVPC) website.

A national sports association, being the sanctioning body of the sport in Singapore, has obligations to its various publics, namely the athletes, coaches, board, paid professional staff, members, sponsors, and government. As such the association will need to provide a host of services to satisfy multiple stakeholders. Also as government funding increases, there have been changes in the management of amateur sport. Those who hold the purse strings want an increased level of professionalism that should lead to better results tied to funding levels. Professional staff are recruited by volunteer boards as required by mandate. Professionalisation has an impact on both the structure of national sports organisations and the behaviour of volunteers and paid staff as it challenges the culture and voluntary ethos of amateur sports organisations that have depended mainly on volunteers to run their sport.

Chelladurai's (1985:70-71) study of non profit sport organisations in Canada highlights that public sector sports organisations are government agencies involved with sport, and operated on tax monies. The primary concern of these organisations is the uniform treatment of all customers and consistency in operations. To fulfill these requirements, the public sector sports organisations have stated quantifiable goals and carry out 
activities with procedures, guidelines and control mechanisms. They rely more on planning with goals rather than directional planning.

In Singapore, the Singapore Sports Council is a public sector organisation involved with sport as it is dependent upon tax derived income for survival. This can be gleaned from the council's Financial Statements (March 2005). While viewed as a public sector body, specifically a statutory board, the Singapore Sports Council has taken on more planning to align itself to the recommendations in the Committee on Sporting Singapore (CoSS) Report 2001. The report informed on three pillars, namely, Sports Excellence, Sports for all, and The Sports Industry. In addition, 40 recommendations and six targets were introduced on NSA effectiveness. The latter consisted of: Starting a sports culture, Creating a new sports environment, Making NSAs effective, The development of a sport for all master plan, Developing sports excellence, and lastly, Selling Sports Singapore. To promote sports excellence, the report recommended that national sports associations improve their planning, athlete support infrastructure, accountability and governance in running sports organisations. This landmark report serves as a blueprint to take Singapore into the top ten sporting nations in Asia by 2010 .

The next major milestone in Singapore sport was the introduction of the Code of Governance (COG) in February 2003. The purpose was to improve the effectiveness of national sports associations and enhance Singapore's sports delivery system. The COG is a set of good governance guidelines for national sports associations to be more effective and improve upon their relationships with stakeholders - athletes, governing councils, management committees, secretariat staff, members, coaches and volunteers. One of the requirements for additional grant aid is the recruitment of professional staff in the national sports associations.

On 10 March 2006, the Singapore Sports Council announced that national sports associations would be getting an increase of annual grants (Singapore Sports Council 2006). However, this was contingent on their plans and programmes to develop high performance, high participation, and industry development. From this observer's point 
of view, the funding criteria appear skewed towards quantitative goals and measurable outcomes.

Figure 2.1 depicts this researcher's diagrammatic interpretation of Singapore's sport delivery infrastructure. This is obviously less sophisticated than larger countries with a sporting tradition such as Canada, Australia or China. Other bodies delivering sports, besides the national sports associations, are the People's Association (consisting of constituency sports clubs, sea sports clubs, and community clubs) and the Singapore Sports School. The Singapore Sports School is constituted under the Ministry of Community Development, Youth and Sports rather than under the Ministry of Education despite it being a school that offers a secondary school curriculum. It is a stay-in school where athletes train under sports coaches and study under Ministry of Education teachers. The Singapore Sports School which depends on government monies for their operations is expected to follow the general directions set out by the Ministry of Community Development, Youth and Sports.

The research undertaken on national sports associations in other countries has mostly been quantitative in nature. The early national sports association literature covered volunteerism; association memberships (demographic characteristics); motivations for participation; types of voluntary associations (typologies); the alignment of goals and functions; contribution to the social structure; changes in centralisation, specialisation and formalisation, in organisational structures and design, upon the introduction of professionals (Komarovsky 1946; Gordon and Babchuck 1950; Dotson 1953; Gallagher 1957; Scott Jr. 1957; Wright and Hyman 1958; Warriner and Prather 1965; Booth, Babchuk and Knox 1968; Bratton 1971; Ross 1972; Tomeh 1973; Dauriac 1980; Williams and Jackson 1981; Slack 1981; Beamish 1985; Malenfant 1987; Slack and Hinings 1987; Whitson and Macintosh 1988; Roberts-Du Bord 1989; Wood 1989; Auld 1994; Cuskelly 1995; Green and Chalip 1998; Watt 2003). 


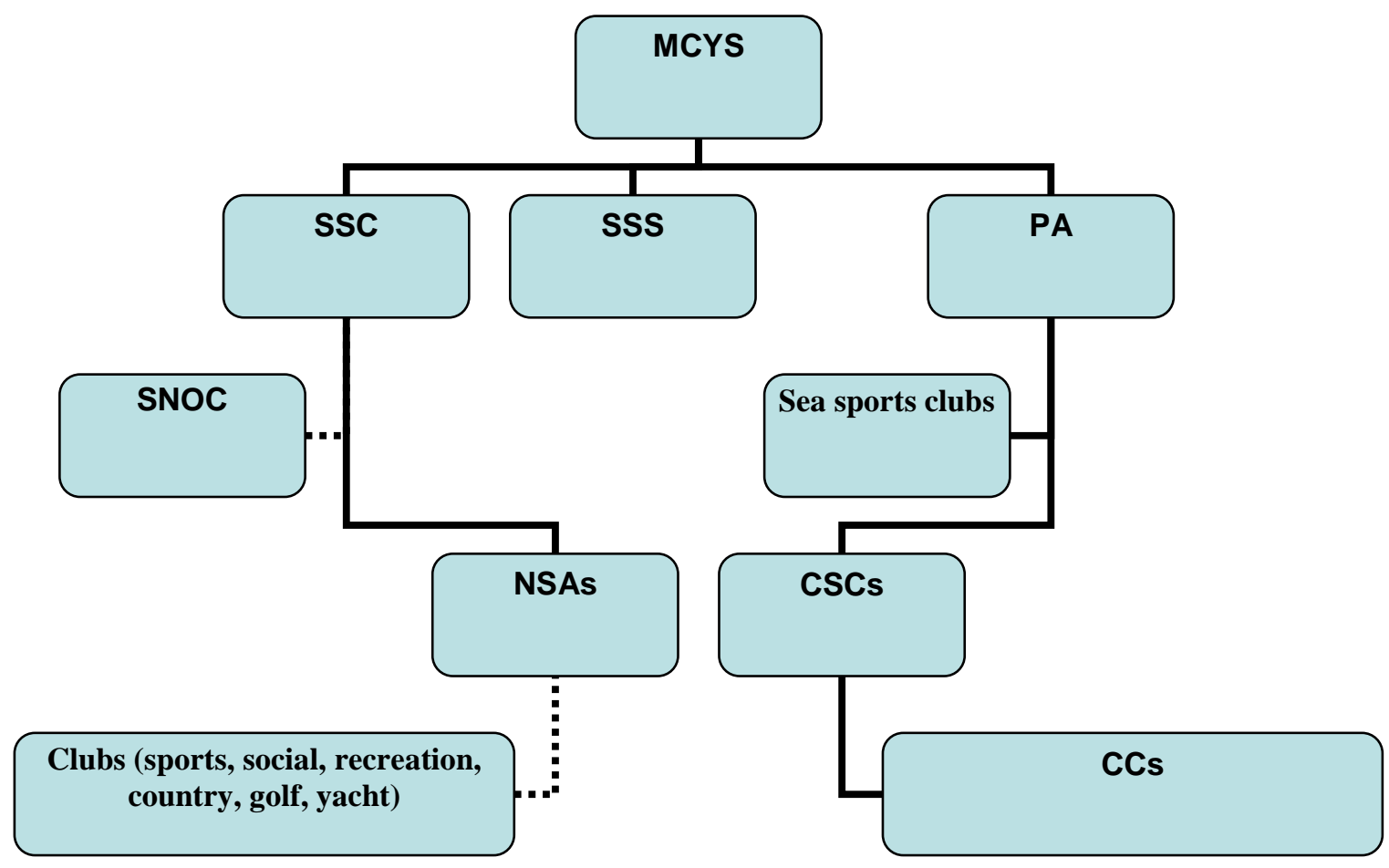

Figure 2.1: The Sport Delivery System in Singapore (Koh-Tan 2006)

Legend:

MCYS - Ministry of Community Development, Youth and Sports

SNOC - Singapore National Olympic Council

PA - People's Association

SSC - Singapore Sports Council

SSS - Singapore Sports School

NSAs - National sports associations

CSCs - Constituency Sports Clubs

$\mathrm{CCs}$ - Community Clubs

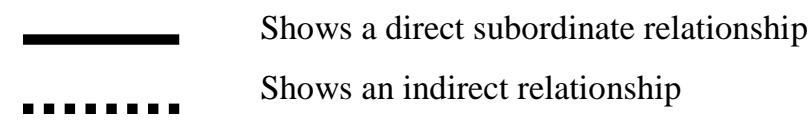

In Singapore, no quantitative nor qualitative research has been conducted or published on the effectiveness of Singapore national sports associations. Thus, it makes sense to start with qualitative work which could be followed up by quantitative studies in the future. Such research in this area in Singapore is beneficial for several reasons: it will add significantly to the sparse sport management literature in Singapore; it can identify gaps between what the Singapore Sports Council views as effectiveness and which tool it uses versus how the different stakeholders view effective measurement and; it can 
help Singapore national sports associations be more aware of the different expectations of their stakeholders and improve their service delivery to satisfy stakeholders' needs and wants.

\subsection{Theoretical frameworks of organisational effectiveness}

Many researchers have stated that while there is a multiplicity of descriptions about organisational effectiveness, and an agreement on its multi-dimensionality, there has been little consensus on its meaning, operational definition, or its measurement (Price 1972:11; Steers 1977:38, 54-57; Connolly, Conlon, and Deutsch 1980:211; Kanter and Brinkerhoff 1981:321-322; Chelladurai 1987:37-38; Cameron 1986:539; Herman and Renz 1999; Shilbury and Moore 2006:8).

On measuring organisational performance, Kanter and Brinkerhoff (1981:321) state that 'the most interesting questions in the area are not technical but conceptual; not how to measure organisational effectiveness or productivity but what to measure; how definitions and techniques are chosen and how they are linked to other aspects of an organisation's structure, functioning, and environmental relations.' Cameron and Whette (1983:262-275) when comparing multiple models of effectiveness conclude that there could not be one universal model of organisational effectiveness and that it was more worthwhile to develop frameworks for assessing effectiveness than to try to develop theories of effectiveness.

Early attempts to measure organisational effectiveness used univariate measures such as overall performance, productivity, employee job satisfaction, profit or rate of return on investment, and employee withdrawal (Steers 1977:39). Kanter and Brinkerhoff's (1981) literature review on performance measurements (in which they did not distinguish terms such as effectiveness, productivity, performance, and success) found that models that recognised the complexity of measurement issues made a distinction among three kinds of 'effectiveness':

a) task effectiveness or goal attainment, including output, results, efficiency; 
b) appropriate organisational structure and process, including organisational characteristics, member satisfaction, absence of strain between subgroups; and

c) environmental adaptation, including flexibility in the face of change, resource acquisition, longer-term adaptation, and survival (Kanter and Brinkerhoff 1981:322).

They concluded that effectiveness appeared more a political rather than a scientific concept as 'the new models of organisations had moved away from rationalistic and voluntaristic assumptions about goal consensus, unity of purpose and the possibility of discovering universal performance standards, to an emphasis on more political views, in which multiple stakeholders both inside and outside, compete to use an organisation for their purposes and to set performance standards that will advance their interests or make their jobs easier.' While practitioners, regulators, donors, managers, and accrediting bodies would continue to search for consensus about effectiveness or performance measures to (a) legitimise objective principles; (b) determine standards of comparison for decision making; and (c) derive techniques of control over performance, the new focus was on (a) how particular measurement systems arose; (b) whose interests they served; and (c) how (or whether) they functioned to guide or shape an organisation's activities (Kanter and Brinkerhoff 1981:344).

Effectiveness in organisations historically has been defined in relation to outcomes or goals. In a seminal work on an inventory of propositions on the effectiveness of organisations, Price (1968:3) defined organisations as 'social systems with specific purposes', and effectiveness, the dependent variable, as 'the degree of goalachievement'. As an example, a prison with a custodial goal, and which had a low escape rate, would be considered an effective organisation (Price 1968:2-3).

As a variable, effectiveness features in many organisational contexts and is discussed frequently in management literature and research. In the history of the measurement of organisational effectiveness, there has been four approaches, each growing out of a dissatisfaction for the earlier:

1. the goal attainment approach (Price 1968) 
2. the system resource approach (Yuchtman and Seashore 1967)

3. the internal process approach (Steers 1977)

4. the strategic constituencies approach (Connolly, Conlon, and Deutsch 1980)

The traditional goal attainment approach studied organisational effectiveness in terms of the degree of goal achievement. The first step was to differentiate between 'official' goals (those that appeared in annual reports, statements by key executives and other official announcements) and 'operative' goals (what the organisation was trying to do through the operating policies regardless of the official goals). Effectiveness was evaluated from what the organisations were trying to do and was well defined only if operative goals were clearly articulated. In addition, it was assumed that among the five intervening variables that were positively related to effectiveness, productivity was accepted as more closely related to effectiveness than morale, conformity, adaptiveness and institutionalisation (Price 1968: 3-5).

The results of Price's (1968) inventory of propositions were that organisations with specific mechanisms in the economic, political (internal and external), control, and population and ecology systems were more likely to have a high degree of effectiveness than organisations which did not have these mechanisms. The mechanisms in the various systems are shown in Diagram 2.1.

However, criticisms of the goal attainment approach, from Price himself, suggested that it had not provided a means to identify organisational goals and it used society, not the organisation, as a basis for evaluation (Price 1972:12-13). It was also not easy to determine the operative goals of the major decision makers. Others have argued that 'the causal associations between certain predictor variables and effectiveness that were claimed to exist simply never had been empirically demonstrated' (Cameron and Whetten 1983:3). Others claimed that the goals were inconsistent, contradictory or incoherent and unclear as to the units used to measure the attainment of goals (Kanter and Brinkerhoff 1981:327). 


\section{Diagram 2.1: The economic, political, control, and population-ecology determinants of the effectiveness of organisations (Price 1968: 205)}

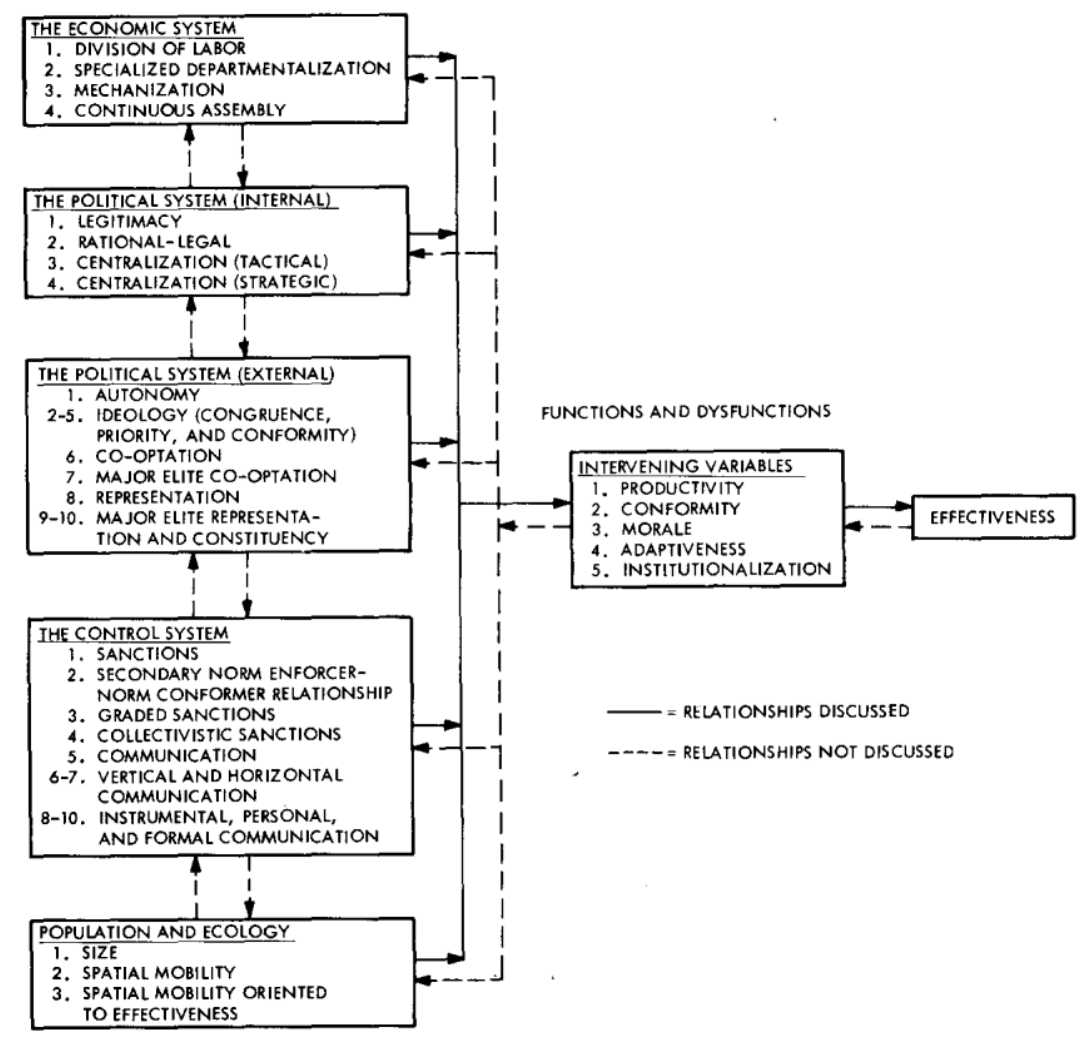

The second framework, the system resource approach, was proposed by Yuchtman and Seashore (1967) to examine effectiveness from the organisation's ability to tap scarce and valued resources from the environment. The premise was that the three processes, resource procurement, transformation, and disposal were so connected that they might be assessed at any point in the loop. However, the criticisms levelled at it include that optimisation of resources is not being measured, that few general measures are used, and the violation of the basic rule of exclusiveness (Price 1972:3).

Frisby (1986) found that the goal and systems models might be complementary rather than alternative approaches to effect measurement. When analysing the relationship between the goal and systems model of organisational effectiveness in Canadian National Sport Governing Bodies, Frisby (1986:95) noted that 'most of the literature on 
the effectiveness of sport organisations had incorporated the goal model whereby the concept was measured in terms of the ability of the organisation to achieve desired objectives ... an emphasis on performance outcome and ... operationalised in terms of win/loss records or performance rankings in comparison to other teams.' Frisby's research showed that one of the goal model indicators, the effectiveness ranking, was positively and significantly correlated with one of the system model indicators, the total operating budget, suggesting that the ability to acquire scarce financial resources was related to the ability of the Canadian National Sport Governing Body to achieve its goal of performance excellence. However, the issue of causality remained debatable as the funding body would prefer to have tangible signs of performance before releasing funds, while it could be argued that funds were required before performance excellence or effectiveness could occur (Frisby 1986:94, 98).

Steers (1977:54-57) proposed eight problems in assessing effectiveness in organisations, namely, construct validity, criterion stability, time perspective, multiple criteria, measurement precision, generalisability, theoretical relevance, and level of analysis. While acknowledging the most widely used evaluation criteria of effectiveness had been adaptability-flexibility, productivity, job satisfaction, profitability and resource acquisition, he identified four major factors associated with effectiveness: organisational characteristics, environmental characteristics, employee characteristics and managerial policies and practices.

Steers (1977) proposed an internal process approach to treat organisational effectiveness multi-dimensionally. Effectiveness is viewed as a set of changing conditions that affect the end, and not an end in itself. The approach emphasised the major process related to effectiveness. Recognising that the organisation and environment would be changing, organisational success could only be garnered by understanding how the components of an organisation were connected, and their interrelationships. The approach examined the three related concepts of goal optimisation, systems perspective, and human behaviour in organisational settings, stating that if organisational objectives were consistent with employee needs and goals, 
the greater the likelihood of increasing organisational performance (Steers 1977:4, 176177). The dynamics between employees was seen as an important criterion and factors such as trust, integrated systems, and smooth functioning were viewed as more accurate measures of organisational effectiveness compared to the goal attainment approach (Shilbury and Moore 2006:10). Steers concluded firstly, that effectiveness was best understood as a continuous process instead of an end state, and that managers emerged as the primary facilitators of organisational effectiveness through actions and behaviour. Secondly, contingencies ought to be recognised, as goals, structures, technologies, people, and environments were unique to the organisation. Thus, training staff members to recognise the nature of a situation and to respond appropriately were more important than prescribed rules for success (Steers 1977:183-184).

The shift of emphasis on human resources led to the development of the strategic constituencies approach. The strategic constituencies approach showed that the organisational goals and systems approaches, though different, shared one critical assumption - that it was possible to arrive at a single set of evaluative criteria and thus a single statement of organisational effectiveness. Being more interested in the features of the environments, the adaptive mechanisms used by the organisation, for example, reactions to changes, Connolly, Conlon, and Deutsch (1980: 216) did not see merit in searching for a single measure of effectiveness on which organisations could be compared. Instead, they proposed a view of organisational effectiveness in which different effectiveness statements could be made about the focal organisation, reflecting criterion sets of different individuals and groups referred to as constituencies. It was 'a view of effectiveness that allowed multiple evaluations from multiple constituencies, so that, for example, one might find the focal organisation rated highly effective on various dimensions by its senior management, moderately effective by the employee's union, somewhat effective by it customers, and quite ineffective by a government regulatory agency’ (Connolly, Conlon, and Deutsch 1980: 212).

More recently, Shilbury and Moore (2006) applied the competing values approach (CVA) of organisational effectiveness to a sample of non profit Australian national 
Olympic sporting organisations (NOSOs) which revealed that the rational-goal model, comprising Productivity and Planning, was the critical determinant of effectiveness in NOSOs (Shilbury and Moore 2006:5).

The above has provided an overview of current academic and practical research on the non profit sector and effectiveness combined with the experiential knowledge of the researcher that existed at the start of the study. To date, while goals, targets or outcomes, have been examined, it is contended that they may not be the best measure of effectiveness in non profit organisations. Some have preferred a tailored approach of measuring effectiveness according to the stage of development of the organisation, with goals or targets being revised periodically and systematically. Others have stated that generating frameworks for assessing effectiveness may be more productive than theorising. Yet others claim that as effectiveness is a social construct, with performance being as good as what others say it is, measurement of effectiveness may be symbolic rather than practical as causality is difficult to prove.

\subsection{Key Research Questions}

In summary, the literature review has covered the theoretical, research and practical issues concerning the historical and current state of knowledge in the non profit sector and organisational effectiveness. In view of the sparse knowledge, data and analysis in Singapore on national sports associations and their effectiveness, this exploratory study proposes to find out:

1a) Do different groups of stakeholders in Singapore national sporting associations have different perceptions of effectiveness?

1b) If so, why?

2) What are the criteria used by the different stakeholders to determine effectiveness of national sporting associations in Singapore?

3a) How are the determinants of effectiveness affected by funding?

3b) Are the outcomes commensurate with the funding received? 


\subsection{Conclusion}

In conclusion, the intent of this literature review chapter has been to highlight research that has been carried out in the field of the non profit sector in general, and the non profit sports sector specifically. The review has clarified terms in the non profit sector, identified concepts, included frameworks, and developed the key research questions to which the findings of the study can be compared and contrasted. Towards this objective, the next chapter will explain the justification for the methodology, the unit of analysis and subjects or sources of data, instruments used to collect data, administration of instruments or procedures, limitations of the methodology, computer software used to analyse the data, and lastly, ethical issues.

END OF CHAPTER TWO LITERATURE REVIEW. 


\section{Chapter 3 Methodology}

\subsection{Introduction}

The primary objective of this chapter is to explain the methodology used in the study. This is a qualitative study. Qualitative research is 'the organized, systematic exploration of some portion of human experience. It is not concerned with the statistical interpretation of data but rather with the discovery of common emergent themes ... its purpose is to gain understanding at the individual or group level' (Donalek and Soldwisch 2004:354). The researcher has applied inductive research in the study to collect and interpret qualitative data on perceptions of organisational effectiveness amongst constituent groups in national sports associations. While using the research findings to re-examine the theory underpinning the research questions, the qualitative study also attempts to generate possible explanations or new theories. To this end, the chapter covers the following seven sections - justification for the methodology; the unit of analysis and subjects or sources of data; instruments used to collect data; administration of instruments or procedures; limitations of the methodology; computer software used to analyse the data; and lastly, ethical issues.

\subsection{Justification for the methodology}

In deciding on the methodology, the four deciding factors were (a) the research questions; (b) the theoretical background; (c) the nature and size of the population; and (d) the practical considerations of doing the research. On research questions, the proposed study attempts firstly, to provide an insight into the different perceptions of effectiveness among the different groups of stakeholders in the Singapore national sports associations and the reasons for the different perceptions. Secondly, it hopes to uncover the criteria used by the different stakeholders to determine effectiveness, and lastly, whether determinants of effectiveness are indeed affected by funding.

Most research on national sports associations in other countries has been quantitative research. In Singapore, there is sparse academic research on national sports 
associations. No qualitative or quantitative study on the effectiveness of Singapore national sports associations could be found. Thus, it is proposed to start with qualitative work, to derive some understanding of the 'perceptions, connotations to meanings, implicit consensus and intentionalities' from research interviews which could be followed up by quantitative studies in the future (Hannabuss 1996:1).

Most of the earlier research conducted on national sport organisations in other countries has focused on volunteerism; association memberships (demographic characteristics); motivations for participation; types of voluntary associations (typologies); the alignment of goals, functions, and its contribution to the social structure and changes in centralisation; specialisation and formalisation in organisational structures and design upon the introduction of professionals (Komarovsky 1946; Gordon and Babchuck 1950; Dotson 1953; Gallagher 1957; Scott Jr. 1957; Wright and Hyman 1958; Warriner and Prather 1965; Booth, Babchuk and Knox 1968; Bratton 1971; Ross 1972; Tomeh 1973; Dauriac 1980; Williams and Jackson 1981; Slack 1981; Beamish 1985; Malenfant 1987; Slack and Hinings 1987; Whitson and Macintosh 1988; Roberts-Du Bord 1989; Wood 1989; Auld 1994; Cuskelly 1995; Green and Chalip 1998; Watt 2003).

Previous literature has analysed the relationship between the goal and systems models of organisational effectiveness in Canadian National Sport Governing Bodies (Frisby 1986), studied the multiple constituent aspects of organisational effectiveness (Cameron 1978; Chelladurai and Haggerty 1991), and explored the effectiveness of Greek national sports organisations using an empirical application of the multiple constituency approach (Papadimitriou 1994). More current research has applied the competing values approach (CVA) of organisational effectiveness to a sample of nonprofit Australian national Olympic sporting organisations (NOSOs) (Shilbury and Moore 2006).

Papadimitriou (1994) included a qualitative element in the research on effectiveness of Greek national sports organisations. Semi-structured interviews were specifically 
employed to explore effectiveness-related perceptions of the constituent groups selected. The reason is that Greek national sport organisations were under-researched with little empirical findings in any organisation theory-related area. The semistructured interviewing was used to distinguish both subtle and specific attributes of the effectiveness construct across the constituent groups (Papadimitriou, 1994: 115-116).

For this study, five constituent groups were originally proposed to be included. They are board members, secretariat staff, coaches, athletes, and volunteers. Examining the perceptions of the major organisational members relevant to the organisation has been documented in literature (Cameron 1978).

There is a population of 59 national sports associations in Singapore. Fifteen of these, previously classified as core and merit national sports associations before 2006, had received the most funding from the Singapore Sports Council. Despite the classifications no longer being applied, the majority of the respondents for the qualitative study still came from these 15 associations as they are better run organisations with secretariats staffed by paid and professional personnel. Because the number of associations from which the informants will be sampled is small, the sports association organisational setting has not been studied in detail previously, and, as it is assumed that the effectiveness construct for non profit sports associations is operationalised differently in each organisation, a qualitative methodology is preferred over quantitative methods.

The objective of the qualitative methodology is centred on reaching the different constituent groups from the various national sports associations for their views on organisational effectiveness. Determining effectiveness is a sensitive issue especially when correlated with outcomes and funding. In addition, the respondents possibly apply different management and operational angles within or across associations. Thus the choice of utilising personal interviews in the qualitative methodology is intended to build trust and to draw out deeper data from the respondents. 
In the process of deciding on personal interviews in the research design, another exploratory method, the single-case study, was also considered. In this study, the single case would be studying a national sports association and its constituent groups. Yin (1989:50) states that the single-case design is usually justifiable under three conditions - where the case represents a critical test of existing theory, where the case is a rare or unique event, or where the case serves a revelatory purpose. Since the objectives of the study are to examine data on perceptions of effectiveness, criteria used by the different stakeholders to determine effectiveness, and finally whether determinants of effectiveness are affected by funding across constituent groups in national sports associations, the evidence from multiple cases (personal interviews across constituent groups and associations) will be more robust. Using a research design of multiple cases will lead to literal replications while allowing the researcher to pursue different patterns of theoretical replications (Yin 1989:53).

Hence, it can be argued that as the case study method focuses on a limited number of associations, the data is less rigourous and transferable as compared to qualitative data from one focus group, seven pilot interviews, and 40 semi-structured interviews across 25 national sports associations which is why a qualitative methodology applied to multiple cases was deemed most suitable for this study.

\subsection{The unit of analysis and subjects or sources of data}

The study had three stages of primary data collection: an exploratory stage through a focus group discussion of 4 participants; a pilot testing stage of 7 personal interviews; and a final personal interviewing stage of 40 interviews. The objective of the exploratory stage was to uncover perceptions on effectiveness, determine the issues involved, and to test the proposed questionnaire so that modifications could be made to sharpen the instrument further.

During the pilot personal interviewing stage, which was the second stage of data collection, the questions were tested on a sub-sample of actual respondents to further refine the instrument. During the pilot interviews, the researcher talked to the 
respondents to find out if there were problems understanding and answering the questions, checked their opinions on the sequence and types of the questions as well as the need for additional questions or elimination of others (May 1997:93). When pilot testing items, Vaus (1995:100-101) recommends examining the questionnaire items for variation, meaning, redundancy, scalability, non-response, and acquiescent response set. These were borne in mind by the researcher. Further, when testing individual questions, the researcher also checked the questionnaire for four things: flow, question skips, timing, and respondent interest and attention (Vaus 1995:101-103).

The third and final stage of data collection was to interview as many members of the targeted constituent groups until data saturation was achieved. During this final stage of data collection, unlike Papadimitriou (1994: 161) who interviewed athletes, coaches, paid staff and finally board members in ascending order of the power they held within the sports organisations. In this study, a different approach was taken for three reasons. Firstly, when the researcher was making contact with the respondents, a few board members had readily agreed to be interviewed. Knowing that accessing board members would be one of the greatest challenges in this study, the researcher interviewed whoever responded affirmatively. Secondly, competence in interviewing and experience in putting respondents at ease, was gained from the earlier focus group discussion and the seven pilot personal interviews. Lastly, the researcher had a decade long career in sport and wellness management education in two polytechnics and a university, as well as being the co-author of Singapore's first introductory textbook on sport management (Ch'ng and Koh-Tan 2006). Thus, despite the researcher knowing that interviewing board members who are often people in positions of status, power and influence may be more formidable than the rest of the constituents, the researcher felt that mutual respect and trust could be established in spite of the sensitivity of information. The researcher was quietly confident about managing the demands of this particular constituent group.

The 51 informants for all three stages of the primary data collection were sourced from contacts in the sports fraternity. Of the 51 informants, the views of 49 were taken into 
consideration in the findings and analysis. The constituent group of volunteers was eventually eliminated from the study after the second stage of primary data collection when the views of the two volunteers were found not to contribute materially to the research. The informants came from 25 national sports associations and the age range was from 18 to 66 years. Some were known personally to the researcher, while others were from associates' referrals. The researcher also made cold calls to potential informants sourced from the Directory of National Sports Associations in Singapore.

For this study, the researcher had made a deliberate attempt to avoid interviewing wellknown sports personalities who served in many government-initiated committees or who were often featured and quoted by the media. The rationale was to get a wider breadth and greater depth of data, and to avoid clichéd or politically correct answers. For these reasons, the researcher tried to get informants from as many national sports associations as possible, and from as wide an age range. In addition, the researcher tried to get balanced gender representation where possible across the constituent groups. However, the fact that female sports administrators, coaches, athletes, and board members, have traditionally been considerably under-represented in Singapore sports, led to more males being interviewed for the study. Table 3.1 summarises the number of male and female informants.

Table 3.1: The number of male and female informants

\begin{tabular}{|l|l|l|}
\hline & Male informants & Female informants \\
\hline Stage 1 - a focus group & 1 & 3 (includes 1 volunteer) \\
\hline Stage 2 - seven pilot interviews & $\begin{array}{l}3 \text { (includes 1 } \\
\text { volunteer) }\end{array}$ & 4 \\
\hline $\begin{array}{l}\text { Stage 3 - 40 semi-structured } \\
\text { interviews }\end{array}$ & 33 & 7 \\
\hline $\begin{array}{l}\text { Total number of informants }=51 \\
\text { Total number of valid } \\
\text { volunteers) }=\mathbf{4 9}\end{array}$ & 37 & 14 \\
\hline
\end{tabular}


The researcher accessed the informants using the following three steps. First, a courtesy call was made to ascertain the identity, position and email address of the potential respondent, as well to make known the objective of the study. Next, an email was sent to explain the aim of the study which also included a brief background on the researcher. Attachments in the email were a personal letter of invitation to participate in the study, a consent agreement form for participation in the study, and a consent agreement form for audio recording. Thirdly, follow up calls, email correspondence, and text messages were executed to confirm the date, time and place of interviews. Therefore, purposive (or purposeful) sampling, which was 'a form of non-probability sampling where cases were judged as typical of some category of cases of interest to the researcher' (de Vaus 1995:78), was used. Purposeful sampling is intended 'to overrepresent those with specific interests rather than "the average view" (Edwards et al 2001:153).

The researcher had originally started with the intention to sample the following five groups of informants for the entire research - Board members, Secretariat staff, Coaches, Athletes, and Volunteers from the national sports associations. However, after the focus group of four participants and seven pilot interviews, the researcher found that the data from the volunteers did not contribute materially to the study on effectiveness, and a decision was made to focus on the first four groups of stakeholders who are formal position holders or representatives of the national sports associations. Thus, ten respondents from each of the four groups of Board members, Secretariat staff, Coaches, Athletes, totalling 40 interviews, during the third and final stage of the primary data collection were targeted and achieved. The objective for the change was to get a wide range of responses on the issues of the study, but in more depth from the selected constituent groups who were the more important stakeholders. While it was the researcher, under the guidance of the supervisor, who decided on the number of interviews, there were some documented guidelines used in determining a meaningful number of cases. Perry's (1995) suggests that as a rule of the thumb, $\mathrm{PhD}$ research requires at least 45 qualitative respondents. The researcher had 49 valid informants 
from the three stages of primary data collection of one focus group, seven pilot interviews and 40 semi-structured interviews.

It was ensured that no informant who participated in the focus group and pilot interviews in the first two stages of the primary data collection was interviewed again in the third and final stage. This allowed for a wider group of stakeholders to provide perspectives of effectiveness. Beyond the national sports associations that were previously categorised as 'core' and 'merit', the researcher also attempted to interview respondents from across as many national sports associations as possible so that voice of the various constituent groups could be heard. These were sampling decisions that employed triangulation of sources and which are techniques for demonstrating validity (Whittemore, Chase and Mandle 2001:553). Furthermore, interviewing respondents from national sports associations beyond the better managed sports bodies offered alternative explanations and explorations that led to uncovering of critical information about a niche group or subculture. This approach also lent integrity and credibility to the qualitative inquiry (Patton 1999:1192).

To ensure rigour in qualitative research, Shenton (2004:73) proposes that the researcher makes provisions for Guba's four quality criteria for trustworthiness so that a convincing case for academically sound work could be made. The provisions were followed where applicable and possible. This is summarised in Table 3.2.

Table 3.2: Provisions that may be made by a qualitative researcher wishing to address Guba's four criteria for trustworthiness Source: Shenton (2004:73)

\begin{tabular}{|l|c|}
\hline Quality criterion & Provisions made by researcher \\
\hline $\begin{array}{l}\text { Credibility (in preference to internal } \\
\text { validity) }\end{array}$ & $\begin{array}{c}\text { Adoption of appropriate well recognised research methods - } \\
\text { A semi-structured questionnaire used in } \\
\text { Papadimitriou's (1994) study of the effectiveness of } \\
\text { Greek national sports organisations was adapted for } \\
\text { use in this qualitative study. } \\
\\
\text { Development of early familiarity with culture of participating } \\
\text { organisations - } \\
\text { The researcher is familiar with the non profit sports } \\
\text { fraternity having been involved in sports and } \\
\text { wellness management education for about a decade }\end{array}$ \\
\hline
\end{tabular}




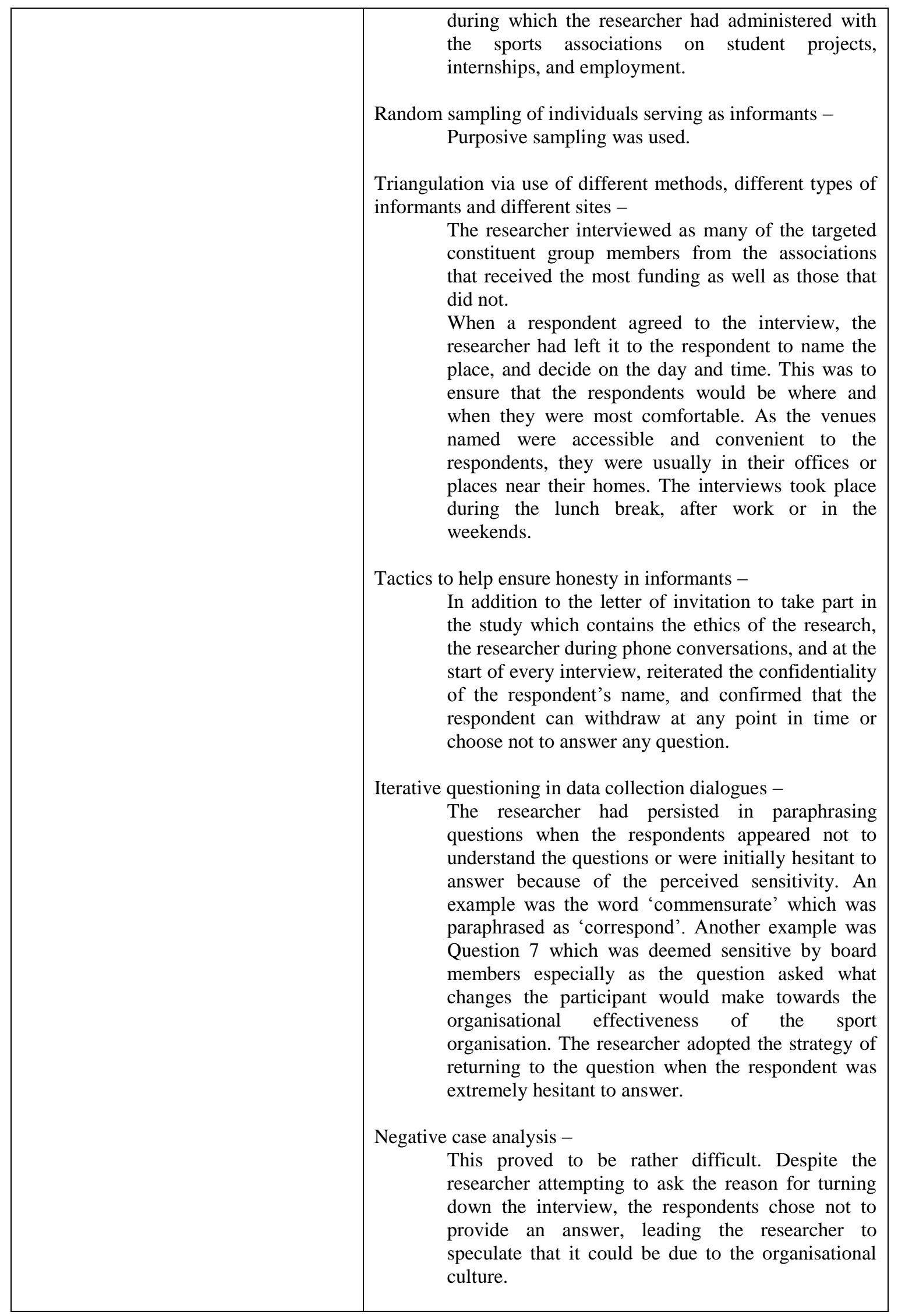




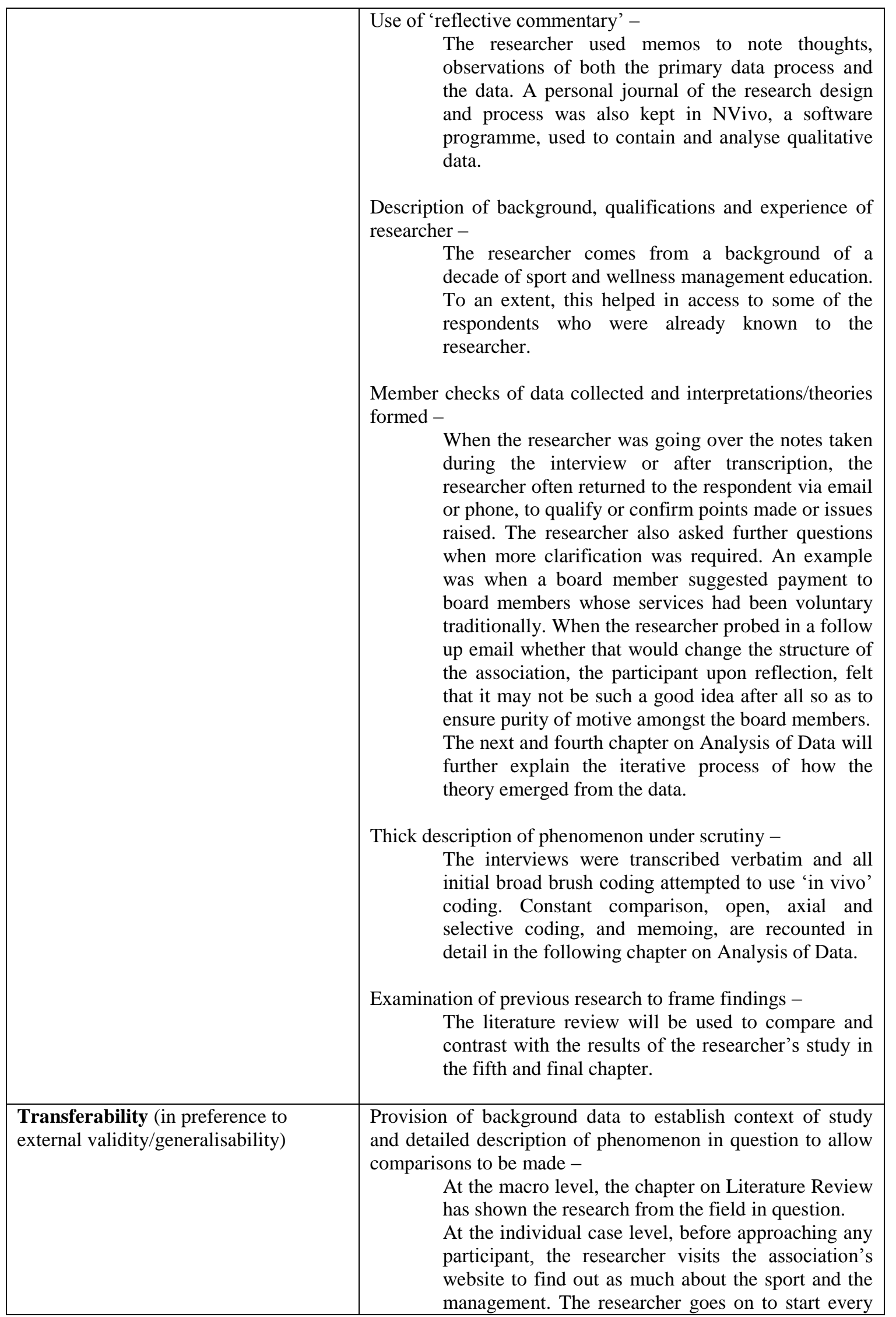




\begin{tabular}{|c|c|}
\hline & $\begin{array}{l}\text { interview by informing the respondent how the } \\
\text { interview process would be. The respondent is told } \\
\text { that demographic questions will be asked first for a } \\
\text { background of the respondent, followed by the } \\
\text { interview proper. }\end{array}$ \\
\hline $\begin{array}{l}\text { Dependability (in preference to } \\
\text { reliability) }\end{array}$ & $\begin{array}{l}\text { Employment of 'overlapping methods' - } \\
\text { The primary data collection was conducted in three } \\
\text { stages, a focus group discussion, followed by pilot } \\
\text { interviews, and lastly the final personal interviewing } \\
\text { stage. } \\
\text { In-depth methodological description to allow study to be } \\
\text { repeated - } \\
\text { This is covered in detail in this chapter on } \\
\text { Methodology. }\end{array}$ \\
\hline $\begin{array}{l}\text { Confirmability (in preference to } \\
\text { objectivity) }\end{array}$ & $\begin{array}{l}\text { Triangulation to reduce effect of investigator bias - } \\
\text { The researcher has attempted to interview as many } \\
\text { stakeholders from the four constituent groups. } \\
\text { Recognition of shortcomings in study's methods and their } \\
\text { potential effects - } \\
\text { The researcher has listed these in the limitations of } \\
\text { the study. } \\
\text { In-depth methodological description to allow integrity of } \\
\text { research results to be scrutinised - } \\
\text { This chapter on Methodology attempts to explain the } \\
\text { research process in as much detail as possible. } \\
\text { When six respondents, two board members, a coach, } \\
\text { two secretariat staff, and an athlete, requested to vet } \\
\text { the transcripts either by themselves or by the } \\
\text { organisation, the transcripts were sent to them for } \\
\text { their comments, all of which were taken into } \\
\text { consideration. This has resulted in amendments } \\
\text { made and to the approval of the respondents. }\end{array}$ \\
\hline
\end{tabular}

\subsection{Instruments used to collect data}

The instruments used to collect data were a semi-structured questionnaire, a focus group, pilot interviews, and personal interviews. The literature review stage led to the discovery of a semi-structured questionnaire used in Papadimitriou's (1994) study of the effectiveness of Greek national sports organisations. This was an empirical application of the multiple constituency approach. The instrument was adopted and used in the focus group and seven pilot interviews, with minor amendments to make the questions clearer, as shown below: 
1. As a board member, secretariat staff, coach, or elite athlete in your national sports association, how would you define the term organisational effectiveness in the context of your NSA?

(Original question: As a participant in the operations of the organisation how would you define the term organisational effectiveness in this context?)

2. Based on your experience, which specific characteristics/factors would affect sports organisations most today?

(Original question: According to your experience, which specific characteristics would effect sports organisations possess today?)

3. Could you please discuss any organisational aspects or characteristics that satisfy you and you do not wish to change?

4. Would you please think of another sport governing body within or outside the country that you perceive as more effective than the one you work or deal with. Now could you identify some factors or characteristics that you think make the organisation more effective?

5. Would you discuss some major problems that your sports organisation has encountered that inhibited its effective functioning?

6. Is there something specifically associated with the organisation's way of functioning that inhibits you carrying out your own responsibilities within the sport organisation?

7. If you were asked to make some changes towards the organisational effectiveness of the sport organisation, what would these be?

8. Can you mention some organisational objectives that your sport organisation is pursuing or trying to achieve?

9. From your own perspective, what criteria would you use to evaluate the overall effectiveness of this organisation?

10. What sort of mechanisms of monitoring organisational effectiveness would be appropriate for the sports organisation? 
Using focus group discussions is a qualitative research method and a focus group is defined as:

a carefully planned discussion, designed to obtain the perceptions of the group members on a defined area of interest. Typically there are between five and twelve participants, the discussion being guided and facilitated by a moderator. The group members are selected on the basis of their individual characteristics as related to the topic of the session. The group-based nature of the discussions enables the participants to build on the responses and ideas of others, thus increasing the richness of the information gained (Langford and McDonagh, ed, 2003:2)

The researcher's reasons for a focus group to precede the data collection phase were not only to test the questionnaire adapted from Papadimitriou (1994), but also to

1) obtain various perspectives on the construct in the respondents' own words, and not wanting to assume perceptions of effectiveness;

2) discover new information not already in the literature review which might be obtained via group interaction;

3) probe for 'why' the respondents felt the way they did, so that beliefs, attitudes, values and other information could be elicited; and

4) find out if there was shared understanding of the construct 'effectiveness' (adapted from Litosseliti 2003:18).

In order to not limit the interviewer to literature-based perceptions of the construct 'effectiveness', a focus group was held during the first stage of the research. Using purposive sampling, the researcher confirmed the attendance of one participant from each of the constituent groups to discuss what constituted 'effectiveness' in national sports associations. The focus group was deliberately kept small so that deeper discussion could take place and the focus group was also used to test whether the adopted questionnaire was appropriate. 
A pressing research concern for the qualitative researcher is to address the issue of gaining access to the potential participants:

For many qualitative investigators, one of the most pressing research concerns lies in 'gaining access'. The researcher's success in this regard will have a significant effect on the nature and quality of the data collected, on the insight into the organisation and its members that the investigator is able to gain, and, ultimately, on the trustworthiness of the findings. Essentially there are two problems of access that must be tackled. The first is that of securing entry into the organisations in which it is hoped that the fieldwork will be conducted ... The second problem lies in persuading individual informants associated with the organisations to contribute data, usually via focus groups or one-to-one interviews ... (Shenton and Hayter 2004:223)

To gain access, a letter of introduction was emailed to participants before calling them for an appointment to conduct the in-depth interview. The one-page formal letter was signed personally and explained the study's aims and usefulness, how the participant was selected, the importance of their response, assurance of confidentiality, an offer to make results available, and details of the researcher including contact number in case the participant wished to ask any questions.

To conduct the focus group discussion, more than ten invitations were sent out by email (Appendix 1) and were followed by phone calls made personally by the researcher. Five participants representing each of the constituent groups - board member, coach, national athlete, secretariat staff, and volunteer, confirmed their attendance. On the actual day, however, four showed up and participated in the focus group discussion held at a conference room in a national sports association in Kallang, National Stadium. Despite the small number of participants, the researcher was not unduly concerned as pilot interviews were planned for the same objectives as the focus group, namely to obtain perceptions of effectiveness, and to test the questionnaire instrument. 
Two participants who had confirmed their attendance were particularly concerned about who was commissioning the research and whether it was funded by Singapore Sports Council. The concern arose over the fact that Singapore Sports Council held the purse strings and the participants did not want to jeopardise themselves and their associations' positions by being honest in their opinions. The researcher explained over the phone that the research was a private endeavour and Singapore Sports Council would not know the identities of respondents. The reassurance was also put in writing and sent to the two participants in an email. Following the apprehension, the researcher decided to include a similar assurance distinctly in all email correspondence that was a precursor to personal interview invitations to participate in the research study.

The focus group discussion took about one and a half hours, and was facilitated by the researcher with a note-taker. Despite the presence of a note-taker, the session was also digitally audio-recorded to help the researcher concentrate on probing and ensuring that all the questions were asked and answered. Written consent agreements were given for participating, and for the audio recording. To protect their identities and to maintain confidentiality, the names of the four participants are not disclosed but symbolically represented by the following:

\begin{tabular}{|l|l|l|}
\hline Participant & National sports association & Constituent group \\
\hline S_FG & Singapore Athletic Association & Secretariat \\
\hline A_FG & Singapore Shooting Association & National Athlete \\
\hline C_FG & Singapore Silat Federation & National Coach \\
\hline V_FG & Triathlon Association of Singapore & Volunteer \\
\hline $\begin{array}{l}\text { Absent with apologies: } \\
\text { B_FG }\end{array}$ & Cuesports Singapore & $\begin{array}{l}\text { Executive } \\
\text { Committee / Board } \\
\text { Member }\end{array}$ \\
\hline
\end{tabular}

Before the start of the focus group discussion, and to settle the participants down, each participant was asked to complete the sentence 'Effectiveness is ...' on A4 sized paper 
individually. The objective was to get participants involved and focused right from the beginning before the discussion proper. Each participant took about five minutes to complete the statement and penned their thoughts. This helped in consolidating their views during the actual discussion.

To start the discussion, the researcher began by assuring the participants that there were no right or wrong answers, no consensus needed to be reached, only aggregate data would be used, and participants were not beholden to the person conducting the research or to The University of Western Australia. Participants were also informed of the objectives of the research which were to learn the determinants of effectiveness in Singapore sporting associations and that the results of the study would contribute to the researcher's doctoral thesis. They were also told that they had been selected as participants in this study because they were either a board member, coach, elite athlete, secretariat staff, or volunteer in a national sports association.

In the next data collection stage, Papadimitriou's questionnaire was piloted on seven respondents through personal interviews from June to July 2006. They comprise two coaches, three athletes, one volunteer, and one secretariat staff. A summary of the respondents, consisting of four females and three males, is shown below:

\begin{tabular}{|l|l|l|}
\hline Participant & National sports association & Constituent group \\
\hline A1_PPI & Football Association of Singapore & National Athlete \\
\hline A2_PPI & Singapore Sailing & National Athlete \\
\hline V1_PPI & Triathlon Association of Singapore & Volunteer \\
\hline S1_PPI & Triathlon Association of Singapore & Secretariat \\
\hline C1_PPI & Netball Singapore & National Coach \\
\hline C2_PPI & & \\
\hline A3_PPI & Singapore Swimming Association & National Coach \\
\hline
\end{tabular}

The piloting revealed that most respondents did not have any trouble identifying and discussing what was ineffective in their national sports associations. However, responses as to what constituted effectiveness, the criteria to evaluate overall effectiveness, and on mechanisms of monitoring organisational effectiveness in their 
associations, required persistent probing from the researcher and more thinking from the respondents. Cameron (1978:604) notes that criteria problems are the major obstacles to the empirical assessment of organisational effectiveness. One obstacle relates to the selection of the criteria and another to the sources of the criteria.

Also during the piloting, in line with Papadimitriou's methodology, some questions produced overlapping responses. However, Papadimitriou had argued that a 'slightly different stimulus-question could provoke the interviewees to explore additional effectiveness related aspects' (Papadimitriou 1994:131). In line with these sentiments, the questions were not changed as the value judgements and information on what constituted effectiveness were important to the study.

The semi-structured interviews (also known as depth or exploratory interviews) aim to understand perceptions, perspectives, and meanings attached to situations and contexts important to the respondents. As affirmed by Edwards et al. (2001:158), one-to-one interviewing generates outcomes 'with greater emphasis on the issues which are most pertinent or sensitive to the individual concerned'. Since data quality is highly dependent on social and communicating skills, the researcher attempted to establish a good rapport with respondents and to gain their trust. Also, the researcher tried to be flexible yet probing, and minimised intervention by listening carefully and recording accurately.

The following techniques were undertaken to improve rapport during the face-to-face interview process. A relaxed atmosphere was promoted in which the respondent could concentrate. The researcher accommodated the respondent's choice of venue, date, and time as long as the place was conducive for audio recording. From the pilot personal interviews, the researcher had discovered that interviewing at public places, such as cafes and restaurants, resulted in poor digital audio recording which became a problem during the transcription of the data. There was no presence of third parties, and the researcher sat opposite or beside the respondent where possible, and used eye contact to establish rapport. At the beginning of the interview, the researcher made light 
conversation by asking questions on the respondent's attributes such as years in the current position, influence on decision making, age and citizenship. After clipping the microphone onto the collar, the respondent was asked to introduce himself/herself and the researcher used an ear phone piece simultaneously to check the recording sound quality before proceeding. The researcher reminded the respondent that the answers would be in the capacity of the respondent's position in the national sports association before starting to ask the first question. While the interview was in progress, the respondent was kept on track by avoiding making the interview sound like a test. No attempt was made to educate or convert the respondent.

To discourage respondents from giving answers that they thought the interviewer might want, the interviewer avoided giving any opinion at all times. Surprise, or any emotion, was also avoided. When respondents did ask for views, the question was deflected until the end of the interview, saying that it was best to wait till then. When a respondent provided an answer to a later question in response to an earlier question, the later question would still be asked. Since the question order could affect responses it was important that all interviewees answered the questions in the same order. In such situations, the apparently redundant question was prefaced by saying 'I'd just like to check ...'. Open-ended questions often required probing. To encourage full answers was accomplished by the use of an expectant glance, or phrases such as 'mmm', 'and?', 'Can you tell me more?', 'I'm not clear what you mean by that', 'What other reasons?', 'What else?', 'Exactly why do you think that's important', or 'Could you be a little more specific?' Because uniformity was important, questions would be read exactly as they appeared in the interview schedule. However, when the respondent appeared not to understand the question fully, by looking puzzled or by making a request to repeat the question, the researcher attempted to paraphrase the question. While the answers were digitally recorded as they were given, the researcher jotted down important points on a writing pad to fill in missing gaps in case the audio recording was not clear and to aid in the checking of the transcript. Finally, upon completion of the interview, the researcher ensured that no questions had been missed by checking the list of questions (adapted from de Vaus 1995:115-116). 
As with the focus group discussion, there was a difficulty in getting board members to participate in the pilot interviews. The pilot personal interviews ranged from 45 minutes to one and a half hours. Both the piloting done on the focus group, and the personal interviews, revealed several issues pertinent to the data gathering which helped the researcher further define the number of constituent groups and refine the recruitment strategies in the final stage of the primary data collection.

One, the piloting showed the researcher that trying to access board members, which is a constituent group for the study, would prove to be challenging as this group consists of professionals, executives, and businessman, who are busy and hard-pressed for time. Also, as their positions in the national sports associations are voluntary, board members may not view granting the interview as priority despite being involved in decision making. The topic too may be seen as sensitive since board members make policy decisions and do have a large say in the day-to-day operations of their respective national sports associations. On the other hand, the athletes, coaches and secretariat staff seemed to welcome the study with three respondents, a coach and two secretariat staff, requesting for the results of the study to be made known to them. Since access to board members would be a challenge, the researcher used the referral system to reach out to potential respondents. Each interviewee, as well as the researcher's contacts in the non profit sports sector, was asked for referrals to help the researcher attain the required number of interviews for the study.

Another issue that surfaced during the piloting was the responses of the volunteers. From the focus group and the pilot interview, the two volunteers did not have extensive dealings, nor comprehensive knowledge, of any management aspect of the associations, as their involvement in events was ad hoc. As such, it was found that their responses did not contribute significantly to the study, and thus the researcher chose to concentrate on the four constituent groups of board members, secretariat staff, coaches, and athletes for the third and final stage of the data collection. 
Interviewing many stakeholders from the four different constituent groups across national sports associations will reveal multiple observations and perceptions. However, the process will allow testing for consistency that will enhance the quality and credibility of the research: 'Finding inconsistencies ought not to be viewed as weakening the credibility of results, but rather as offering opportunities for deeper insight into the relationship between inquiry approach and the phenomenon under study’ (Patton, 1999:1193).

The personal interview is a commonly used qualitative technique and potential respondents are purposefully sought for their knowledge in the areas and their ability to articulate their perceptions of the phenomenon under study. Sue Jones (in Clive 2004:257-258) explains that 'in order to understand why persons act as they do we need to understand the meaning and significance they give to their actions ... the depth interview is one way ... of doing so ... For to understand other persons' constructions of reality we would do well to ask them (rather than assume we can know merely by observing their overt behaviour) and to ask them in such a way that they can tell us in their terms (rather than imposed rigidly and a priori by ourselves) and in a depth which addresses the rich context that is the substance of their meanings (rather than through isolated fragments squeezed onto a few lines of paper).' Gratton and Jones (2004:141) advised that the semi-structured interview 'uses a standard set of questions, or schedule. However, the researcher adopts a flexible approach to data collection, and can alter the sequence of questions or probe for more information with subsidiary questions'.

Since the study proposes to find out whether the determinants of effectiveness are affected by funding, and whether the outcomes commensurate with the funding received, the researcher made a decision to add two more questions after piloting the questionnaire. Question 11 asked 'How are the determinants of effectiveness in your national sports association affected by funding?’. The last question, Question 12, asked 'Do you think the outcomes are commensurate with the funding received so far, in your national sports association?'. The table below shows the final questionnaire used in the personal interviewing stage of the study: 
1. As a board member, secretariat staff, coach, or elite athlete in your national sports association, how would you define the term organisational effectiveness in the context of your NSA?

2. Based on your experience, which specific characteristics/factors would affect sports organisations most today?

3. Could you please discuss any organisational aspects or characteristics that satisfy you and you do not wish to change?

4. Would you please think of another sport governing body within or outside the country that you perceive as more effective than the one you work or deal with. Now could you identify some factors or characteristics that you think make the organisation more effective?

5. Would you discuss some major problems that your sports organisation has encountered that inhibited its effective functioning?

6. Is there something specifically associated with the organisation's way of functioning that inhibits you carrying out your own responsibilities within the sport organisation?

7. If you were asked to make some changes towards the organisational effectiveness of the sport organisation, what would these be?

8. Can you mention some organisational objectives that your sport organisation is pursuing or trying to achieve?

9. From your own perspective, what criteria would you use to evaluate the overall effectiveness of this organisation?

10. What sort of mechanisms of monitoring organisational effectiveness would be appropriate for the sports organisation?

11. How are the determinants of effectiveness in your national sports association affected by funding?

12. Do you think the outcomes are commensurate with the funding received so far, in your national sports association?

Source: Questions 1 to 10 from Papadimitriou (1994); Questions 11 and 12 added by the researcher. 
A summary of research methods used in the study is shown here:

\begin{tabular}{|c|c|c|}
\hline Purpose of research & Information required & Research method \\
\hline $\begin{array}{l}\text { To find out what the five groups of } \\
\text { stakeholders (board members, paid } \\
\text { secretariat staff, coaches, national } \\
\text { athletes, and volunteers) in the core } \\
\text { and merit national sports associations } \\
\text { in Singapore perceive are the } \\
\text { determinants of 'effectiveness'. }\end{array}$ & Qualitative & Focus group \\
\hline $\begin{array}{l}\text { To explore the perceptions of } \\
\text { organisational effectiveness in sports } \\
\text { associations from the various } \\
\text { stakeholders' perspectives. }\end{array}$ & Qualitative & $\begin{array}{l}\text { Semi-structured } \\
\text { interviews }\end{array}$ \\
\hline
\end{tabular}

Below is a summary of the process undertaken to pilot and modify the questionnaire, and revise the number of cases used to collect data for the study:

\begin{tabular}{|c|c|c|}
\hline $\begin{array}{l}\text { 1) Related study } \\
\text { to previous } \\
\text { literature: } \\
\text { a) adopted } \\
\text { Papadimitriou's } \\
\text { (1994) semi- } \\
\text { structured } \\
\text { questionnaire } \\
\text { instrument, and } \\
\text { b) selected five } \\
\text { constituent } \\
\text { groups for the } \\
\text { study - athletes, } \\
\text { coaches, } \\
\text { secretariat staff, } \\
\text { board members } \\
\text { and volunteers. }\end{array}$ & $\begin{array}{l}\text { 2) Pilot-tested } \\
\text { questionnaire on: } \\
\text { a) a focus group, } \\
\text { and } \\
\text { b) personal } \\
\text { interviewees }\end{array}$ & $\begin{array}{l}\text { 3) Made } \\
\text { modifications to } \\
\text { research design: } \\
\text { a) to the } \\
\text { questionnaire by } \\
\text { including two more } \\
\text { questions on } \\
\text { whether } \\
\text { effectiveness and } \\
\text { outcomes are } \\
\text { affected by } \\
\text { funding, and } \\
\text { b) to the cases by } \\
\text { concentrating on } \\
\text { four constituent } \\
\text { groups instead of } \\
\text { five by excluding } \\
\text { volunteers. }\end{array}$ \\
\hline
\end{tabular}

As the researcher progressed from the focus group to the pilot personal interviews, the data was constantly compared as the researcher revisited the transcripts, noting what was emerging from the data from one pilot interview to the next. The analysis of text involves four key tasks according to Ryan and Bernard (2003:85). The first is the 
discovering of themes and sub-themes. Second is the winnowing of themes to a manageable number. Third is the building hierarchies of themes or code books, and lastly, the linking of themes into theoretical models. The researcher followed the steps listed here using an inductive approach as well as an a priori approach termed theoretical sensitivity, and looked for themes using the following recommended eight observational techniques: repetition; indigenous typologies or categories; metaphors and analogies; transitions; similarities and differences; linguistic connectors; missing data; and theory-related material (Ryan and Bernard 2003:89-94).

NVivo is a qualitative software package that allows the researcher to handle rich and voluminous data by having capacities for storing information from various sources (memos, transcripts and scanned documents) and in several forms (text, audio, and pictures). Providing also a range of tools for coding, classifying, and handling records, it allows swifter access to data and facilitates exploration and analysis. In NVivo, seven attributes were created to capture the demographic information of the respondents in both the focus group and the pilot interviews and they are age, gender, citizenship, sport, length of service, position held and decision making. Using broad-brush coding as a first step to coding by going through the transcript line by line to 'break open' the data and the concepts in them (Bazeley and Richards, 2005:54-55), a total of 38 free nodes was initially coded in NVivo after examining the transcript of the focus group (Appendix 2). As broad-brush coding allows the researcher to identify text that is relevant to the areas that needs focus, the organisation of the tree node level was attempted only after the seven pilot interviews. Thinking about the structure of tree nodes was done by visiting the focus group data, examining the personal interview data and considering the initial free node coding. Next, concept coding was employed which resulted in an integrated process combining development of codes, coding, memoing and reflective journaling (Bazeley and Richards, 2005:55), with early categories created 'up' from the data.

During the third and final personal interviewing stage of the primary data collection, special recruitment strategies were used to address unique barriers, beliefs, and 
concerns of the respondents. When one secretariat staff informed the researcher that his Board had wanted to see the questions before the interview, the researcher duly supplied them. Subsequently, the Board requested that he penned his answers for their approval first. The potential respondent then informed the researcher that he would turn down the interview because it required too much effort. To go round the problem, the researcher suggested that he provided his views in the interview, after which the researcher would email the transcription to him for the Board's approval. The respondent was agreeable and the interview went ahead. Another respondent, a board member, required the researcher to speak to two gatekeepers and after numerous calls, finally agreed to be interviewed. A national athlete, who was employed by the association was specifically instructed by the high performance manager to refer all requests for interviews to the administration manager of the secretariat. The researcher had to reassure her that it was not a request for a media interview but for academic research. Since the athlete was about to resign as an employee and was kind enough to provide her private email address, the researcher suggested that they meet up after she was no longer in the employ of the association. From that particular episode, the researcher realised that some athletes, like some secretariat staff, had been instructed to refer requests upwards. As such, for the national sports associations perceived to be not as open or more bureaucratic, the researcher avoided the use of the word 'interview' by changing the subject in the email from 'Request for a 30 minute interview' to 'Request for 30 minutes of your time for a research study'. Within the email too, the word 'interview' was avoided, while repeating the assurance of confidentiality and anonymity (see Appendix 3). When the researcher had no response to the email invitation and follow up calls, the first email was resent in case the potential participant genuinely missed it the first time (see Appendix 4).

For potential respondents who had refused the interviews, follow up emails were sent in an attempt to persuade them to assist. The example shown in Appendix 5 is a reply penned to a secretariat staff from a national sports association who had emailed to turn down the interview invitation and suggested for the researcher to approach the Singapore Sports Council for assistance. The rationality of the potential respondent's 
suggestion will, of course, not be debated here. Instead the researcher replied and clarified that the study was private, self-sponsored, and confidential (see Appendix 5).

For all respondents who had been interviewed, the researcher sent an email to thank them for their time and information, occasionally addressing issues raised by the respondent in the interview. An actual email is shown in Appendix 6. In this example, the respondent had referred several times apologetically to their association's widelypublicised case of the lack of financial controls resulting in a secretariat staff absconding with a large sum of money yet to be recovered (see Appendix 6).

It was found that referrals from respondents who had been interviewed were particularly helpful as they opened doors to other interviewees that the researcher had previously found difficult to access via cold calls and the directory. During the final personal interviewing stage of the primary data collection, twelve potential respondents replied in the negative to the researcher's email invitation, did not respond, or did not provide a firm reply. For those who did not reject outright, the researcher attempted to remind and reassure them in order to get these respondents to agree to an interview, but after weeks and sometimes months of following up, the researcher had to let go and move on.

With permission from all the respondents, the oral data from the qualitative interviews was captured using digital audio recording. As each interview lasted from 40 minutes to one and a half hours, the benefits of using digital audio recording were increased fidelity, longer recording time, and the ability to index recordings. These resulted in quicker transcription and project completion times, lower costs, and reliability. These benefits are similar to Given's (2004) findings on using digital audio recording to capture oral data from qualitative interviews. No respondent appeared particularly influenced by the presence of the digital recorder. In the rare occasion when the respondent had requested the digital recorder to be turned off, the researcher recorded the views in writing, and the contents were analysed in conjunction with the recorded data later. The researcher also engaged the respondents in conversation after the 
interview and found that information rendered after the interview and recording were particular useful. These important points were noted in the researcher's memos which were stored in NVivo and analysed together with the transcripts.

In addition to the digital audio recording, the researcher had also made notes on important points during the personal interviewing. This proved invaluable when the researcher wanted to clarify points made immediately after the interviews and during the checking of the transcripts. Transcription of the data was done, in part by the researcher herself, and in part by outsourcing. Digital audio files were emailed to the service provider. When going through each transcript for accuracy of meaning, the researcher called and emailed the respective respondents to clarify data that were not fully understood. The analysis of the data will be covered in-depth and more holistically in the next chapter.

\subsection{Administration of instruments or procedures}

Taking into account the ethical considerations of the research which had to give adequate consideration to respondents' welfare, rights, beliefs, perceptions, customs and cultural heritage, the following were ensured:

- A formal letter of introduction was given to potential respondents that outlined the key research objectives, possible outcomes of the study, how the respondent was selected and importance of the response. The researcher's email and mobile number were in the letter in case the respondent had questions.

- Consent of respondents was obtained.

- As no monetary incentive was given, an offer to make results available to respondents was made.

- Voluntary participation was emphasised so that respondents were not unfairly burdened by participating.

- Recruitment did not discriminate on the basis of age, gender, or race as these factors were not essential to the purposes of the research.

- Anonymity and confidentiality were assured. 
- Respondents were informed that they could withdraw from the research at any time and that they did not need to provide a reason for the decision.

The table below sums up the three stages of the primary research undertaken from May 2006 to May 2007:

Table 3.3 The stages of development of the research undertaken (2006-2007)

\begin{tabular}{|l|l|l|l|}
\hline Month $\rightarrow$ & May 2006 & Jun - Jul 2006 & $\begin{array}{l}\text { Dec 2006 - } \\
\text { May 2007 }\end{array}$ \\
\hline Research stages $\downarrow$ & & & \\
\hline Focus group & $\sqrt{*}$ & & \\
\hline Pilot personal interviews & & $\sqrt{*}$ & $\sqrt{\#}$ \\
\hline Semi-structured interviewing & & & \\
\hline
\end{tabular}

* Used existing instrument with minor amendments.

\# Modified questionnaire to include two more questions on whether effectiveness and outcomes are affected by funding

\subsection{Limitations of the methodology}

The focus of the study was on Singapore national sports associations and might be difficult to generalise across countries. It might also not be representative and thus difficult to replicate. The data was collected cross-sectionally and was a snapshot of a single time frame.

There was also the challenge of generalising from a small sample. As board members are usually very important people, the researcher had anticipated barriers to access. The researcher had to be prepared for this by enlarging or substituting the sample size to include past board members, but eventually all respondents turned out to be current Board members. Also, inherent with purposive sampling strategies, one sampling limitation in qualitative research design is that 'findings would be limited based on selectivity in the people who were sampled either for observations or interviews, or on selectivity in document sampling' (Patton, 1999:1197). There might be problems of interviewer bias and subjectivity, so special effort would be undertaken by the researcher to be unobtrusive, avoid a researcher's pose, and aim for the interview to take place in as 'natural' a context as possible for the respondent, for example in his/her workplace, neighbourhood, or a neutral setting. 
In the process of data collection during the third and final stage, the researcher discovered that trying to access national coaches was a limitation that was not foreseen. As the number of national coaches in each association, compared to the number of board members, secretariat staff, and national athletes, is the smallest, the researcher found that accessing them through the associations or themselves directly, was a challenge for at least half of the coaches interviewed. Many were actively coaching and finding time to see the interviewer was a challenge. Quite a few salaried national coaches also feared offending either the management of the association or the Singapore Sports Council and thus were restrained in their views.

The researcher carried out the research alone. While the personal characteristics of the researcher helped open many doors, it could have contributed to a formal interviewer and interviewee relationship thus not enabling the researcher to be on more relaxed terms with respondents and getting even more in-depth data. Thus, at the time of the data collection, the researcher introduced herself as an academic involved in sport and wellness education for more than a decade, having taught in two polytechnics full-time and two universities part-time, and a co-author of Singapore's first introductory sport management textbook. In addition, in the email, letter of request, tele-conversations, text messages, and face-to-face, the researcher addressed the potential respondents formally using 'Mr' or 'Ms' and in standard English all the time. The address of The University of Western Australia penned at the top left-hand corner of the letter of request, together with the statement that the research was undertaken at the doctoral level, lent considerable weight to the request. Lastly, in all sign-offs, the researcher included two surnames showing clearly her marital status. All these probably signalled, consciously or unconsciously, to the respondents the maturity, credibility, and possibly serious disposition of the researcher in advance, leading to an interviewer and interviewee relationship during the interviewing which led to generally wellconsidered, polite, or politically correct answers. 
Time was another limitation most felt by both the respondents and the researcher. Most respondents were time conscious, with board members being the most pressed. This resulted in the researcher consciously trying to abide by the time agreed upon before the interview, and in so doing, had to hasten asking some questions, leading to selective probing.

Another impediment was the respondents' understanding of the terms of reference which might differ as they were qualitative in nature. The researcher could attempt to overcome the limitation by defining the terms of reference prior the interview during the invitation to participate in the study and at the beginning of the interview again, to ensure consistency in interpretation. Several respondents felt that the term 'organisational effectiveness' was wide and were worried about giving correct answers. The researcher explained to these respondents that it was the individuals' perceptions of effectiveness that mattered most in their position and the carrying out of their responsibilities in the national sports association.

As there were a number of foreign talents in the form of athletes and coaches, the researcher had to ensure, even before inviting them to take part in the study, that their command of the English language was sufficient for them to understand the questions, the interviewer, and for the researcher to understand them. For foreign talent coaches and athletes who did not understand English well enough, they had to be consciously left out of the study as the researcher was not in favour of using interpreters which will incur additional costs and time. However, what the researcher did not quite anticipate, but discovered during the research, was Singapore citizens by birth, would be apprehensive to speak to the researcher because they had felt that their command of the English language was not proficient enough. The researcher later found out that these two respondents, a board member and a coach, were more comfortable in the vernacular languages, Mandarin and Malay respectively, while meeting and interviewing them. 


\subsection{Computer software used to analyse the data}

The researcher developed records from a focus group, personal interviews, observations, and literature review, with sources from field notes, memos, and transcripts, in various forms such as digital recording and text. As qualitative research requires the management of complexity of data from various sources and forms, and does not often use a fixed body of previously collected data, NVivo provided a range of tools for handling rich data records and information about them for browsing and enriching text, coding it visually or at categories, annotating, and gaining accessed data records accurately and swiftly. In addition, as the researcher linked, coded, shaped and modelled data, the software helped in the management and synthesis of data, and for constructing and testing answers to research questions (Richards 1999:4).

After the personal interviews had been transcribed verbatim, together with field notes, observations, memos, and literature review, the qualitative data was analysed using NVivo software to organise the data into general themes. A manual organising system was used to break the data down into specifics or sub-themes. Validation of the results was ensured at two points: one, during the interview and two, after the data had been analysed. During the interview, the interviewer reaffirmed or reworded any ambiguous statements made by the respondent. In the event that the researcher was still in doubt, the researcher would seek clarifications from the respondents so that the latter could ensure that the data had been accurately represented (Pohl, Borrie, and Patterson 2000:421).

The analysis started with the researcher getting to know the data well by listening to the digital recordings of the interviews several times while revisiting the transcripts. The researcher penned further impressions and added to the information stored in the memos created for each respondent after each interview, while also constantly noting information that did not contribute meaning at that point, but in case they might be of value later. The identification of concepts started mentally with the transcribing of the digital audio recording. When the interview transcripts and memos were imported to NVivo for coding and analysis, broad brush coding started with the data from the focus group and after each pilot interview. As much as possible the researcher practised 'in 
vivo' coding, which is to create a new node by naming it with the word in the text that is being coded, so as to prevent over interpretation and reading too much into the data. By so doing, the researcher was trying to avoid finding only what the researcher was trying to look for, also known as researcher bias.

During the process of coding and simultaneous analysis, the researcher struggled and faced frustrations in coding the data. The difficulties included trying to truly understand the coding process, and distinguishing core and sub-categories, and their descriptions. There were also countless iterations and re-examinations of the data, and as the researcher kept focus by having the research objectives in mind, many free nodes were recoded, others deleted, while some were added. Other nodes were compressed due to previous multiple coding, and some were renamed to better reflect the concepts generated from the data. Throughout the process, the researcher who was a novice coder, was anxious about doing the coding correctly, and felt overwhelmed by the quantity of data amassed. Finally, the researcher decided to heed the advice of Glaser (1998) in Heath and Cowley (2004:149) by 'adhering to the principle of constant comparison, theoretical sampling and emergence ... and discover an approach that best balances interpretation and data that produces a grounded theory ... with the aim of discovering a theory that will aid understanding and action in the area under investigation.' The researcher also followed Heath and Cowley's (2004:141) advice for novice researchers 'to select the method that best suits their cognitive style and develop analytic skills through doing the research' rather than worry about the various grounded theory approaches, their respective definitions of the different types of coding and coding methods, and the anxiety of getting things right.

To summarise the coding process in NVivo, the researcher used an adapted grounded theory method where interviewing, coding, and analysis were carried out simultaneously. Organisation began with the holding of all qualitative data sources, often messy, comprising transcripts, memos, and project documentation in NVivo, so that the narratives could be easily accessed, described, and analysed. During broad brush coding in NVivo resulting in more than 200 nodes, the data were closely 
examined for matching, recurring, and new themes through iteration and constant comparison. For the data that did not fit then, the researcher kept an open mind and included the data in the tree node 'Context' in case it might be useful later or simply to pose a challenge to the researcher that the analysis may be broader than it would otherwise be. This ground up approach allowed categories and sub-categories to emerge from the data which were further redefined or refitted in a hierarchical tree node system to catalogue the nodes in NVivo. During the various stages of data analysis, the researcher attempted to find causal and intervening conditions, interactions among the constituent groups with respect to the category, consequences of the interations and context, for the objective of increasing knowledge of the categories. The researcher consciously avoided the want to see things, and pre-empted researcher bias, by being sceptical, finding counter examples or evidence that disconfirmed, questioning if it made conceptual sense, before acceding that the pattern provided useful knowledge (Miles and Huberman 1994:246). Finally, after detailed development of categories, the selection of concepts took place in relation to the properties and dimensions of the core categories.

\subsection{Ethical issues}

Formal permission had been sought from The University of Western Australia's Ethics Committee before undertaking the qualitative research to ensure that all ethical issues were addressed. Potential informants were invited to participate voluntarily and consent was sought with assurance of confidentiality and anonymity. They were sent an introductory letter by email to inform them of the research objectives, time frame, and use of digital voice recording. It included a consent form for return to the researcher. Informants were allowed to withdraw at any time (see Appendix 7).

Typically, giving informed consent means the informants were informed about:

1. the purpose of the study and its basic procedures

2. an outline of any reasonably foreseeable risks, embarrassment or discomfort (e.g. questions that may deal with very private or sensitive matters)

3. a description of the likely benefits of the study 
4. a description of how the respondent was selected for the study

5. an offer to answer any questions

6. a statement that participation was voluntary and that the respondent was free to withdraw at any time or to decline to answer any particular question

7. the identity of the researcher and the sponsor, and

8. some information about the way in which the data and conclusions might be put (Vaus 1995:334).

The informants were assured that only aggregated data would be used and that personal information would be kept confidential. Data security would be ensured with notes, transcripts, computer files, and drives password protected. Only the researcher and the supervisor would be privy to the information and all records would be destroyed after five years. To maintain the confidentiality of informants, no information or responses would be given to other person/s or organisation/s.

\subsection{Conclusion}

In summary, this chapter on Methodology has outlined and justified the qualitative methodology chosen for the study as the research explores perceptions and constructions of the meaning of effectiveness in national sports associations that have not been examined previously. Concerns on internal validity, external validity, reliability, and objectivity in qualitative research have been addressed explicitly.

The chapter has also shown how Papadimitriou's (1994) semi-structured interview was modified and adapted through pilot testing on a focus group and seven personal interviews before embarking on the final primary data collection of forty interviews. In addition, the chapter has also attempted to provide an audit trail showing how the final four constituent groups of athletes, coaches, secretariat staff and board members were derived.

The instruments used to collect data, the response rates, and the handling of interview protocols, have been documented to ensure that the research can be repeated. While 
most of the limitations have been listed and explained, another possible limitation could be that some potential respondents could have been missed because of the time and access constraints.

To observe the ethics of the research closely, the consent forms to be an informant in the study and for the digital audio recording were signed before the data collection with assurance of confidentiality and anonymity. The computer software NVivo is selected to analyse the data as NVivo allows for the management of complexity and the software can be self-learnt during the research process.

The next chapter on Analysis of Data will present patterns of results and analyses pertinent to the research questions.

END OF CHAPTER THREE METHODOLOGY. 


\section{Chapter 4 Analysis of data}

\subsection{Introduction}

The previous chapter explained the research methodology. This chapter presents an analysis of the data without seeking to draw conclusions. Such conclusions form the substance of the next chapter. The chapter is organised by first describing the subjects, secondly by showing patterns of data for each key research question, and finally a summary of the key points.

\subsection{Participants}

The descriptive data of subjects is provided in this section. Excluding the two volunteers who did not contribute materially to the study (one from the focus group and another from the pilot interviews), the final participants from the four constituent groups of athletes, coaches, secretariat staff, and board members included:

- three participants from three national sports associations at the focus group,

- six participants from six national sports associations during the pilot interviews, and

- forty participants from twenty-four national sports associations during the personal interviews.

Thus, there were 49 valid participants. The respondents who participated in the research study were from the following 25 national sports associations:

1. Basketball Association of Singapore (BAS)

2. Cuesports Singapore

3. Fencing Singapore

4. Football Association of Singapore (FAS)

5. Netball Singapore (NS)

6. Persatuan Sepak Takraw Singapura (PERSES)

7. Singapore Amateur Cycling Association (SACA)

8. Singapore Athletic Association (SAA)

9. Singapore Badminton Association (SBA)

10. Singapore Baseball \& Softball Association (SBSA)

11. Singapore Bodybuilding and Fitness Federation (SBBF)

12. Singapore Bowling Federation (SBF)

13. Singapore Dragon Boat Association (SDBA)

14. Singapore Gymnastics (SG)

15. Singapore Hockey Federation (SHF) 
16. Singapore Rugby Union (SRU)

17. Singapore Sailing Federation (SSF)

18. Singapore Shooting Association (SSA)

19. Singapore Silat Federation (SSF)

20. Singapore Squash Rackets Association (SSRA)

21. Singapore Swimming Association (SSA)

22. Singapore Table Tennis Association (STTA)

23. Singapore Taekwondo Federation (STF)

24. Singapore Tennis Association (STA)

25. Triathlon Association of Singapore (TAS)

The demographic information of the participants comprising Age, Citizenship, Decision making, Gender, Length of service, Position, and Sport, were gathered at beginning of each interview. The information was stored in NVivo as Attributes, and each respondent was termed a Case.

When the broad brush and preliminary axial coding was completed on the data from all three stages of the research (the focus group, pilot personal interviews, and personal interviews), there were 210 nodes. The large number of nodes suggested the need for greater coherence. Some node reduction was required as some nodes had no references due to the re-coding and modification process while others had a handful of references. Thus, the researcher continued to focus the analysis by coding-on and reducing the number of nodes. The data was re-visited and intensive coding continued on the data of each respondent, identifying similar themes, ideas, concepts, meanings and terms used, and organising the information into coherent categories and sub-categories in a hierarchical tree node structure. Many revisions were made yet again to the codes with some being added, re-coded, and others discarded. The node system continued to develop from the time the researcher started on the broad tree structure framework. It was only during analysis and at the end of the study, and after many iterations, reflection and review of the coding process, in addition to data reduction, reorganisation, explanation and verification, that a final hierarchical structure with saturated categories was arrived at. The structure also functions as a taxonomy, a way of organising, visualising, and locating categories and sub-categories and is shown in Table 4.1 below: 
Table 4.1 Hierarchical tree node system

\begin{tabular}{|c|c|c|c|}
\hline & Themes / issues & Described as & $\begin{array}{l}\text { Relating to broader concepts / } \\
\text { outcomes }\end{array}$ \\
\hline \multicolumn{4}{|l|}{ Perceptions of effectiveness } \\
\hline & communication & $\begin{array}{ll}- & \text { two-way and open } \\
- & \text { formal and structured } \\
- & \text { timeliness } \\
\text { - } & \text { voice for athletes }\end{array}$ & $\begin{array}{ll}- & \begin{array}{l}\text { ability to manage athletes } \\
\text { professionally (athletes) }\end{array} \\
\text { - } & \begin{array}{l}\text { ancillary to managing } \\
\text { organisational relationships } \\
\text { (board; coaches; secretariat) }\end{array} \\
& \text { professionalism versus } \\
\text { voluntarism (athletes; } \\
\text { secretariat) }\end{array}$ \\
\hline & showing results & $\begin{array}{ll}- & \text { participation numbers } \\
- & \text { medal count } \\
- & \text { programmes } \\
- & \text { awareness } \\
- & \text { alignment with Code of } \\
& \text { Governance } \\
- & \text { improving the sport delivery } \\
& \text { system }\end{array}$ & $\begin{array}{l}\text { - } \text { ability to attain organisational } \\
\text { goals in the micro (internal) } \\
\text { and macro (external) } \\
\text { environments (board; coaches; } \\
\text { secretariat) }\end{array}$ \\
\hline & $\begin{array}{l}\text { good financial } \\
\text { management } \\
\text { practices }\end{array}$ & $\begin{array}{ll}- & \text { operating within budget } \\
- & \text { financial governance and } \\
\text { - } & \text { gentrol } \\
& \text { streams } \\
- & \text { allowing for planning } \\
- & \text { technical and relationship } \\
\text { - } & \text { management } \\
\text { cutting red tape }\end{array}$ & $\begin{array}{ll}\text { - } & \text { ability to manage associations } \\
\text { professionally (board; coaches; } \\
\text { secretariat) } \\
\text { - } \\
\text { strategic planning (board; } \\
\text { coaches; secretariat) }\end{array}$ \\
\hline & $\begin{array}{l}\text { athlete } \\
\text { management }\end{array}$ & $\begin{array}{ll}- & \text { management committee } \\
\text { involvement } \\
\text { - } & \text { a system that works for athletes } \\
\text { - } & \text { recognition of the issue and } \\
\text { addressing the gap of high } \\
\text { performance management } \\
\text { - } & \text { management of grants } \\
\text { - } & \text { review of the carding system }\end{array}$ & 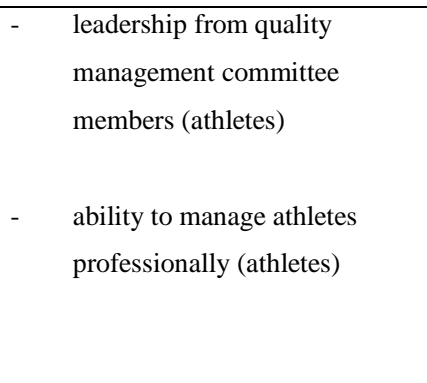 \\
\hline & $\begin{array}{l}\text { organisational } \\
\text { processes and } \\
\text { procedures }\end{array}$ & $\begin{array}{ll}\text { - } & \text { processes implemented by } \\
\text { right people in roles with clear } \\
\text { job responsibilities } \\
\text { - } \quad \text { putting procedures in place and } \\
\text { adhered to } \\
\text { - } & \text { facilitating faster decision }\end{array}$ & $\begin{array}{ll}\text { - } & \text { ability to improve relationship } \\
\text { management of internal and } \\
\text { external stakeholders (athletes; } \\
\text { board; coaches; secretariat) } \\
\text { - } \quad \text { precursor to better and quicker }\end{array}$ \\
\hline
\end{tabular}




\begin{tabular}{|c|c|c|c|}
\hline & & 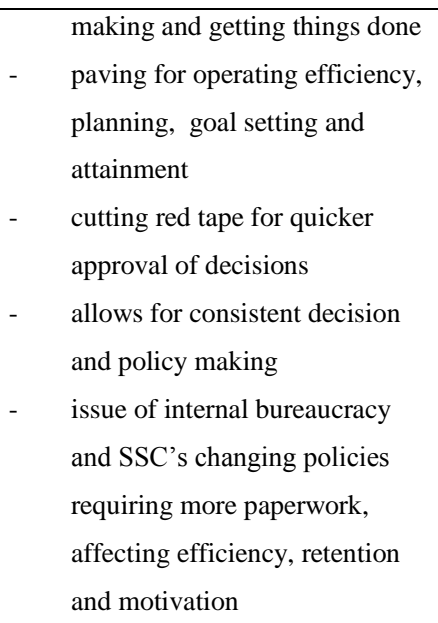 & 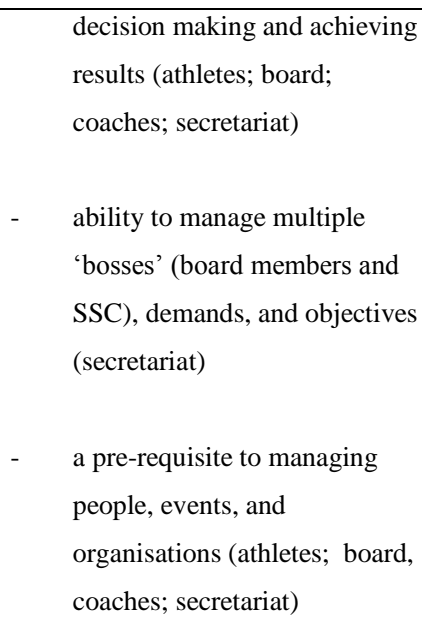 \\
\hline & $\begin{array}{l}\text { commitment and } \\
\text { organisation of } \\
\text { the management } \\
\text { committee }\end{array}$ & $\begin{array}{ll}- & \text { motivation and transparency } \\
& \text { leading to organisational } \\
& \text { improvements and results } \\
- & \text { leadership and strategic } \\
& \text { planning } \\
- & \text { diverse yet cohesive make-up } \\
- & \text { issue of voluntarism versus } \\
& \text { professionalism }\end{array}$ & $\begin{array}{l}\text { - combined knowledge and } \\
\text { experience of management and } \\
\text { sport (athletes; board, } \\
\text { coaches; secretariat) }\end{array}$ \\
\hline \multicolumn{4}{|l|}{ Criteria of effectiveness } \\
\hline & participation & $\begin{array}{ll}- & \text { participation numbers } \\
\text { accounted for by participants in } \\
\text { competitions, events, and in } \\
\text { schools and clubs } \\
\text { - } & \text { popularity of sport } \\
\text { - } & \text { level of play } \\
\text { - } & \text { participation in workshops and } \\
\text { coaching clinics }\end{array}$ & $\begin{array}{l}\text { - } \begin{array}{l}\text { qualitative criteria for funding } \\
\text { and sponsorship (secretariat) }\end{array} \\
\text { - } \quad \text { organisational and marketing } \\
\text { of events (board) }\end{array}$ \\
\hline & performance & $\begin{array}{ll}- & \text { meeting targets, goals and KPIs } \\
\text { - } & \text { medals won } \\
\text { - } & \text { targets achieved }\end{array}$ & $\begin{array}{l}\text { minimisation of qualitative } \\
\text { evaluations during requests for } \\
\text { funding, sponsorships; and } \\
\text { during benchmarking and } \\
\text { appraisals (board; coaches; } \\
\text { secretariat) }\end{array}$ \\
\hline & $\begin{array}{l}\text { balancing } \\
\text { outcomes with } \\
\text { continual process } \\
\text { indicators }\end{array}$ & $\begin{array}{ll}\text { - } & \text { periodic improvements in } \\
\text { performance and processes } \\
\text { considered as successes. } \\
\text { - } \\
\text { response to feedback from } \\
\text { stakeholders such as } \\
\text { participants, staff, clubs, } \\
\text { volunteers, and public } \\
\text { - } \quad \text { steps taken collectively towards } \\
\text { a common goal } \\
\text { - continual improvement }\end{array}$ & $\begin{array}{ll}\text { - } & \text { balance between short and } \\
\text { long term goals (athletes; } \\
\text { secretariat) } \\
\text { - } \quad \text { balance goals and KPIs with } \\
\text { stakeholder satisfaction } \\
\text { (athletes; secretariat) } \\
\text { strategic planning (athletes; } \\
\text { board; coaches; secretariat) }\end{array}$ \\
\hline
\end{tabular}




\begin{tabular}{|c|c|c|c|}
\hline & & $\begin{array}{l}\text { indicators such as } \\
\text { administrative efficiency in } \\
\text { releasing funds and processing } \\
\text { standard requests; sports } \\
\text { development; organisation } \\
\text { - } \quad \text { recognition of the sport for } \\
\text { technical, management and } \\
\text { event expertise }\end{array}$ & \\
\hline & $\begin{array}{l}\text { development of } \\
\text { athletes' potential }\end{array}$ & $\begin{array}{ll}- & \text { reducing attrition rate of } \\
\text { - } & \text { uthletes } \\
\text { understanding conditions of } \\
\text { non-performance } \\
\text { - } \quad \text { understanding improvement } \\
\text { without results } \\
\text { - } \quad \text { overcoming the paradox of } \\
\text { wanting to win all the time } \\
\text { - } \quad \text { overcoming the tug of war with } \\
\text { social and cultural } \\
\text { environmental factors. } \\
\text { training and development } \\
\text { programmes } \\
\text { talent identification } \\
\text { competition exposure } \\
\text { coaching } \\
\text { - } \\
\text { fair selection } \\
\text { high performance athlete } \\
\text { management } \\
\text { retaining and re-channeling of } \\
\text { sports talent } \\
\text { improving organisational } \\
\text { structure and design for } \\
\text { empowerment, coaching and } \\
\text { technical excellence. } \\
\text { - }\end{array}$ & $\begin{array}{l}\text { realistic target setting amidst } \\
\text { the social, cultural and funding } \\
\text { environmental factors } \\
\text { (coaches) } \\
\text { technical and organisational } \\
\text { excellence before sports } \\
\text { excellence (athletes) }\end{array}$ \\
\hline \multicolumn{4}{|c|}{ Funding on effectiveness and outcomes } \\
\hline & $\begin{array}{l}\text { sports } \\
\text { development }\end{array}$ & $\begin{array}{l}\text { a combination of elements: } \\
\text { competitions, programmes, } \\
\text { events, and facilities to make } \\
\text { sports accessible and } \\
\text { competitive }\end{array}$ & $\begin{array}{l}\text { supplementing public funding } \\
\text { for mass and elite sports } \\
\text { development (board, coaches, } \\
\text { secretariat) } \\
\text { better system for allocation } \\
\text { and distribution of funds to } \\
\text { ensure more money is filtered } \\
\text { down to athletes and coaches; } \\
\text { or associations that may not } \\
\text { have met the results criteria }\end{array}$ \\
\hline
\end{tabular}




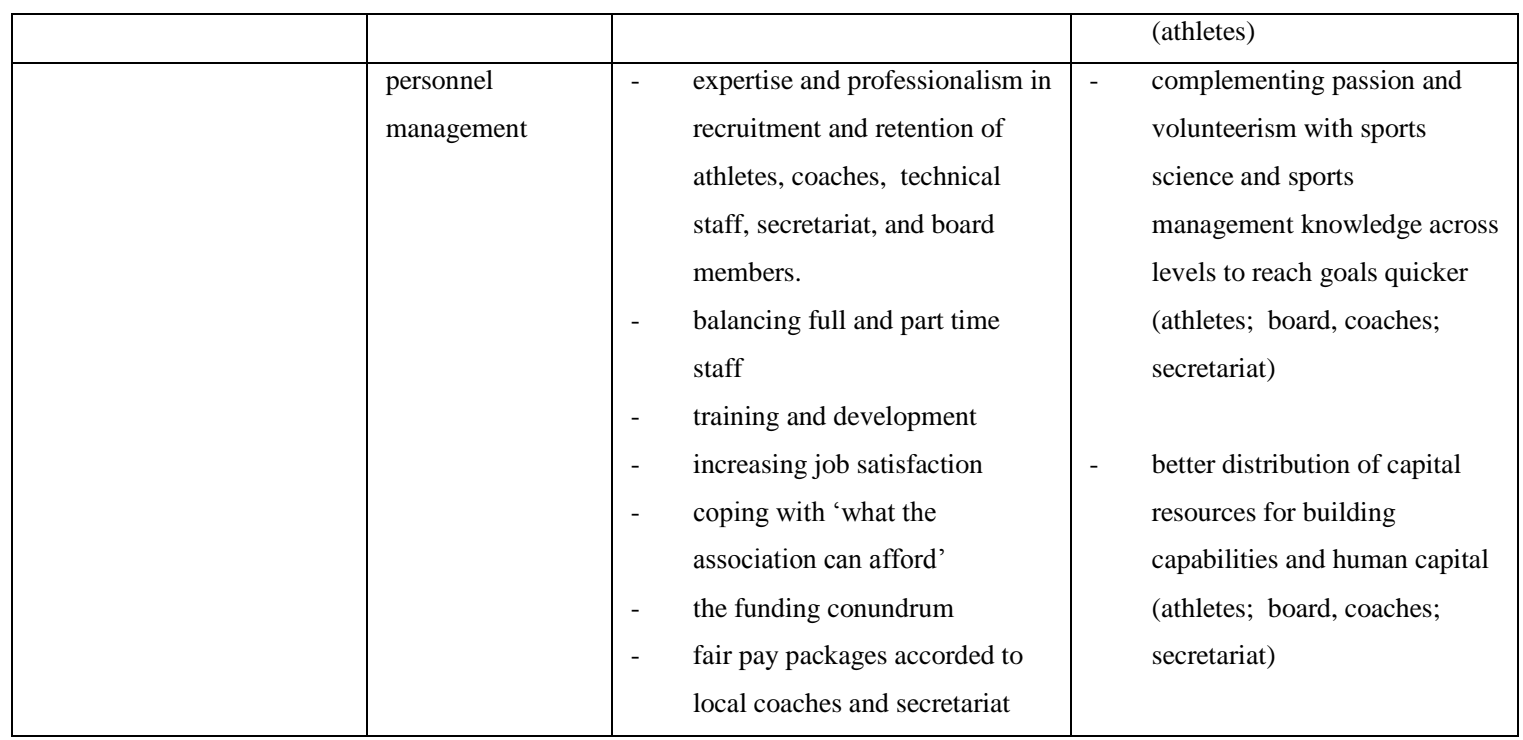

\subsection{Patterns of data for each key research question}

A national sports association is the sanctioning body of the specific sport in Singapore, comprising many internal and external stakeholders who can be individuals, clubs, institutions, or corporations. While the four major constituent groups for this study, athletes, coaches, board members, and secretariat staff, may understand implicitly the important roles they play in a nation's sports development, how this understanding is translated into behaviour and action, within the controllable and uncontrollable parameters, has led to varying perceptions of what effectiveness might mean and whether their organisation has achieved it or not.

There are respondents who have been positive about the effectiveness of their associations and yet others who feel that the associations have not been effective. Perceptions of effectiveness are shaped by the roles respondents play and the barriers they face, or do not face, while performing or being involved in those roles.

To restate, the key research questions of this exploratory study are:
1a) Do different groups of stakeholders have different perceptions of effectiveness of Singapore national sporting associations?

1b) If so why? 
2) What are the criteria used by the different stakeholders to determine effectiveness of national sporting associations in Singapore?

3a) How are the determinants of effectiveness affected by funding?

3b) Are the outcomes commensurate with the funding received?

Respondents from the four constituent groups defined effectiveness as communication, showing results, good financial management practices, athlete management, organisational processes, and commitment and organisation of the management committee. The findings relating to these six dimensions of the concept of effectiveness are elaborated in the sections that follow.

\subsubsection{Two-way, formal, and timely communication}

All respondents who had defined effectiveness as good communication were athletes. They answered from the perspective that their associations lacked this factor of effectiveness. To the athletes, communication means openness, timeliness, and having formal and structured channels within the association to facilitate a two-way exchange. This is because in the present fast-paced world of sports, athletes feel that decision makers and volunteers in associations need to keep pace with the changing external environment. While acknowledging that administrators are volunteers and that dealing with external agencies, coaches, and elite athletes can be challenging, athletes saw the need for open, and two-way communication on planning and selection: To be fair to the NSA, I do know that it is tough for them to deal with SSC, prima donnas, SNOC, and coaches, when they are volunteers having a family and career with many doing out of passion. However, passion is not enough in today's world. Not in today's life as things happen so fast. The day we never get this sorted out, we will not move ahead fast. There are a lot of basics that should be in place. At least having a two-way communication, discussing about plans, goals, open and transparent selection process (FG_A).

Timeliness and formality are other facets of two-way communication stressed by athletes in the context of training and competitions. When messages and instructions on 
training and competitions are relayed to all involved ahead of time, there is less waiting, worrying, and wasting of resources, leading to greater efficiency and effectiveness in high performance athlete management. Thus, formality of communication to athletes means that there is a system of communication known to all, with clear roles, responsibilities, and guidelines for the senders: Organisational effectiveness as an athlete would be when you are doing ... training sessions, drills, you don't have a lot of waiting time; once training is called, there is a certain structure that information is disseminated, and after which, you don't have to worry and everyone will get the information at the same time, or in a very short time span (A3_P1).

The preference for formal communication channels within the association so that the voices of the athletes can be heard for better decision making, is seen as a complementary factor of effectiveness: From the athlete's point of view, it will be good communication, and seeking joint decisions (A2_PI). How well the association sets up the formal structures for communication among the athletes and all departments supporting them, are viewed as factors contributing to how athletes determine organisational effectiveness: Structure and communication are the two most important in defining organisational effectiveness (A1_PPI). In addition both intelligence and emotional quotients are perceived to be necessary qualities required for managing athletes and contributing to high performance athlete management: The hierarchy and how well the communication channels are provided by the organisation, whether the various departments work in tandem ... and whether the management have the required skills such as both IQ and EQ in handling the athletes. That would basically define the term organisational effectiveness (A1_P5).

Exploring the evidence above on how athletes define effectiveness as communication, it appears from the responses that when athletes perceive effectiveness as two-way, timely and formal communication, it is seen primarily as a facilitating factor to enable them to train efficiently, perform competitively, and a platform for their voices to be heard. Good communication within the association allows them to perform and achieve 
the results during training and in the competitive arena. To the researcher, it seems a single-minded way of looking at effectiveness.

Exploring data sources of the other constituent groups concerning communication, board members perceive communication more broadly, relating formal communication to an ancillary role of facilitating meetings, administration, and as mechanisms to monitor effectiveness. The sporting outcome, while important, is not overriding. Communication is interpreted as a mechanism to monitor effectiveness, rather than as a definition of effectiveness. Some allude to external feedback given by teams in competitions as efficient, structured, and objective ways to evaluate the effectiveness of their associations: ... to be in constant communication with the corporate league teams ... it's all about evaluation and feedback. ... There must be a platform where we can meet these people and ask them are they enjoying it? Are there ways we can improve... it's really about engaging I think and having a proper mechanism for feedback (B2_PI). Other board members affirm the value of communication through internal reporting, consensus, and documentation, at council meetings and subsequent follow up as mechanisms that ensure effectiveness: We have monthly council meetings where we go through specific areas. We go back and tell the people involved what needs to be done if the areas are lacking and all these are documented. Next, would be email communication, and thirdly, ad hoc meetings for urgent matters. Not one person makes the decision but the council members will agree on the direction and the decisions. (B7_PI).

Formal communication is preferred by board members as a way of being kept informed about the day-to-day operations and decisions made by the secretariat. Communication channels between the board and secretariat are critical since both board members and secretariat staff work very closely with one another. The board members make the policies while the secretariat staff implement them. A board member shares his difficulty of trying to balance between allowing the secretariat to run autonomously and yet being kept informed about the more important decisions during daily operations: Sometimes we do want them to be independent in running the organisation, but other 
times we also hope that certain decisions (are) communicated with all exco members ... which unfortunately sometimes it doesn't happen due to breakdown in communication. ... the secretariat staff run things so autonomously that the exco members are not kept informed (B10_PI).

For secretariat staff, formal communication through meetings with the affiliated clubs was of paramount importance and was seen as a positive move towards greater organisational effectiveness. In the discussion, the issue of professionalism versus voluntarism surfaced. Volunteers who do not place their obligations to the sport as a priority are seen as less effective than paid full-time personnel. The formal meetings discuss the running of tournaments so that both full-time and volunteer staff understand the decisions made, and conflicts can be anticipated. However, these meetings take time to schedule due to the work commitments of the volunteers and may not be well attended: ... more communication with the affiliates. But the problem is also because most of them are volunteers so it is difficult to link up a suitable time to meet up. On paper, everyone knows that this has to be done but when you actually try to do it, somewhere down the road, it just breaks apart (S4_PI).

Communication, as a facilitating channel and contributing to effectiveness, is also evident when coaches speak of communication used to support training and selection decision making. One coach relates how fusion and transfer of knowledge from the coaches to the athletes produced the desired performance results, and could only come about through communication: We have three head coaches ... specialised in different fields and ... the advantage ... is, we have three different ideas going towards the same direction ... from last year's results you can (tell) it's really helping us... so we're actually just riding on the wave, and organising it according to the locals (local coaching expertise) ... and that's why we're doing pretty well. At the end of the day, it's really all about communication (C4_PI). For greater effectiveness in associations, coaches prefer frequent and formal communication between key technical personnel. This is strongly affirmed especially in the selection of athletes for competitions where coaches would like more dialogue with other coaches and the technical director for 
parity: I think we need more communication between the coaches, the national coaches, and the high performance committee. And, we asked for many times we need a boss who ... has daily contact with the coaches, as the national head coach. Because I would like to share my opinion before I make my decision in the more important things but I would like to listen what is their opinion (C3_PI).

In summary, the above section has explicated evidence of the issue of communication. It is of paramount importance to the athletes, who firmly define effectiveness as twoway, open, structured and timely communication. While athletes have discussed communication in the context that their associations generally lack this factor of effectiveness, they have expressed that good communication translates into better planning, goal setting, selection, training, and consensus. The other three constituent groups tend to view communication as an ancillary to facilitating and managing organisational relationships with the various stakeholders, and as a mechanism to monitor effectiveness. Coaches speak of communication among themselves and technical personnel that supports better training and selection decision making. Board members view communication, in the form of internal reporting at council meetings and external feedback from teams or affiliates, as mechanisms for monitoring effectiveness. Lastly, secretariat staff see formal communication as a necessity to continue a productive relationship with their affiliated clubs and the board, despite expressing that voluntarism does get in the way of being more professional and effective.

\subsubsection{Showing results}

The next dimension of effectiveness, showing results, is most strongly expressed by the three constituent groups of secretariat staff, coaches, and board members. Effectiveness is viewed from a numbers perspective: We're effective because of the responsibility that we have which is to make the sport more popular, growing the base of players in Singapore. This can be seen from the number of juniors taking up the sport (S8_PI). The dimension often is referred to quantitatively and relates to mission and goals in terms of achieving targets set, making the sport popular across the various segments, 
growing the base, and generating awareness for the sport. These indicators are operationalised as the number and types of programmes that are managed, the participation rate, standards achieved, level of media exposure, the number of people who know about the sport, medals won, and percentage of compliance with the Code of Governance for National Sports Associations. This is summed up by: I think for organisational effectiveness we're looking at ... the kind of programmes that we're able to lay out. The kind of results that we're able to show and ... in relation to also the sort of goals that we want to have ... we're looking at mainly development of local athletes ... promoting the sport to the masses, both casual, recreational and the those competitive ... whether we're able to support our elite athletes in their endeavours, to achieve international success (B9_PI). Since effectiveness for these constituent groups is all about achieving goals and targets set, they view the association as effective when they have managed to grow the sport and enlarged the participation base by running different types of sports programmes: I suppose at the end of the day it's a matter of reaching the goals and the targets that are being set. If the targets are being met, then ... that itself equals to a certain amount of effectiveness because you have a certain amount of people and programmes to run to be successful (B10_PI).

Coaching is seen to be an important area for improving overall standards and increasing the medal count. For coaches, their key performance indicator is the performance of their athletes. The coaches' mission is solely to produce results and medals through organised training: When people ask you what is the business you're in ... your business is to produce results. And so which function is important? It is in the coaching committee (C5_PI). Thus, for coaches, transfer of knowledge and skills, and changing the sport delivery system, are issues that matter most and shape their definitions of effectiveness. These key coaching areas and structural issues involve years of learning and planning, are viewed longitudinally, and are totally results-based.

Being effective is viewed as an approach to change the sports development delivery system and structure so as to achieve results in the long term. Seen as a process that takes time and a change in mindsets, effectiveness is stated as: Changing in many 
ways... has a lot to do with how we approach getting our national players better, the local scene, clubs scene better ... an overall change has to happen... it would take time, probably long term. These benefits won't be seen till probably 2010 (C2_PI). Given Singapore's history of being a young nation, there has been dependence on foreign sports coaching expertise. The formula of learning from foreign expertise and experience, with the flexibility of adapting the knowledge and skills to coaching Singapore athletes to international success, is viewed as effectiveness: Organisational effectiveness ... what we do is not just depend on ourselves ... we actually invite and get overseas help in the sense of a professional help ... we archive everything ... Singaporean style, and we learn it from our own base. I think that will be our effectiveness because it's over the years (C4_PI).

An important part of effectiveness is sporting achievements that pave the way for more media exposure and awareness of the sport. As Singapore does not have a history of local talent achieving international success, the athletes and their achievements are seen to be both icons and magnets opening more pathways to future success. The nation has only one silver Olympic men's weightlifting medal won in 1960 (Teng 2002), and after 48 years, a celebrated silver in the ladies' team table tennis event in the Beijing Olympics 2008 (The Straits Times 18 Aug 2008). In the view of one coach: Organisational effectiveness has to relate to mission or organisational goals. ...We want numbers playing the game and coaches, umpires, competitions to support it ... a whole range of people playing for recreation and elite teams as the standard in Singapore reflects how good the national team is. How good the association is in putting all these in place. How effective are we in doing it. ..If our national team is in the top 10, this will indicate that we are pretty good and with that we will be in international competitions and hosting international events. If everyone wants to know and play the sport ... and is seen as a cool thing among kids (C1_PPI).

Because of the relationship between potential funding and potential results, it is important to the three constituent groups that the results achieved ought to be in alignment with the SSC's expectations. After all, SSC, together with the Ministry of 
Community Development, Youth and Sports, initiated the Code of Governance for National Sports Associations. Effectiveness in associations is measured by the guidelines set by the Code of Governance, and the outcome-based funding model will determine the level of funding for each association. It is for these reasons that the constituent groups are mindful that the results achieved have to match the expectations of the funding bodies: We have basically transformed the organisation. We are focusing a lot on what SSC wants us to govern our organisation ... this year, the Council will focus on streamlining the process and moving towards that direction, or else we will be out of the context of them going forward to fund us further (B7_PI). However, results achieved may not meet targets set. Secretariat staff are particularly conscious of the multiple objectives of association management and the difficulty in achieving all the objectives laid out by the association and the targets of the funding bodies.

While both the funding body and the association want the best for the sport, how they go about working towards that outcome may result in differences. The association may have different objectives compared to the funding body and when targets are not realised, the bottom line is inevitably affected. This, in turn, affects the number of programmes leading to a vicious cycle of under-achievement: ... when we set out, we wanted to push on the sports to the masses. We wanted to achieve excellence in the SEA games, by bringing the gold medals, or silver medals. We wanted to develop the sports industries by bringing in title events like Singapore Open, and so on ... but in reality you have so many constraints, and you have to meet certain targets set by Sports Council, because if you don't meet those targets then your funds are, for whatever reason, may be withheld, or delayed, and at the end of the day you don't meet your key objectives (S3_PI).

In summary, how the three constituent groups, of board member, coaches and secretariat staff, perceive showing results as effectiveness, appears to relate to a broader concept of the ability to attain organisational goals within the micro (internal) and macro (external) environments. The micro environment is the internal environment of 
the association comprising structure, procedures and processes. The macro environment is made up of government agencies who have constituted the Code of Governance and advocated the outcome-based funding model. Both environments need to be carefully managed by the associations as their funding is highly dependent on the results achieved, their alignment with the Code of Governance, the outcome based funding model, and the expectations of the SSC.

\subsubsection{Good financial management practices}

Some respondents view organisational effectiveness in terms of good financial management practices - operating within the budget, financial governance and control, resourcefulness in generating other income streams, and allowing for planning. This view was shared by coaches, secretariat staff, and board members but not by athletes.

When respondents acknowledged that their respective associations are already involved in good financial management practices, it is usually for two reasons. One, the funding from the SSC is never enough and good financial management is required to manage the money prudently: Good management means ... income (B8_PI). Two, the funding is rarely 100 per cent of what is requested by the association, and thus the association has to raise their own supplementary funds: We have no choice because the government can support us only so much. We're already so glad and happy that Singapore government is really fantastic in supporting sports, (but) the budget ... it's never enough, ... so that's why we have to generate our own (C4_PI).

Many associations have been resourceful in finding alternative sources of income from sponsorships, with many creating their own business units within their association, to manage events, market their sport-related services such as timing systems, testing systems, certification, or rental of equipment (B8_PI; C3_PI; C9_PI; S9_PI). The respondents from those associations that have been resourceful in finding other income streams attribute their effectiveness to the management of current income, and the generation of potential income. They are rather proud that they have found resourceful ways to supplement funding from tax payers: ... the business unit ... makes money for 
the association. As you know, subsidies from Sports Council will never be enough. We have to find other sources through sponsorship or some kind of business dealings (B1_PI).

The inadequate annual budget given by the SSC is viewed positively as it is perceived to be a form of financial control contributing to strategic planning. In these instances, prior knowledge of the promised sum is seen to be a pre-requisite for both short and long term planning as well as target setting. This has been compared to other countries where the sports federations are unsure of the following year's income: We can work better here (in Singapore) because we have more subsidies from the government, from the Sports Council, and ... with a fixed budget, we can make plans (C3_PI).

Getting out of debt is perceived as another positive financial management measure. This is a task usually undertaken by management committees. When successful, they pave the way for more programmes for the masses, and centres of excellence for youth and elite sports development: I find (name of association) effective with the new committee ... they were in debt in the past. ... Now, the number of Learn To Play and SPEX (Sports Excellence) programmes has grown from 200 to 900 players. We are able to send some players to overseas tournaments and we also have a number of players in the international junior ranking, both boys and girls ... and then we have one player ... who is trying to be full-time. (C9_PI).

It is not normal for Singapore citizens to train and compete on a full-time basis. Thus, when there are sufficient financial resources to have sports excellence training centres, the result will be more local players who are willing to commit to sports and play fulltime. It is every coach's ultimate goal that local players train full-time and achieve some international success so that they can become icons and beacons for other to follow suit.

In summary, it is generally agreed among coaches, secretariat staff, and board members who had defined effectiveness in terms of good financial management practices, that the SSC budget and supplementary self-generating income are pre-requisites for 
strategic planning, implementation of plans, and achievement of goals. From the above evidence, this dimension of effectiveness, appears to relate to the broader concept of managing associations professionally, and is a pre-requisite for another dimension of effectiveness, showing results.

\subsubsection{Athlete management}

As with the theme of two-way, formal, and timely communication, the issue of athlete management is most apparent among athletes' responses. Mature athletes with many years of training, hold part-time or full-time jobs, have family commitments, and draw a long term and causal relationship between the quality of the management committee and the holistic management of their sports careers. Wishing for more active and genuine involvement from the management committee on high performance athlete management, these athletes acknowledge that determining effectiveness in the context of their national sports associations can be difficult and complex. The management committee is like a nerve centre that starts the wheel in motion, and thus the need for quality volunteers is paramount as they are responsible for putting in place processes, procedures, and policies on fairness, transparency, and ethical conduct in the critical areas that concern athletes. One athlete summarises a 'holistic' system: If the NSA has good and responsible management committee members and leaders, a team that is dedicated, and a plan of short and long term goals and moving towards a target, ... everything will fall in place. Quality of management is crucial. Having... elected members, see the importance of quality coaching, trials and selection process, transparency, high performance objectives, a system that works for athletes (FG_A).

The mature athletes prefer a more comprehensive approach, often referred to as high performance athlete management. Beyond expected technical advice, these athletes consider an association to be effective if they understand what the athlete is going through during the various stages of their life cycle, which encompasses their personal life and career. When associations recognise that a mature athlete has to manage multiple public and personal roles, and support the athlete in the juggling and balancing of roles, there will be less attrition and more retention of the already scarce talent pool 
in Singapore. Using the metaphor of a fruit tree that will be axed when barren, an athlete opines that other countries are way ahead in their high performance athlete management practices and thus more effective: Good training programmes, competition, transparent selection process, other countries are way ahead, including, adjustment to family and career, to manage athletes' sports and personal life. I am in the midst of adjusting to my career and family and I can put some time to train but they expect the athlete to have one life and that is sports. Nobody has sat with me to discuss my problem, a goal to win a medal, and all they do is say that you have not been training recently. The high performance manager does not ask about my personal life and work but concerned only about training. Having a conducive environment and ... communication ... To me, effectiveness is professionalism. We are like fruit trees left on our own to bear fruit and when there are no fruits, the tree will be cut (FG_A).

For the athletes who are still in school or not working, the disbursement of grants and competition management, are the other issues that shape their perceptions of effectiveness. A common complaint among athletes is the tardiness in which grants are handed to them, sometimes six months late. In addition, the athletes often do not know when overseas competitions are till the last minute because of the late release of funds: ... they're (the association) not that effective because they depend on SSC ... certain things are pretty slow, like our grants and funding ... and information for us is always last minute, like tournaments, we don't even know if we have the funding to go ... so usually we know last minute whether we're going or not ... previously we waited like for half a year to get our grants (A6_PI).

The carding system is also seen as adding to inefficiency. The spexTEAM carding, as stated in the Athlete Assistance Handbook (Singapore Sports Council, High Performance Group 2007), is part of SSC's High Performance Management Division (HPMD) where athletes are recognised and managed by sports featured in the four major games (SEA, Commonwealth, Asian, and Olympic Games). Depending on their carding or categorisation and based on achievements and potential to excel, the athletes are given access to comprehensive and customised athlete support programmes and 
services that includes financial assistance for training, education, and medical. Athletes would prefer a tailored carding system to reflect local standards so that more athletes can be given ample training grants: ... for us athletes, we've encountered a few problems in terms of their effectiveness. One of our main concerns would be the carding system where according to your timing, they give you a certain carding, Al to B3...from A1 to B2, we will get a sum of money, but for B2 provisional, to B3, you don't get any money except for medical services. So the current women's team ... we're all under B2 provisional ... in that sense we feel that the association is rather ineffective because...we're already the (best) in Singapore ... and ... we're not getting any form of monetary help or financial assistance. ... we feel that they've been rather ineffective because they ... set the timing ... according to international standards, knowing that we'll never be able to reach there ... (they can set) something that we should be able to achieve (A7_PI).

In summary, the above evidence has shown that the issue of athlete management relates to two concepts. One is the ability to manage athletes professionally. The other is leadership from quality management committee members. There is a high relationship between leadership and the quality of the management committee and high performance athlete management.

\subsubsection{Organisational processes and procedures}

To all four constituent groups, organisational process and procedures feature prominently in their definitions of effectiveness. They see their respective associations as effective when there are efficient processes and standard operating procedures in place, with the right people in the right roles and clear job responsibilities. Having good processes and procedures adhered to provides for greater efficiency in the running of associations and their programmes: Organisational effectiveness ... is putting proper procedures in place, and ensuring those processes are actually done properly with the respective people in the respective roles. ... we've got coaches, regional developments officers all the way up to ... the management committee, everybody should understand that certain procedures need to be adhered to, to run as effectively as possible (S2_PI). 
And: How things are running in the organisation, how it is viewed by outsiders, and the SOPs are in place, whether whatever goals we have set out we are achieving those goals. That, to me, is organisational effectiveness (S4_PI).

Next, processes need to be carefully thought through before application and implementation: What's important is there's a set of standard procedures, a set of processes, and these processes are being thought through ... processes would be most important because it includes the policies ... how we define the policies, what are the rationale behind the policies (B4_PI).

Others link organisational processes such as goal setting and planning to execution ability. Results achieved are then seen as outcomes of having processes in place: Organisational effectiveness would be the efficiency in setting clear goals and ... then the ability to execute according to those goals (B3_PI).

As the sports environment is seen to be dynamic, procedures must facilitate faster decision making: First thing is getting things done in sports and the decision-making process from the secretariat's point of view, and how fast things get done constitute effectiveness. Whether to compete, or have a plan and to implement it, who to decide to go for the competition. Sometimes, decision may take a year. So speed is important. It has to be fast, prompt and on time, for in sports if too slow will be over, as sport is dynamic (FG_S).

Hindering efficient processes and standard operating procedures is organisational bureaucracy, and also the changing policies of SSC are seen by some respondents to hinder effectiveness. Both affect staff motivation. Bureaucracy is evidenced by the number of board members and limited guidelines for board members and secretariat staff: I think it happens in all NSAs. Very bureaucratic, one. Two, the ...members of the board, or the council members themselves, are all volunteers. So if for example, we have 15 members, so indirectly I have 15 bosses. ... the unfortunate thing is the Board changes every year ... so...the culture is not fixed. ...Now once your culture changes, your organisation behaviour changes. Everything changes. So you can't actually work 
on it unless you see I have a fixed guideline you know, more or less like a guideline you don't deviate from (S10_PI).

One reported barrier to effectiveness is the amount of paperwork required by the SSC. This is not commensurate with the number of association staff. The massive paper work that has to be shouldered by already lean secretariats affect morale and effectiveness despite having processes in place: Of course, too much red tape also doesn't vote well considering we're a very small organisation ... we face a lot of paper work from Sports Council and I can say that openly ... especially the last couple of years... every two years they keep changing their policy. So every year, it just gets more and more words and ... actually hinders a lot of effectiveness (S2_PI).

Tensions between the need to submit the required paperwork so that there can be funding, and the extensive on-the-ground work that needs to be carried out to run programmes, can culminate in associations not meeting their goals: Right now, you have to put up a lot of papers. You need to justify why you want to send this group of people overseas for training, where do you see them in two to three years' time. You know, business plan, it has become very corporate like, the association has become like that, evolved. And you know people are asking for proposals. And with a staff strength of two or two and a half, when I say two and a half I mean part-timers, you simply can't cope with the capacity that is being put on our associations right now. So, you talk about organisational effectiveness, you want to meet so many objectives at the same time, no way you can do that. (S3_PI).

Some board members recognise the difficulties of secretariat staff who often have to come up with the process, procedures and implementation of plans, despite bureaucratic demands: I think it will mean like minimum red tape to get the decisions approved so that the secretariat could carry out the decisions ... we are there to make policy decisions, approve certain bills ... (we) have regular meetings ... or even sometimes certain things can be established via email if it is short, if there are matters that don't need so much discussion. ... we don't want the secretariat to be tied down. Otherwise they cannot implement all the things that we have discussed and approved on. (B2_PI). 
The previous section has explored the evidence about how the four constituent groups define effectiveness as having organisational processes and procedures in place. Having organisational processes and procedures in place is a precursor to better and quicker decision making and to achieving results. In addition, they pave the way for more effective relationship management of internal and external stakeholders so that associations can manage multiple 'bosses' (board members and SSC) and their demands, while still trying to fulfil the association's objectives of running programmes and developing the sport.

Secretariat staff view organisational processes and procedures as effectiveness when they are seen as ways to manage both internal and external stakeholders, on both the technical and the relationship management fronts. They understand the importance of paperwork submission required by the funding body, SSC in principle, but may not agree with the volume of paperwork that is required. If anything, they feel that cutting down on unnecessary paperwork will improve effectiveness. On the technical side, processes and procedures are necessary to ensure more efficiency when handling stakeholders on programming, training, competition and selection issues.

Coaches understand organisational processes and procedures as necessary preludes to planning, funding of programmes, and youth development. For them effectiveness in associations is when they are allowed to do their job 'without encumbrances of any issue'.

Board members consider organisational processes and procedures as effectiveness in the light that they allow for the setting of goals, paving the way for more successful execution, cutting down bureaucracy, and effecting quicker decision making. Echoing the views of secretariat staff for 'minimum red tape', board members see organisational process, procedures, and structure as a first step towards goal attainment. 
Specific to developing sport, athletes recognise and give credit to their associations for the people and processes behind the running of events and organisation of competitions. These competitive events attract a keen field from overseas and provide welcomed competition exposure that is lacking in Singapore. However, athletes recommend areas of improvement in processes and procedures pertaining to: coaching to ensure continuity, and a better match between athletes and coach; and secretariat management to ensure work satisfaction (A3_PPI; A2_PI; A9_PI). These improvements can be achieved if the organisational processes and procedures be allowed for an adjustment of plans periodically when needed: An effective organisation is good in carrying out plans and objectives, evaluating the process that contribute to the plans, and adjust to plans periodically to see if plans are achieved. This is the task-oriented side of the definition of effectiveness. (A2_PPI).

\subsubsection{Commitment and organisation of the management committee}

Respondents across the four constituent groups referred to effectiveness as how committed and organised the management committee were, and whether results were apparent under their leadership. For these respondents, their perception of effectiveness in the associations hinges on the motivation of the management committee members, the diverse strengths of the board members, and evidence of what the decision makers have done to improve the state of affairs in the associations. To all, the president is the captain of the ship and features prominently in how the association is being steered. As organisational culture tends to be top down, it is important who the president is and how he makes decisions, implements policies, and how he collaborates with the stakeholders. A capable president can make all the difference in regard to the organisation's vision and the subsequent impact on both technical and tactical decision making in sports development: Our president has this vision that we will be running on our own ... there are some glitches right now, like who's heading what, but we're actually fine-tuning every position ... because at the end of the day we want to promote the sport to its maximum possibilities (C4_PI). Improvements made during a president's term of office, and whether there is a long-term plan over three to five years, are often held as evidence of effectiveness: I've worked under three different 
presidents ...for the past four years we have our own strategic plan, we set our road map ... compared to last time there's a big improvement (B5_PI).

Board members, coaches, and secretariat staff stress the diversity and composition of the management committee members (B1_PI; B2_PI; B6_PI; B8_PI; C8_PI; C10_PI; S7_PI), and their view is that these factors will encourage more wide-ranging opinions and discussion, leading to better policy, decision making, and programming: We do have a fair number of management committee members in the board, all professionals in their own way. They come together to make decisions and run events quite effectively (B1_PI).

Of equal importance are the capabilities and integrity of the board members. Ideally they should be knowledgeable in both administration and technical aspects of the sport so that their decision making can be seen to be credible. A respondent comments on the nepotism and corruption of the previous board: I think it is effective now because we have got a committee that involves former players, people that know what is going in the game locally and regionally ... we were quite fortunate that the old committee had left. You know we are on the right steps towards progressing... The last one was a oneman show ...The guy who ran before put his friends in the management committee who didn't have a clue of the game, were not former players, and did not know what was going on, and he used it to his benefit (C10_PI).

The board members understand effectiveness as cohesiveness among themselves. They speak of how despite the challenges, there is no finger pointing and politicking: I think our organisation is rather effective ... we got a group of very committed, dedicated volunteers. Although they are all working personnel, they really pay particular attention to the sport and ...there's no in-house politics ... nobody is fighting for the president post or the secretary post, all the executive posts. We work as a whole team. Anything goes wrong, we all gel together and try to resolve the matter(B6_PI). 
Teamwork among the board members is also emphasised by the secretariat staff who also affirm the importance of a board who can work together for effectiveness: We need a core of very dedicated volunteers, who can work, read from the same page ... put the shoulders together and work as a team (S7_PI). However, the conflict of voluntarism versus paid work arises and can interfere with commitment when board members give precedence to their paid work. While board members acknowledge this fact with honesty, no solutions were given by them: ... the commitment of the Board Members. All of us are voluntary members so sometimes when it clashes with our (paid) work, one has to give way ... So I think if (this) could be improved on, I think at a very basic level, I think effectiveness could be approved upon (B2_PI).

Board members are emphatic that they have processes and structures in place which allow them to plan strategically according to their vision and mission statements. Many compare 'before and after' scenarios especially for those who have served several terms of office and under different presidents. They refer to marked improvements that are symbolised by clearer definition of policies, organisational structure, and more efficient implementation of plans through processes and procedures which were previously absent or had taken a longer time to materialise. An example is: I think first of all is the combination of the Exco, and next processes ... then we can come up with the transparency. ... We have a proper structure of all the council members' responsibilities so they are all in place already (B7_PI). Respondents in general impress that there is a strong causal relationship between the commitment and quality of the management committee and results achieved by the associations. The measurable outcomes are expressed as quantitative and tangible benchmarks such as the increasing number of participants and medals won in the international arena. The commitment of the management committee is reflected by the number of programmes that can be rolled out with the view of leading to international success: I think for organisational effectiveness we're looking at programmes that we're able to lay out, the kind of results that we're able to show ... in relation to ... goals... mainly development of local athletes, and athletics ...promoting the sport to the masses, both casual, recreational and competitive ... and whether we're able to support our elite athletes in their 
endeavours to achieve international success (B9_PI). And: ... we are effective ... I suppose at the end of the day it's a matter of reaching the goals and the targets that are being set. If the targets are being set, then I suppose that itself equals to a certain amount of effectiveness because you have a certain amount of people and programmes to run to be successful ... actually we have been quite successful in terms of medal tallies ... (B10_PI).

Athletes are less concerned with the composition of the board than with board members' motivations for serving. Athletes view associations as effective if the intentions of the board members are upright. To athletes, effectiveness stems from the management committee (council or board) and starts with the understanding that associations, the board and the various committees exist because of athletes and not vice-versa. For this reason, athletes understand effectiveness as facilitating the needs of the athletes so that they can perform to their maximum potential (A1_PI; A5_PI; A6_PI; A7_PI; A9_PI; A10_PI). This can only come about when management committee members are serving voluntarily in associations for the right motives and not have overriding personal agendas. When personal agendas come first, the athletes are the first to suffer as issues concerning their training, coaching, and competitions become secondary, affecting their performance in the field. This is best summed by an athlete: Well, from the viewpoint of an athlete, first and foremost, the association or the management must understand that they exist because of the athletes and not the other way around. Over the years ... I've seen the ugly side of competition ... where the people just want to be management so that they can gain recognition for unknown reasons. I suppose this is the first thing they must understand, and of course, looking into and fulfilling the needs of the athletes under their charge, and to make sure they are successful in this area (A2_PI).

The athletes thus see a direct relationship between the commitment of the board and their performance. Their view is that decisions made by the board can make or break an athlete's career. Also given Singapore's small talent base, athletes feel that talent ought 
not to be frittered away by management committee members who are not there for the right reasons.

From the evidence above, all constituent groups who have defined effectiveness as the commitment of the management committee feel strongly that, with the right intentions and correspondingly correct actions, the management committee can make a significant contribution to associations. This presupposes the right mix and calibre of management committee members.

The above sections have explained what and how the different stakeholders in Singapore national sports associations understand by the term effectiveness. In summary, the six issues of effectiveness are defined as communication, showing results, financial management, athlete management, organisational processes and procedures and commitment and organisation of the management committee. The next section will examine the criteria used by the different stakeholders to determine effectiveness of national sporting associations in Singapore.

The two key quantitative criteria expressed by the four constituent groups are participation and performance. Participation is operationalised as the number of programmes, participation numbers, and level of play/sport. Performance is stated in terms of goals and key performance indicators or KPIs and expressed as the number of medals won and percentage of targets achieved. The number of medals won is paramount because of its direct correlation to funding from the SSC. The section below will elaborate on the four issues raised by constituent groups when discussing criteria of effectiveness: participation; performance; balancing outcomes with continual process indicators; and development of athletes' potential.

\subsubsection{Participation}

The participation criterion, defined as the number of people participating in the sport, is mentioned most often by secretariat staff, followed by board members, and coaches. Participation is seen as measurable and quantitative. The constituent groups would like 
to see the numbers increase annually as it signifies that their programmes (competitions and events) are successful in schools and clubs: The most important criteria would be ... to maintain the masses ... and how to increase more. And how to get more schools to come forward for (name of sport) as leisure, or as a competitive sport ... Yes all quantitative. ... we always measure, whenever we organise an event, whether the number of entries per team is increasing or dropping (B6_PI).

The issue of quality, besides the numbers participating, is also cited. While knowing that numbers contribute to mass participation (one of the three pillars for funding purposes), it is the level of play that decides medals: The popularity of the sport, that's one. The level of play, that's two (S8_PI). Secretariat staff especially, noted that participation numbers are what the SSC and sponsors are most interested in. Constituent groups express regret at this narrow view: I think it has to be both quantifiable and in terms of quality. Let's say quantity wise it's number of schools, clubs, teams, and participation numbers. Unfortunately that's what a lot of, not only Sports Council but sponsors want to see, numbers coming in, especially the youth market $\left(S 2 \_P I\right)$. They feel that the quality of play should be another equally important criterion for funding and sponsorship.

Coaches who cite participation as a criterion of effectiveness, allude to the popularity of the sport among the young. If the sport is part of the core curriculum in school and is perceived as a great sport, it is then seen also as a viable benchmark of effectiveness: If everyone wants to know and play (sport), and is seen as a cool thing among kids. We need to look into the participation, the number of participation in (sport) ... we want to increase that number. That's effectiveness (C1_PPI).

Board members also look at numbers playing the sport but, in addition, consider workshops, coaching clinics, and tournaments as contributing to enlarging the participation base: We can also look at the number of coaching clinics and workshops we organise, and the number of tournaments we run, internal in Singapore (B5_PI). In addition, the number of people in the corporate sector, besides schools and clubs, 
playing the sport is sometimes seen to be an important quantitative criterion of effectiveness as it means broadening the participation segments: Definitely statistics, number of people, taking part in all the carnivals... that's a criteria. If you can reach a larger sector, not just schools and clubs, but now we are reaching the corporations, so enlarging our customer base (B2_PI).

From the above data, it is clear that participation numbers is seen as the prime funding criterion of effectiveness. Issues such as quantity and quality, participation and results, are mentioned as related issues and sometimes give rise to tensions and compromise. The issues are elaborated in later sections.

\subsubsection{Performance}

The second quantitative criterion is performance. This is operationalised as meeting the set sports excellence targets. Particularly for the three constituent groups of secretariat staff, coaches, and board members, these targets are essentially the key performance indicators often expressed as the number of medals won. While secretariat staff readily admit that governance and financial management are important criteria of effectiveness, the most important remains showing the tangible results: Good governance, sound financial position, effective training programmes and, I will go for achievements $\left(S 7 \_P I\right)$. Secretariat staff claim that the medals achieved is unquestionably the most important criteria of effectiveness as they are easily measurable: My personal view is it ties in with the very first question on how I define organisational effectiveness. It's meeting the mission and vision of the association which is basically to achieve sports excellence and at the same time sports promotion. And all the other things are just processes and steps to help us achieve that so that's how I would measure it and that's straightforward (S5_PI). The thinking is that if an association can deliver the results, quantitative or hard measures cut down qualitative debates: We have KPIs for all the individuals and these are definitely quantifiable so that we minimise the qualitative opinion aspect of evaluation (S5_PI). This is particularly useful when funding is being requested by associations as medals achieved symbolise the associations' overall successes: We're talking about winning of medals as the criteria. The reason is Sports 
Council is now going for result-based funding already. If no medals, you'll have problems getting grants and sponsorship (S9_PI). Trying to justify that an association is successful and effective without medals to show for, can be particularly difficult when external funding is being sought from SSC or sponsors: We're using very hard measures to measure effectiveness, so at the end of the day when we talk to all external parties in defining whether we've been a successful NSA or not, we're not going to go on very qualitative measures but look, we produced and delivered the medals and that's it (S5_PI).

Coaches share a similar matter-of-fact view on the importance of medals achieved as a criterion of effectiveness. Knowing that medals is used as a figure to check on effectiveness (C4_PI), they understand and accept that sports excellence is equated with results achieved by the athletes and little of anything else: Sports excellence is nothing but our results from our athletes (C4_PI). Like the secretariat staff, one of the main reasons for using results as a criterion of effectiveness is its correlation to funding. Aside from funding, the number and colour of the medals are important to most coaches as this is also a measure of their coaching success. It is also the key performance indicator for the renewal of their contracts: Performance is the criteria to live and die by as that is only thing that is measurable (C2_PPI). For coaches, the reality is that everyone evaluates the association by the medals won, and the coaches' bread and butter hinge on this quantifiable aspect rather singularly: I can evaluate my own performance but how everyone perceives the NSA depends on gold medals and that is the way of life. If not performing, must leave. When performance is shown, reward athletes as well as coaches (C2_PPI). While most coaches monitor the progress of athletes by using continual performance indicators such as regular evaluations of mental strength, physical fitness, and discipline, they acknowledge that at the national level, it is the medals that count in most peoples' eyes: Improvement by the individual players. But for the national level, of course, our main target is to bring back medals. If they can bring back medals, it is much, much better (C7_PI). 
Board members agree that results are an important criterion especially when benchmarking internationally. At the fundamental level, the board and association will use the targets set by SSC because of funding implications: We use the targets set by SSC because SSC use that same criteria to grant us funds (B1_PI).

While target setting is absolutely necessary to achieve results, board members assert that it is also the most difficult thing to manage in sports, as stakeholders tend to think that if targets are not met then things are not going right. As articulated by a board member, the point really is you don't get results overnight (B3_PI). Plans need to be rolled out and fine-tuned before results can be achieved. A time frame for evaluation is needed: You have to set a plan and then you have to stick with it for two or three years and if you don't see any changes or improvements in three years then it's time to put your hand on your heart and say sorry we've messed up and obviously we didn't make the right decisions (B3_PI).

From the above evidence, it is clear that performance is a criterion used to evaluate the effectiveness of associations. However, the associated difficulties of achieving targets set within a specific time frame has led to discussions on other criteria such as continual improvement indicators.

\subsubsection{Balancing outcomes with continual process indicators}

Outcomes are defined as tangible medal results, while continual process indicators include how feedback is handled, how athletes are assessed progressively, if service and administrative improvements are made, and if stakeholder needs are addressed. The implementation and management of these continual process indicators is perceived to generate more holistic stakeholder satisfaction. As stated previously by secretariat staff, all processes in an association ought to be facilitating sports excellence and promotion. However, this is not always perceived to be the case. The constituent groups profess some tensions and compromise in their direct and indirect responses to the question on what they think are the criteria of effectiveness. 
Athletes feel that criteria of effectiveness indicators should not be focused on outcome indicators such as the number and colour of the medals alone. This is because periodic improvements in performance and the processes that are relied on to produce these performance improvements are also counted as successes: I think, basing the organisation purely on gold medals, to me that's bad. Because then they don't think about the process. They just think about the outcome. So outcome specific is a poor indicator. Even though it is an indicator, it is not a very good one for sporting organisations. For my organisation, I feel that the indicator should be periodical performances, and evaluation of the athletes should be unbiased (A1_PI).

Other athletes espouse qualitative criteria in the fraternal environment such as friendliness, camaraderie, and cooperation during training. While acknowledging that goals and key performance indicators in the strategic plans are criteria of effectiveness, they feel that the success of the sport is also determined by other indicators such as the response to feedback from internal and external stakeholders.

How an association unifies stakeholders and gets them to work towards a common goal is another indicator mentioned by athletes. Angst is felt by athletes when they see the association cutting corners and ignoring the needs of important stakeholders for results in the short term, thereby missing the longer term goals altogether. They feel this will impede the progress of the athletes in the long run. Suggesting a more holistic approach of getting all stakeholders to see the association's broad goals and to unify them to move in the same direction, is considered more strategic than trying to satisfy shortterm objectives deemed important for the next year's funding. In addition, athletes would like to see a balance between being led by SSC's long-term directives and that of the association's own objectives: The whole organisation's goal should be amplified throughout the organisation ... If everybody can work in the same direction, which includes the referees, the judges, moving together as an organisation going forward ... This is not an immediate kind of process. It takes a long time, and it takes strategic planning. I think the way the organization is moving is very short-term. And their long 
term goals are purely SSC determined, which to me is like a 'cow being pulled by the nose' (A1_PI).

Secretariat staff also feel that continual indicators, such as feedback from stakeholders must be taken seriously by board members for the sport to be lifted to a higher level. These indicators, besides achievement of tangible results, will also show whether the sport is truly successful: Goals and KPIs are criteria, but there are other indicators such as whether sports is successful or not, for example, climate within the fraternity, response from clients, participants and the public, most direct feedback will be from staff and volunteer coaches. While goals and KPIs are clear cut, they must be balanced by the feedback $\left(S \_F G\right)$. While stating that there are formal and periodic evaluations of associations on five main areas (high performance, sports development, climate, management, and achievement), secretariat staff sadly admit that no qualitative data is sought and interpretations of the scale can be different $\left(S \_F G\right)$. Other continual service improvement indicators, such as the efficiency of the administration in releasing funds, and in processing standard requests (application for leave and deferment of national service), are seen as important internal indicators to balance the focus on visible medal outcomes.

Some board members agree that how an association is being managed, the efficiency of the secretariat support, and financial governance, are other continual indicators that are also criteria of effectiveness. These board members look to incremental improvements in key areas, such as sports development and organisation, within a time frame as signs of being on the right track: If we don't see any incremental improvement in a year's time then obviously we're not on the right path and we need to review again, are we targeting the right areas of development? (B3_PI).

For coaches, besides the quantitative key performance indicators, recognition of the sport by the media, general public, and the international community, are stated as other criteria of effectiveness besides medals. Among the sports associations that do not receive top tier funding from the $\mathrm{SSC}$, some coaches feel that their associations are already recognised internationally for technical, management and event expertise, and 
this ought to be seen as a criterion of effectiveness despite not achieving the medals. Others feel that the lack of public awareness and media interest contribute to the low recognition of the sport: General awareness is not there in Singapore. People knowing about the sport would also be a criterion (C1_PPI). Most coaches agree that the development of the technical and coaching infrastructure should also be considered another criterion of effectiveness.

\subsubsection{Development of athletes' potential}

The constituent group that commented most widely on this issue were the athletes, followed by the coaches. The other two constituent groups did not allude to this issue in the context of criteria of effectiveness.

For coaches, the main tension emanates from how they felt they were being perceived when no medals were achieved during the protracted process of developing athletes. To them, reducing attrition or the drop-out rate of athletes is a criterion linked to development of athletes' potential as there is a trend in Singapore for athletes to stop training in their late teens. This reduces the base of young sportsmen and sportswomen and prevents potential champions from emerging. The drop-out rate is highest usually after 18 years when the males are being enlisted in the army for national service, and when the females are furthering their studies or joining the workforce: I think the young (athletes) ... method is very good. Now the problem is after the age 18, how can we keep the talented in the sport? How can they find the gold ...it's difficult because the boys, after their A levels they go into the national service, university, family, so usually they stop the active sports, so this is the age where we are losing a lot of good (athletes) (C3_PI).

While attrition, by the players that drop out from the programme (C7_PI), is an easily quantifiable criterion for coaches to gauge effectiveness in their associations, it is less about how to quantify, than to recruit and retain the already small pool, and to improve performance. Coaches describe their disappointment over how the funding body evaluates them and views success. Developing athletes is a long process comprising 
multiple factors working together at the individual and organisational levels. However, when the funding body looks only at medals and not continual improvement indicators, coaches are discouraged. This is particularly so when athletes' allowances are reduced, and coaches have to stand up for their charges: When we do not do so well, SSC wants to cut my athletes' pay. But he (the athlete) was changing his game. We had to give examples why he was doing that, but they didn't want to listen. They only judge upon results. ... After the change, he won all the tournaments he could ever win (C4_PI).

How little the SSC notices periodic performance improvements of the individual or the team is a source of disenchantment, especially for national coaches of team sports where getting a medal collectively can sometimes be more difficult than individual medals. The SSC gives the impression that they are impervious and insensitive to the fact that there can be substantial improvement without results defined by medals: It's $a$ hard thing to swallow, but as a coach, I can see things that are happening which are great. But if you (SSC) walked to me and say you finished $5^{\text {th }}$, when you should have finished 4th, I'm going to say well, we did our best but we are improving. But people

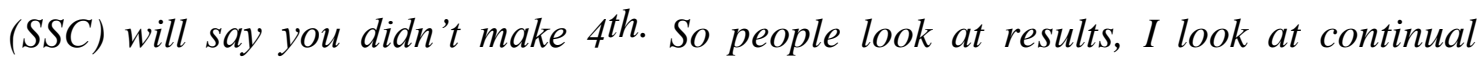
improvement, continual pursuit of improvement towards excellence is my philosophy. ... Once the team develops in their structures of play, which is happening, results will take care of themselves. They are improving without getting results (C2_PI). Coaches acknowledge that they too want results, but also see other means of assessing effectiveness: A lot of people look at results. You must get a result. As a national coach, that's always in the back of my mind but I'm here to improve players. If I improve players to the point, individually and as a team, results will take care of themselves (C2_PI).

When discussing the criteria of effectiveness, coaches describe the social and cultural context as another area where the jobs of coaches are continually being stretched and challenged while attempting to develop athletes. Singapore athletes have been influenced by the environment to want to win at all costs. This appears to some coaches a cultural phenomenon that will be difficult to shake off but is an issue that the nation 
needs to address to move sports forward. When local schools, administrators, parents and coaches focus on trying to win all the time, the right skills and mindset are not being imparted, resulting in too much self-confidence being tied to outcome. So when an athlete or a team loses, it is taken very hard like someone has died (C1_PPI). The focus on winning in the short term is at the expense of lifting the game in the long term and excelling in the international arena: In Singapore we struggle with winning because in all our programmes, everyone wants to win. NSAs are trying to put developmental programmes in place and will take about 10 years to produce a national player but all along the way they have been influenced by 'you must win you must win' ... In Singapore as long as we win, there is no concern for how good Singapore is in the international game...we emphasise winning but ultimately we are scared to lose because it is all about winning. It is bizarre. (C1_PPI).

Besides the attrition rate, and the emphasis on winning, the importance placed on education is another social and cultural factor discussed. While coaches feel the pressure to produce results and accept it as part and parcel of their jobs, training is often hampered by other educational priorities. This brings coaches to question how realistic it is in the Singapore environment to support sports excellence: Told from SSC to be the top sporting nation by 2010 but is it realistic? Giving more leeway in national service ... have schools who are more lenient, have better buy-in, rather than now insisting on school work taking over training ... the athlete has got to be active even if there is no training. In Singapore, school work tends to be all encompassing, for if the kids are not in school, then they are with tutors. If not as good as the next kid, the parents feel that they are losing face. Cultural differences are vast. (C2_PPI).

For athletes, the development of athletes' potential can be operationalised as training and development programmes, identification and development of talent, coaching, selection, and high performance athlete management (A_FG; A3_PPI; A1_PI; A2_PI, A3_PI; A5_PI; A6_PI; A7_PI; A8_PI; A9_PI; A10_PI). In general, athletes do not think that their associations have shown sufficient concern for the above and thus feel 
that their associations could be more effective. In their view, there is a lack of professionalism.

Professionalism, to the athletes, means doing things in a business-like manner ( $\left.A \_F G\right)$ and the premise is that professionally managed associations ought to provide quality high performance athlete management which, in turn, will lead to the development of more potential champions. However, athletes feel that Singapore associations are not moving fast enough compared to other countries in the areas of good training programmes, exposure to competitions, transparent selection processes, and management of athletes' sports and personal lives. Thus, in relating the Australian experience of creative use of retaining and channeling sports talent across sports, one athlete remarks: Analyse and look at sport from different perspectives, for example, if a talent retires, can put a swimmer in synchronized swimming, if in gymnastics, can channel to diving and skiing, innovative ways to channel talent (A2_PPI).

Equally frustrating can be the organisational structure in some associations where coaches have to take on management or operational roles affecting the quality of the coaching. One athlete advised employing and empowering professional staff for the day to day running of the association: getting qualified people in for the management of the association ... and to empower your employees. You hire them for a reason. You need to let them make decisions (Al_PI). Athletes advocate clearer job demarcation, so that the coaching department can be independent in order to also make the technical and selection decisions without the over-interference of the board or president. This will enable the association to move quicker and in the right direction towards sports excellence.

On the subject of quality coaching, athletes consider it a bane that their associations are either not hiring the right coaches or have an organisational structure that defeats technical and organisational excellence. Athletes cite a lack of financial resources, inexperienced recruiters of coaches, short term coaching contracts, and a lack of 
disciplinary coaching depth as systemic difficulties and barriers to effectiveness (A2_PPI; A3_PPI; A9_PI).

Athletes further contend that some associations focus too much on the Sea Games that are held every two years among the Asean countries, thus neglecting a longer term view of athlete development. If athletes are not of standard to be sent to Asian and Commonwealth Games, associations seem to think that the Sea Games is the only chance for medals. However, in the lead up to the Sea Games, associations do not always send athletes to regional or small international competitions for exposure: Send us for other regional competitions or other international, small international competitions where we can get exposure first. And then slowly build on it instead of just focusing on the SEA Games which is every 2 years ... and make a big deal out of it which I don't think is very necessary ... all these small tournaments will actually make SEA Games very easy for us. We're seeing the same people, and there might be other countries as well, which are not in the SEA Games, so we'll be seeing more people ... better exposure (A9_PI).

Athletes also noted that inability in meeting international standards in equipment and venues lowered effectiveness. For example, new courts for the national team were poorly built and not constructed to standards. They resulted in injuries: It's not like they don't have enough money. They wanted to build a court for us to train in but they didn't even build it with most effort. They did it half-heartedly so now the court we train in is crap. It's dangerous, like recently we've had injuries because of the court (A5_PI). This athlete contrasts the Singapore sports association with a professional Taiwanese club where training facilities are superior and where additional professional trainers such as dieticians, and fitness, strength, and conditioning coaches, attend to players to help them improve performance.

A number of athletes contend that selection has been biased, depending very much on the board members or coaches and their affiliations, thus creating tensions among athletes, coaches, and associations (A3_PPI; A2_PI; A5_PI; A7_PI; A9_PI). If an 
association is transparent in selection by having proper guidelines and involving the relevant people in selection, it will be seen to be fair and ethical. This also has the advantage of being perceived more positively by the public: ... for public image they also need to be more transparent in the ways that they communicate with the coaches and also just basically improve their ties with the coaches and the athletes, and set down proper guidelines ... (A7_PI). The lack of selection guidelines for coaches and athletes have led to breakdown in communication at crucial times leading to personal, coaches, or club agendas being placed above the associations' and national interests. This is due, in part, to the fragmented coaching and development structure, and the fact that there are coaches of national athletes who are not full-time employees (A3_PPI; A2_PI; A7_PI).

In summary, when discussing criteria of effectiveness, the two key quantitative criteria expressed by the four constituent groups are participation and performance and two key tensions discussed most by coaches and athletes are balancing outcomes with continual process indicators, and development of athletes' potential. The next section will examine how the determinants of effectiveness are affected by funding and whether the outcomes are commensurate with the funding received.

All four constituent groups agree that funding affects effectiveness and outcomes. This section attempts to correlate the constituent groups' definitions of effectiveness with their perceptions on how funding affects effectiveness and outcomes. To recap, in the earlier section on perceptions of effectiveness, respondents had defined effectiveness as: communication, showing results, financial management, athlete management, organisational processes, and commitment of the management committee.

Broadly, funding affects two main dimensions and effectiveness: sports development, and personnel management. Sports development is operationalised as a combination of multi-factoral elements working together to make sports accessible and competitive: competitions, programmes, events, and facilities. Personnel management is operationalised as the expertise and professionalism in the recruitment and retention of 
athletes, coaches, secretariat, and board members. Linked to these two areas is a key issue, the sustainability of funds. On one hand, the constituent groups discuss how they manage with the current level of funding and function as effectively as they can within the constraints. On the other hand, all constituent groups express a desire to engage full-time athletes, coaches, and professional secretariat staff for a more optimal level of effectiveness, should there be more funding.

\subsubsection{Sports development}

For athletes, there are direct and indirect effects of funding on performance and competitiveness. Funding for international competitions is necessary for overseas exposure to keep athletes competitive. This is important because of the limited competition potential in Singapore itself: ... overseas, where the sport is really popular, they have more competitions, whereas in Singapore we play once, and we have to wait another two, three months. It takes a long time and then it gets really stale (A10_PI). Another impact of funding on competitions is the uncertain timing of approval of funds which leads to last-minute communication on tournaments and inadequate preplanning. Athletes find the late notice of funding to reduce efficiency: ... the amount that we are funded is not known very early in the year, so sometimes they still have to wait, to figure out if they have funds for tournaments ... that's why in the end the (athletes) will know last minute whether we're going or not (A6_PI).

The majority of athletes state that the outcomes achieved are related to the funding received, and refer to their performances and results as evidence. An example is: I think we have matched up to it. I won't say we have exceeded. (A7_PI), however, the non financial impact is unrecognised: I think just more support for us, more acknowledgement that ok you all have done this and we're very grateful ... when we broke the national junior record two years ago, the very first time we broke it, very little was said. We broke the national record last year, very little was said again, ... apart from the fact that they gave us the reward (A7_PI). 
A minority of athletes believe that outcomes have not been commensurate with the funding. Instead, they believe outcomes have exceeded funding expectations: My team mates are doing better and better in overseas competitions... We're getting more results (than the funding received) (A4_PI). A contrary view is that there is underperformance due to the high turnover of athletes affecting the team sport: Our funding is enough at the moment but we are not really playing at where we should be because of availability of players. People come and go. When you get new players in you have to start from scratch. The cycle goes over and over again (A3_PI).

Coaches feel that, at a basic level, funding for the allowances of the athletes is necessary and critical to retain the athletes in training. A monetary incentive for athletes is seen as a retention strategy. This is perceived as very important for many schoolgoing athletes who can choose between staying at home to study and train. In Singapore's environment that emphasises academic pursuits, sports is often seen as secondary and immaterial. One coach asserts that his association has no issues with providing transport allowances for the athletes as they understand that it is an effective way to encourage athletes and keep them in training: Students need transport allowance, an incentive for them ... we have three different categories, youth development or Spex, intermediate, and the national, so the allowances are different (C7_PI).

Coaches naturally prefer a steady monthly income for full-time athletes. Currently, a select number of athletes are given a monthly income or salary, and this applies more consistently to the foreign sports talents than to local sports talents, resulting in one coach questioning: Why our own local talents are put onto the second tier? (C4_PI). A monthly income is important in cases where athletes come from families who may not be able to support them financially in their pursuit of sports excellence. For such families, studying and working are more important than sports: We, of course, have very, very, good players who had to give up because of studies, because of work $\left(C 8 \_P I\right)$. Most coaches do not wish for their athletes to have to choose between survival and playing the sport, especially in an already small population of sports talent as that 
would affect the base of national athletes: If you don't pay the athletes, you lose in excellence (C4_PI).

At a macro level, besides allowances and monthly salaries for athletes, coaches have suggested more funding in specific areas to recruit and retain sports talent. If materialised, these areas will also have a lasting impact on the sports development structure. They recommend more funding for sports schools dedicated to specific sports, scholarships, the development of a sports institute, structured talent identification, and sports-specific sports science specialists (C2_PPI; C1_PI; C2_PI; C5_PI). These, according to coaches, will further boost sports development and effectiveness in their respective associations.

Coaches, in particular, contend that funding too is necessary to get more school-going children initiated into sport. Funding for taster sessions is viewed as an initiation strategy. These sessions are used as carrots to entice school principals to allow the introduction of the sport to their pupils. When schools are receptive, their students are introduced to the sport and coached at no expense to the schools: If you don't have funding to give some free packages to schools to entice them to sign up, to try out the sport, then the number of schools that sign up will be reduced. This is how the money affects us (C1_PI). Thus, more funding will result in associations being more successful and effective in their outreach efforts and programmes as they strive to build a bigger mass participation and sports excellence base: You must break into the schools. Once the kids are interested, from secondary school up to junior college, they go to the poly or university, then they'll carry on, and join the national squad (B6_PI).

On the correlation between funding and outcomes, several coaches think that the funding received is not commensurate with outcomes achieved (C1_PI; C5_PI; C8_PI; C9_PI). These coaches feel that they and their athletes have achieved more despite the funding received, proven by the performances on the field. In addition, their associations had actively sourced for sponsorship and generated additional income from the running of programmes and events. Conversely, the rest of the coaches deem that 
the outcomes are commensurate with the funding but contemplate that money is rarely sufficient: I think the money is never enough, but I think our budget ... corresponds with the results (C3_PI). Some coaches reflect that they have done well despite budget cuts because of sacrifices made and corners cut in youth development for the sake of channeling the funds to sports excellence. They maintain that regardless of results, funding levels ought to be constant to ensure a continuous stream of youth athletes: ... last year they cut our budget ... the youth development programme was all sacrificed ... it means our feeder system has gone further back ... the funding has to be maintained, whether result high or low, the funding has to be there (C4_PI). One satisfied coach remarks that he is happy with the performances of his players considering the funding they have: We've done very well with the funding we've got, to what the process, the performances have been. I can say that it's been quite adequate (C2_PI).

Coaches would like themselves and their local athletes to be renumerated as equitably as foreign sports talents to keep them in the sport (C4_PI; C5_PI; C8_PI; C1_PI). One local coach remarks that foreign sports talents in other associations are paid better than his top talents. His athletes have to look after themselves as the sports industry is not mature enough to see them through after their athletic careers. Thus, many turn to studies as a fallback and leave their sports careers in the back seat: I'm very sure people like our (name of sport) stars are earning better than my own local top athlete ... our top athlete ... has to look out for herself ...our industry is not matured yet, and our environment is not there. Singapore doesn't have the environment for you to be a fulltime (athlete). You go and do your studies (C4_PI). Another local coach who has athletes either studying and training, or working and training, prefers that the athletes get sufficient funding to train full-time and continue their studies locally or overseas, after their successful sports careers: Imagine if you have such funding ... to train full time, they can get all kinds of exposure ... all kinds of training ... exposure, and this is what they actually need ... if they are successful, studying is not a problem, because they will get a sponsorship or scholarship to study overseas (C8_PI). Lastly, other coaches wish for funding to be allocated for good administration and management that are essential to support the development infrastructure and produce the key result 
outcomes (C2_PPI; C1_PI; C9_PI).

Board members acknowledge that funding affects programmes and overseas exposure most (B1_PI; B4_PI; B7_PI; B8_PI; B9_PI; B10_PI), followed by the recruitment and retention of professional administrative and coaching staff (B2_PI; B3_PI; B5_PI; B8_PI; B9_PI). The majority of board members state that funding is commensurate with outcomes. For the two board members who do not think so, one feels that the association had generated other income and thus have achieved more than the funding received, while the other thinks that the association could have done more with the existing funding from SSC.

Funding affects results and effectiveness because of the correlation to participation: Without funding, we can't run international events. Secondly, we need the money to run local competitions (B5_PI). In addition, funds are required to put up attractive prize money in events to attract a larger field of participants: ... if you don't have enough funds to raise the prize money, then that will affect the participation numbers (B2_PI). In associations where the shortage of funds is an issue, hard decisions such as prioritizing the needs of the various teams will need to be undertaken: ... we would have to look at which team has the priority to receive the funding first (B4_PI).

In general, board members are grateful for the public funding as that is usually the chief income stream for most associations: ... the fund to us is really important, apart from (being) our main source of income ...(B8_PI). As would be expected, the funding is often considered inadequate: I think we're very grateful to the SSC, you know, for supporting us all these years, but I think sometimes the question is how much is enough ...(B10_PI). And: For the past one or two years, funding from SSC has been good and no amount is too small. However, funds must be generated by the association as well (B7_PI). The funding is important even to associations that have raised supplementary income as the additional income: ... the fund to us is really important, apart from (being) our main source of income ... we still need the government to support ...(so that) we can have extra activities like regional competitions. If we tax our own funds, 
we will dry out faster (B8_PI). Being creative about raising money to supplement the SSC's funds is also a necessity to provide more help to the athletes: ... we've got to supplement, ... what sort of assistance the athletes need, overseas competitions, all these need funding (B9_PI). Thus, there is an implicit necessity to supplement the SSC's funding from other income or revenue streams if associations wish to reach a desirable level of mass and elite sports development.

Secretariat staff affirm that overseas competitions are most affected by funding and this has a direct correlation with performance and medals (S1_PI; S4_PI; S5_PI; S6_PI; S7_PI; S8_PI; S9_PI; S10_PI). Secretariat staff explain that players need to compete frequently in recognised tournaments to better their rankings especially for those in Olympic sports (S5_PI). Funding affects high performance and results as the money determines 'where teams can go to, training times, how many of the outside instructors like sprint trainers we can engage, the amount of food we can give our national players.' (S4_PI). Secretariat staff state that funding for facilities will increase their effectiveness and cite examples of how other associations, with adequate facilities, had improved performance. The issue of owning the facilities, versus rental, is an issue for secretariat staff (and for some board members). Rentals are considered to be exorbitant (S1_PPI; S2_PI; S10_PI). Secretariat staff, who think that the outcomes were commensurate with the funding achieved, reason that they have achieved the targets as planned and delivered the results with the funding given (S1_PI; S3_PI; S4_PI; S5_PI; S6_PI; S9_PI). For those who do not think so, the reason is that associations have raised their own funds from sponsorships and fundraising activities and thus have achieved more than the funding received (S2_PI; S7_PI; S8_PI; S10_PI).

In summary, the above section has shown that all constituent groups agree that funding affects sports development. As the funding from SSC has never been sufficient, the outcomes were considered to be either commensurate with, or in excess of, the funding received. Funding is essential to send athletes for more overseas competitions, and to host more local and international events. 


\subsubsection{Personnel management}

At the organisational level, athletes discuss how funding impacts the recruitment of coaching, technical and administrative staff, and how this in turn affects them. Athletes feel that they can perform better when there is sufficient funding for the recruitment of coaches: If there is more funding from SSC for coaches, the quality of (athletes in the sport) will go up (A4_PI). Athletes consider the recruitment of the right coaching expertise as more important than whether the coaches are local or foreign. This implies that boards need to have the expertise to make the right choices: The management ...doesn't have enough expertise in selecting the right coaches to come in, and because the coaches are not right, basically the level of (the sport) is not being pushed up (A9_PI). The employment of appropriate foreign technical personnel led to a first female athlete, in a long time, being exposed to the right competitions and qualifying for a higher level: ... so the experience the technical director brought over to Singapore ... helped put at least one (athlete) at the international level (A9_PI).

Athletes expand their notion of recruitment to secretariat staff in particular. They suggest employing them on a full-time basis, and retaining them on the basis of qualifications and experience rather than whether they are local or foreign: ... engage professional staff ... secretariat yeah... because the current Exco is made up of volunteers, so we need professional full-time staff running the show for us (A2_PI). Concomitantly, the team managing athletes and leading the talent identification process is also critical. On this issue, an example of an association that has its act together and is reaping the results of bringing in the right management expertise is given: No doubt it's a Singapore sports association, they were willing to invest in professional management ... they're bringing in guys from Australia, Germany, and ... all over the world, because they see the need, and this has led to them to being one of the most successful sports associations in Singapore ...whatever it takes ... I mean if we have these people, we won't be looking overseas (A2_PI). In the case of another sports association that had their funding reduced because of the lack of results, an athlete agrees that employing qualified people may be difficult but not impossible. If proper recruitment methods of contacts, referrals and headhunting are used, and justification made to SSC, that shows long-term planning and alignment with the organisation's 
goals, the athlete believes that the Council will provide the allowances. Conversely, if the association chooses to take the easy route of getting people in based on relationships rather than merit, the result will be less transparency. The ramification is an inefficient and ineffective association that is unable to fully support the athletes who are required to produce the results for future funding, continuing a vicious cycle: ... to get their own people, is where power politics come in ... I can run the organisation very easily because all these people listen to me ... but then there is no transparency ... when this is your student, and he is the marketing manager, your people, your friend ... everything can run, but whether it's run well or not, you will end up handling it (Al_PI).

Funding also affects the recruiting of coaches and coaching development. All four constituent groups agree that funding is required to hire the right calibre and number of coaches to bring in results. While associations do their best to stretch their funding, it is also important for coaches that the right number of coaching staff be employed: I think right at the moment we're doing quite well with what we have, and they (the players) are right down the track, but again, if there're more money available... I'd like to see... a national coach for the women, and a national coach for the men. That's on the coaching side, and it's back to dollars and cents (C_PI).

Both local and foreign coaches agree that more can be done for coaches' upgrading and to increase the sports science knowledge in the coaching fraternity. This will raise the effectiveness of coaching and training. For coaches in youth development who are training the national athletes in the various age groups, sports science knowledge is seen to be important as they have been relying on experience and the acquisition of knowledge by self-reading (C1_PI). Ultimately too, when the development plans are on course, and the feeder systems comprising not only of schools but clubs start to grow, funding is required for coaching development to deal with the positive growth in participation and excellence numbers: Coaching development. So here are the big things, getting ourselves better coaches for the club scene, which would improve the club players, and of course then the national coaches will improve their players, and 
they can spend more time with them. ... As we expand, ... that means more coaches, more money required, if there's no money there, you can't expand...(C2_PI).

On the issue of job satisfaction, foreign coaches discussed empowerment, trust, and commitment. One foreign coach, who applauds the professional administrators of a successful association for their initiative and foresightedness to raise their own funds and to bring in the right people to manage, has negative remarks of his own association when it comes to employing foreign coaches and not entrusting them to do the job they know best: In Singapore, NSAs take foreign coaches in, but do not give us the authority to put in place what we want to do (C2_PPI). Another foreign coach states the paradox of being recruited from a country where the sport is played at a world level with the best practices to one that has the means to employ, but lacks the social and cultural environment to change: The strange thing about being a national coach as a foreigner is that you come from an environment with best practices, but go to another environment that you can't change anything in the new community (C1_PPI). Speaking of trust, the foreign coach echoes the sentiments of others who sense innately that the Singapore sporting fraternity bears distrust for foreign coaching expertise. These foreign coaches are particularly aggrieved by the mistrust and lack of empowerment when they have already taken a step back in their careers by coaching in Singapore (C1_PPI).

On coaching development and train-the-trainer programmes, one coach notes the lack of commitment among young coaches that he mentors and laments about the missing management skills. These he feels, cannot be taught out of a written text but will have to come from the willingness to be present and to undergo the full experience: I have two young guys whom I mentor but I can't mentor someone who is not committed. A lot of things can't be taught out of a book. You need to stand, and witness on a daily basis, to know what coaching is about. Singaporeans are outstanding at reading and memorising but putting into practice is another matter. Management skills are not good and that is part and parcel of a good coach (C2_PPI). 
Board members believe in increasing the quantity and improving the quality of coaches for better results to be achieved. They comment that funding towards the recruitment and development of coaches will increase effectiveness and think that more can be done in the area of technical development. This is a similar view shared by athletes and coaches. Coaches will need to produce results to warrant better salaries, but in order to produce the results, they will need to be better coaches. A board member thinks that it is the responsibility of the association to ensure coach development: ... no one will come forward unless you get a good pay ... But if you want to get a good pay you must produce results, so the main responsibility for the NSA is ... to upgrade the coaches (B8_PI). Placing the importance of funding to recruit more coaches for specific aspects of the sport, a board member summarises the role of his association: If we have more money, we can hire more coaches for the different aspects of the game. They can be cotrainers. Basically the role of the NSA is to fund generate, play, and win (B7_PI).

One board member notes that funds are needed to subsidise coaches for overseas training as there are not many international tournaments in Singapore and coaches do not have many opportunities to plan periodically and strategically. Ironically, these gaps surfaced when Singapore held coaching workshops for the countries: ... (we) do a lot of attachments and we hold coaching workshops for these different countries, we can feel a big gap there, in drills, planning, in strategic planning. In Singapore, there is a lack of international tournaments, so in Singapore this type of experience is very hard for them (the coaches) to gain (B5_PI).

Financial resources are needed to ensure that more technical staff can be hired to prevent one person to have multiple responsibilities which affects effectiveness. A board member compares her association with the structure of another richer association, showing that more coaching and technical staff can lift the sport to a different level: ...they seem to have the money to bring in different coaches for different events ... they have a technical director and below ... two or three high performance coaches whereas, we only have one national coach and (is) also the technical director so I think that's why things can't move as fast ... our technical executive is also a national 
captain ... so when (the person) is playing, the whole technical department shuts down! ... only two of them ... if (we) could re-organise a little bit and have the resources to bring in a technical director just focusing on technical development of umpires and coaches, that would really push the game to the next level (B2_PI).

Board members also think that there is a need to complement passion and volunteerism with sports science and sports management. Funding is needed to hire the right people in all paid positions: If you have the funding available to pay someone to focus on a particular aspect and to drive that, then obviously you're going to get where you want to get a lot quicker. Without that funding, you're going to get there a lot slower or not there at all because efforts are diluted (B3_PI).

Secretariat staff discussed coping with what the association can afford. They raised several issues that undermine their effectiveness when there is inadequate funding for hiring the right professionals in administration and coaching, and rewarding them with salaries, increments, and bonuses. Turnover is relatively high as associations are not be able to pay as well as the other sectors. The lack of manpower results in the sub-optimal functioning of the organisation (S8_PI; S9_PI).

On the inadequate funding but high expectations from the SSC, one general manager remarks caustically that they just do not have the resources and the facilities to be world class: Here you're asking us to be on World Class but ...the resources that we have are low class, not even middle class, how to be world class? (S10_PI). While understanding that salaries will not be comparable to the private sector, one secretariat staff feels that bonuses ought to be given to staff even though the SSC does not allocate funding for such purposes: ... in terms of staff welfare, like bonuses, we can't just give bonuses according to civil servants, whatever rate they give for civil servants, because Sports Council doesn't give us that amount (S1_PI).

In summary, the section above has shown how funding affects the human resource management of key personnel in associations. The evidence has alluded to broader 
concepts such as better distribution of capital resources for building capabilities and human capital, and complementing passion and volunteerism with sports science and sports management knowledge across levels, to reach goals quicker.

\subsection{Summary}

This chapter has described the subjects of the study, the coding process, and showed patterns of data for each key research question. Summing up, the perceptions of effectiveness are: communication, showing results, good financial management practices, athlete management, organisational processes and procedures, and commitment and organisation of the management committee. The criteria of effectiveness are participation, performance, balancing outcomes with continual process indicators, and development of athletes' potential. Lastly, funding affects sports development and personnel management, and is largely perceived to be commensurate with planned association outcomes. In the next chapter, the Discussion and Conclusion of this study will be presented.

\section{END OF CHAPTER FOUR ANALYSIS OF DATA.}




\section{Chapter 5 Discussion and Conclusion}

\subsection{Introduction}

The purpose of this final chapter is to provide a conclusion that addresses the following three research questions:

1a) Do different groups of stakeholders have different perceptions of effectiveness of Singapore national sporting associations?

1b) If so why?

2) What are the criteria used by the different stakeholders to determine effectiveness of national sporting associations in Singapore?

3a) How are the determinants of effectiveness affected by funding?

3b) Are the outcomes commensurate with the funding received?

Chapter 1 of this thesis detailed the broad field of study and the focus of the research problem, namely to explore organisational effectiveness in Singapore national sports associations. Special attention was given to four constituent groups - board or executive committee members, secretariat staff, athletes and coaches - to draw out their perceptions and determinants of effectiveness and the connection to outcomes desired of the associations.

Chapter 2 reviewed the general literature on the non profit sports sector, including the definitions and characteristics of the non profit sector of which sports associations form a part: corporate (or institutional) governance; the difficulties operationalising effectiveness and measures of organisational effectiveness; background and blueprint of Singapore sport; and lastly, theoretical frameworks of organisational effectiveness. 
Chapter 3 provided details of the qualitative methodology used. Chapter 4 described the subjects of the study, the coding process and patterns of data for the key research questions.

In this fifth and final chapter, which is divided into eight sections, all of the findings will be examined and discussed in relation to the three major research questions. Following this first section that revisits the aims of the previous chapters, the second section (5.2) presents the conclusions regarding the three key research questions. The third section (5.3) aims to formulate a conclusion in relation to the research problem. The fourth and fifth sections (5.4 and 5.5) establish the implications for theory, and policy and practice respectively. The sixth section (5.6) notes some of the limitations of the study, and the seventh section (5.7) provides implications for further research. The eighth and final section (5.8) presents an overall conclusion to the chapter and the study.

\subsection{Conclusions about the key research questions}

In this section, the distinct findings and conclusions from the three research questions are elaborated, starting with the first question on perceptions of effectiveness among the different stakeholders.

\subsubsection{Conclusions from the findings on perceptions of effectiveness}

The study confirms much of the literature concerning multiple perceptions of effectiveness among the key stakeholders comprising athletes, coaches, board members, and secretariat staff (Cameron 1978; Chelladurai and Haggerty 1991; Papadimitriou 1994; Herman and Renz 1999). The four constituent groups perceived effectiveness as: communication, showing results, good financial management practices, athlete management, organisational processes and procedures and commitment and organisation of the management committee. These determinants are multi-dimensional, and depending on the constituent's role in the association can be interpreted rather differently. The findings also concur with Baruch and Ramalho (2006) that the body of knowledge on non profit organisational effectiveness has 
become more sophisticated than merely attempting to measure effectiveness solely through organisational goals and that there has been little consensus on its meaning, operational definition, or its measurement (Price 1972:11; Steers 1977:38, 54-57; Connolly, Conlon, and Deutsch 1980:211; Kanter and Brinkerhoff 1981:321-322; Chelladurai 1987:37-38; Cameron 1986:539; Herman and Renz 1999; Shilbury and Moore 2006:8).

Of the six themes of effectiveness, three - showing results, good financial management practices, and organisational processes and procedures - were covered in the literature review and concur with the research done by Price (1968), Steers (1977), Kanter and Brinkerhoff (1981) and Frisby (1986), while the other three were not mentioned definitively in previous studies. They are communication, athlete management, and commitment and organisation of the management committee. Both communication and athlete management relate to the broader concept of the ability to manage athletes professionally, and refer to leadership from skilled and capable management committee members as the catalyst. It is interesting to note that these two themes are cited predominantly by one constituent group - athletes. However, all four constituent groups concur on the importance of commitment and organisation of the management committee and this relates to the broader concept of twinning technical knowledge and management experience to achieve goals faster.

The findings on the theme of showing results most strongly expressed by secretariat staff, coaches, and board members, concur with early attempts to define effectiveness by outcomes or goals (Price 1968:3), and to measure organisational effectiveness using univariate measures such as overall performance, productivity, employee job satisfaction, profit or rate of return on investment, and employee withdrawal (Steers 1977:39). The study shows that this dimension is stated quantitatively and relates to mission and goals in terms of achieving targets set, making the sport popular across the various segments, growing the base, and generating awareness for the sport. These indicators are operationalised as the number and types of programmes that are managed, the participation rate, standards achieved, level of media exposure, the 
number of people who know about the sport, medals won, and percentage of compliance with the Code of Governance for National Sports Associations.

However, the study also shows that when the same three constituent groups further discussed showing results beyond a univariate measure, they stressed the strong link between results and funding. This is because an association's funding is highly dependent on the outcome-based funding model and compliance with the Code of Governance. This particular finding and the findings on the themes of good financial management practices, and organisational processes, are in line with Kanter and Brinkerhoff's (1981) literature review on performance measurements in which terms such as effectiveness, productivity, performance, and success were not distinguished.

Kanter and Brinkerhoff (1981) found that studies that recognised the complexity of measurement issues made a distinction among three kinds of 'effectiveness': task effectiveness or goal attainment (including output, results, efficiency); appropriate organisational structure and process (including organisational characteristics, member satisfaction, absence of strain between subgroups); and environmental adaptation (including flexibility in the face of change, resource acquisition, longer-term adaptation, and survival). This study shows similarities with the review as the three themes of effectiveness - showing results, good financial management practices, and organisational processes and procedures - relate to broader concepts of effectiveness such as the ability to attain organisational goals in the micro and macro environments, the ability to do strategic planning and manage associations professionally, the ability to improve relationship management of internal and external stakeholders, and the ability to manage multiple 'bosses', demands, and objectives.

The findings on good financial management practices where coaches, secretariat staff, and board members state that the funding from the SSC and supplementary selfgenerating income are pre-requisites for strategic planning, implementation of plans and achievement of goals, are also in agreement with Frisby's (1986) research that showed that one of the goal model indicators, the effectiveness ranking, was positively 
and significantly correlated with one of the system model indicators, the total operating budget. While this suggests that the ability to acquire scarce financial resources was related to the ability to achieve sports excellence, causality remained debatable as the funding body would prefer to have tangible signs of performance before releasing funds. However, it could be argued that funds were required before performance excellence or effectiveness could occur (Frisby 1986:94, 98).

This paradox, of whether results should come before government funding or funding for the achievement of results, is also significant in the findings on the theme of athlete management and the theme of performance (under the section on criteria to determine effectiveness). The findings on athlete management show that school-going athletes in particular point out that grants are late, notice of competitions is last minute due to untimely approval or release of funds, or athletes are carded unrealistically leading to inefficiency and ineffectiveness. The findings on the theme of performance show that while the three constituent groups of secretariat staff, coaches, and board members are unanimous in stating performance as the second quantitative criterion of effectiveness (after participation), associations that do not have demonstrable results nevertheless still have a hard time trying to justify their success and effectiveness to the funding body. Without medals, seeking external funding from the SSC or sponsors for sport development can be particularly difficult. As for the other associations who have international success, the intense focus on sports excellence can come at the expense of youth development. These findings again concur with Frisby (1986) and with Drucker (1973) who noted that judging performance and measuring effectiveness in non profit organisations are particularly challenging because of intangible social and psychological goals compounded by measurement difficulties.

The findings on organisational processes and procedures reveal effectiveness perceived in relation to organisational structure and processes and show convergence with the research by Steers (1977), Kanter and Brinkerhoff (1981), and Salamon (1994). Constituent groups view their associations as effective when there are efficient processes and standard operating procedures in place, with the right people in the right 
roles and clear job responsibilities. These are seen as antecedents to achieving goals and results within the associations (Steers 1977; Kanter and Brinkerhoff 1981). Outside the associations, the findings show constituent groups discussing bureaucracy and timeconsuming mandatory paper work required by the funding body as obstacles to effectiveness. Like the research done by Salamon (1994: 118-121), the findings reveal proneness to bureaucracy especially when the major source of financial support is government funding, tensions between flexibility and effectiveness, and between grassroots control and administrative accountability.

The previous section has presented a discussion on the three definitions of effectiveness (showing results, good financial management practices, and organisational processes and procedures) in conjunction with the secondary literature. The following sections draw inferences from the study's three themes of effectiveness - communication, athlete management, and commitment and organisation of the management committee which were not cited directly as definitions of effectiveness in previous research.

While preceding work did not define communication specifically as effectiveness, the findings on communication indirectly support Lewis, French, and Steane's (1997) review of literature on culture and conflict in non profit organisations in Australia where the human component of managing non profit organisations is seen to be critical. People brought together by altruistic motives expect to be part of the decision-making process and have their opinions listened to and their values considered. Without competent conflict management strategies, division and fragmentation results in either excessive rigidity or a lack of innovation.

Translating this to the context of a national sports association, athletes feel that they often do not have a voice: are not sought for their views on training, coaching and competitions: and are often being told what to do, rather than being consulted on major decisions or crucial matters (carding and funding) by either their association or the Singapore Sports Council. With these perceptions, athletes seem to think that their associations are ineffective as they are only practise the most basic linear model of 
communication where the elements of sender, message, channel, receiver and noise are present but without feedback.

According to Rothwell (2004:12), senders of messages without feedback are insular and independent from receivers. Senders will not be able to make adjustments based on feedback received and this will become a serious communication competence issue. Thus athletes wish for an interactive model where communication is dynamic and twoway. Receivers become senders, and senders become receivers of messages, through listening and feedback. This will pave the way for mutually beneficial self-correction in communication as well as establishing common fields of experiences where intentions and meanings will be better understood (Rothwell 2004:12). The common bases of experiences can then be built on firstly, an evaluation of the channels of communication used, and secondly, timely sharing of information among all stakeholders in the association, including annual and long term planning and rationale for decision making. The preferred structured communication and formal platforms for feedback advocated by athletes will form the basis for high performance athlete management, better planning, and realistic goal setting. While three of the 10 stipulated conditions of the Code of Governance for National Sports Associations were to ensure that national sports associations comply to 'Proper management of conflict of interest', 'Transparent actions' and 'Responsive public relations and corporate communication', athletes who perceive two-way, formal, and timely communication as effectiveness claim that most of their associations do not measure up to this.

Other findings on communication show board members (defined as administrative or advisory volunteers who work with professional staff to determine policies, assist in fundraising, and participate on advisory boards (Roberts-Du Bord 1989: 39, 40)), relegating formal communication to an ancillary role. In this role, the function of communication is for the facilitation of meetings, administration, and as a mechanism to monitor effectiveness. Contrary to the athletes, they do not perceive communication per se as effectiveness and neither do they assume it to be an issue in their associations. 
In discussing communication secretariat staff, in particular, raised a relational issue of professionalism versus voluntarism. The findings on this emanation concur with previous work done on the relationship between professionals and volunteer boards (Auld 1994; Auld and Godbey 1998; Watt 2003). Inevitably, professionalisation challenges the culture and voluntary ethos of amateur sports organisations that have depended on volunteers to run the sport historically. Secretariat staff opined that they would like volunteer boards to be quicker in their decision-making and to respect their professional expertise and experience by being more conscious of time and human resources. Board members shared their difficulty in balancing empowerment and their expectations of being kept informed of the more important day-to-day operations and decisions made by the secretariat. These findings on decision-making as a source of conflict between volunteers and paid employees are similar to Auld's (1994:14) who had argued that professionals needed to be 'sensitive to the needs of volunteers and volunteers needed to recognise that professionals also seek satisfaction through their involvement with the organisation. This calls for mutual recognition of both parties' needs and a climate of cooperation and reciprocity for organisations to succeed in serving sport (Auld and Godbey 1998:20; Watt 2003:47-48).

In addition, the findings on professionalism versus voluntarism show some congruence with Auld and Godbey's quantitative research (1998:20) on the influence in decisionmaking between volunteer and paid administrators. Like the results from Auld and Godbey's study on 61 NSOs in Canada, the study shows paid professional staff would like a more equal relationship in policy development and implementation for improved organisational decision making.

The second theme not cited as a definition of effectiveness in previous research is athlete management. The findings on athlete management relates to two concepts: the ability to manage athletes professionally; and leadership from quality management committee members. There is a clear relationship between how involved the management committee is and the management of high performance athletes. The strongest voices on this issue are the athletes'. When a metaphor of a barren fruit tree 
being axed is used to signify the end of support to athletes who were no longer useful to the association as they were not able to bring back the medals, the athletes' perceptions of their associations are that the athletes are simply a means to an end. The personal well-being and welfare of the athletes during and after their careers are not important considerations to their associations who may not have quality elected members and the expertise of high performance athlete management.

These findings, however, bear some similarities to qualitative research done by Whitson and Macintosh (1988) who were trying to assess the impact of professionalisation on policy-making in six selected Canadian sports organisations. Both raise questions on 'athletes rights' (especially the inclusion or not of athletes in decision-making); and whether sport can have meanings other than the rationalization and production of performance (Whitson and Macintosh 1988:86). In addition, their study questions quadrennial planning and whether such planning attempted to provide a catalyst for citizen input into planning, or whether it was designed to assist in the ratification of an already decided upon solution. This is a point often brought up by athletes in the study who want a voice in major policy and decision-making, rather than to be presented with plans or decisions that have already been pre-determined by their associations or the SSC. An example is the carding system pegged to international standards which cannot be realistically achieved according to athletes. As the carding is used to determine training allowance, aggrieved athletes argue that expenditure on training gear, equipment, transport, supplements, and medical requirements remain fixed, regardless of the level of sport.

The third theme not cited in previous literature as a definition of effectiveness is commitment and organisation of the management committee. Notwithstanding, some of the findings on commitment and organisation of the management committee concur with Steane's (2001) work in Australia who found non profits could tap diverse board members with a broad base of skills. However, it is less apparent whether associations are equally effective and successful in doing so, as only the board members emphasised their cohesiveness and effectiveness in getting things done. 
Other constituent groups pointed out that the conflict of voluntarism versus paid work inevitably interfered with commitment, a fact some board members agreed but without offering solutions. The same issue of professionalism versus voluntarism was also brought up by secretariat staff and its inferences were elaborated under the findings on communication above.

The Singapore Sports Council had hoped to professionalise the national sports associations by advocating compliance to the Code of Governance and tying funding to it. Steane (2001:15), on the contrary, argued that it was incorrect to expect organisations to adopt governance practices developed for corporate sector boards. This is because divergent practices, rather than convergent expectations, are manifest in the governance of non profit boards for two reasons. The first is the diversity of the board that allows skills to be tapped for funding, lobbying and management. The second is an ideological foundation where commitment underlies strategic-decision making at board and senior management levels. Thus, in non profit governance, there is a strong link between structure and mission because of the composition of organisational members (Steane 2001:15).

The study also found that respondents perceive a strong causal relationship between the commitment and quality of the management committee and results achieved by themselves and the associations. The difficulty is in ascertaining the desired characteristics of board members for association effectiveness. The study shows all constituent groups perceive a diverse (with technical and management knowledge) and committed board as an antecedent to effectiveness and results. In particular, athletes put equal importance to the boards' motivations for serving as they see a relationship between the ideology of the board, and their own performances and careers.

If a diverse and committed board with the right motivations result in transparent leadership, strategic planning, effectiveness, and tangible outcomes, the question next will be where to find members with the desired characteristics and a willingness to 
serve. When the Code of Governance was introduced in 2003 and the terms of office for the governing council/management committee members had to be renewed more frequently (two years to a maximum of eight years) to encourage leadership renewal and rejuvenation, a valid concern was where to find the already scarce volunteers and how to convince the potential sports officials to serve on boards. This is not a problem pertaining to sports associations alone but is also prevalent in the social services sector. The solution in the social services sector has been a scheme to match board members to the organisations. The sports sector can do the same. The study reveals that volunteer board members in associations tend to put their own paid work first and these findings concur with Cuskelly (1995: 361) who had noted that the reasons for the decline in sport volunteers was due to 'personal, organisational, social and economic factors'. By matching volunteers to the sports associations, there would be a sense of belonging, better understanding of the organisation's goals, and more opportunities to use their expertise in decision-making (Cuskelly, 1995: 363, 365). Finally, beyond the SSC and MCYS, it is less clear if compliance to the COG has contributed to greater association effectiveness in the eyes of other stakeholders.

The above has provided conclusions to the first research question on perceptions of effectiveness among the different groups of stakeholders. The section that follows discusses the conclusions from the second research question on criteria used by the different stakeholders to determine effectiveness of national sporting associations in Singapore.

\subsubsection{Conclusions from the findings on criteria of effectiveness}

The findings on participation, the first quantitative criterion of effectiveness, suggest that increasing participation is necessary to grow the sport and thus there is a need for extensive outreach efforts. The nature and scope of participation can, of course, be measured easily by the number of members, frequency of attendance, duration of membership, amount of time spent in activities, and the leadership positions assumed. To increase participation, associations have to market the sport to as many segments as possible. High levels of participation make it easier for the association to attract 
sponsors. Increasingly internal stakeholders, especially board members and secretariat staff, see a need to expand their markets by reaching out to segments who will support them not only by funding for sport development, but also by long term involvement in the sport.

However, it is claimed that donor organisations and individuals besides simply giving dollars to any cause also engage in what has been termed 'social entrepreneurship' (Chow 2008). It is acknowledged that philanthropy in non profits is not just about 'giving someone fish or teaching them how to fish but also how to sell the fish'. From the donor's point of view, they would like to see organisations with strategic and governance frameworks in place first so that these organisations can eventually be selfsufficient to address problems on their own. As giving is seen as a way of business by this new breed of donors, associations who are seeking sponsorship in cash, kind or deed, necessary to supplement government funding, will need to realise that they will have to demonstrate a capacity to 'scale up'. Associations will also have to understand that there is considerable competition for donor dollars and will need to show accountability.

Both the Singapore Sports Council and the Ministry of Community Development, Youth and Sports have put in place the Code of Governance to help professionalise sports associations. Thus, as associations strive to increase their participation numbers through various outreach efforts there is also the need to professionalise quickly in response to the tougher challenges and new government demands.

The findings on performance, the second quantitative criterion of effectiveness, concur with previous work done where outcome goals achieved (such as results and targets) are seen as organisational effectiveness. This is covered in the research by Price (1968), Steers (1977), and Kanter and Brinkerhoff (1981).

However, the findings in this study deliver a paradox. The athletes, who are most directly responsible for producing the results and getting the medals, have the weakest influence among the four constituent groups, This is despite funding being a priority in 
associations, and that it is athletes who directly or indirectly determine the level of funding through their performances. The evidence is drawn from the study's findings on the themes of communication and athlete management and from the perspectives of the athletes.

Previous research by Norton (1998) on voluntary organisations and business organisations shows that products and services produced by the voluntary organisations were consumed primarily by their own members who pay dues and render their services voluntarily. In a private sector context, the customer is usually external to the organisation and is the most important stakeholder with a strong influence on inputs, outputs, and processes.

While the athletes are in a sense both members and customers of the associations at the same time, they are not accorded the same importance as customers in profit organisations where they are courted. This confirms that the measurement of performance and effectiveness in national sports associations is complex. Though secretariat staff, coaches, and board members affirm the number of medals won as a criterion of effectiveness, there exists the difficulty in tracing factors that directly influence the outputs of sport development.

The findings on the first key tension balancing outcomes with continual process indicators, discussed under criteria of effectiveness, show that associations would like to be allowed to use continual operating or process objectives, as indicators of effectiveness, aside from medals or outcome goal indicators. For associations that may not be able to win medals in the short term, athletes, coaches, and secretariat staff recommend periodic improvements in performance and processes, response to feedback from stakeholders, administrative efficiency in releasing funds and processing standard requests as continual process indicators that indicate effectiveness.

While these findings are a contribution to knowledge as this concept of defining criteria of effectiveness was not found in previous literature, it can be related in part to Herman and Renz's (1999) concept of responsiveness in non profit organisational effectiveness. 
Herman and Renz claim that measuring responsiveness may offer a solution to the problem of differing judgments of effectiveness by different stakeholder groups. In other words, the focus is on what makes an organisation effective, and the capacities that will enable the smooth and efficient operations of an organisation through structures, processes and procedures, rather than concentrating on the outcome goals as indicators of effectiveness. The associations that have more funding, are better staffed and have easily measured goals in the form of medals can continue using the rational goal model approach or the SSC's NSA Review model.

A service excellence certification for sports associations can perhaps be a viable alternative or supplementary to the SSC's NSA Review, especially for associations that may not have sports excellence as their sole mission. The quest will unify an association and encourage stakeholders to work towards a common goal of offering quality services to a more strategic goal of exceeding customer expectations. To do so, processes and procedures will need to be in place and service standards pre-determined and benchmarked.

The findings on the second key tension development of athletes' potential follow those on balancing outcomes with continual process indicators in the section above. They relate to the ability to satisfy key internal stakeholders (athletes and coaches) and the tensions involved. Athletes and coaches were most vocal about this issue in the context of discussing the criteria of effectiveness.

Firstly, the findings show athletes stressing both management (organisational structure) and programme/sport development (training, coaching, and technical) effectiveness, as being critical to maximise their potential. Tensions are felt most by athletes when they feel that their associations are less than professional; when they do not pay sufficient attention to training and development programmes; and when they do not identify and develop talent, coaching, and high performance athlete management. They wish for organisational and technical excellence to be in place before sports excellence, and stress professionalism in all areas of association management. 
Secondly, coaches wish for more realistic target setting by Singapore's social, cultural, and funding environment. Unrealistic targets have resulted in a high attrition rate of athletes. The findings stress the importance of athletes and coaches being recognised for continual performance improvements on the playing field.

The tensions expressed by both athletes and coaches put Singapore's goal to be among the top ten sporting nations in Asia by 2010 in jeopardy. The findings on the tensions above contribute to knowledge on criteria of effectiveness in association management. There appears to be stressors and barriers in existing sport administration and delivery structures that prevent open communication and dialogue. These result in athletes and coaches perceiving a lack of professionalism in the management, and insufficient consultation before decision making by the association and funding body.

This section presented the conclusions in regard to the second research question on criteria used by the different stakeholders to determine effectiveness of national sporting associations in Singapore. The following section will present conclusions to the third research question on how the determinants are affected by funding and whether the outcomes are commensurate with the funding received.

\subsubsection{Conclusions from the findings on funding, outcomes and effectiveness}

The findings on sports development, one of the two determinants of effectiveness affected by funding, reinforce the role of national sports associations which is to scout, develop and train talent. However, funding determines the breadth of sport initiation efforts (number of taster sessions in schools and outreach efforts), the level of sustainment (training allowances or salaries for athletes) and the right mix of competitive exposure, coaching and technical expertise, and planning efficiency. All the four constituent groups are unanimous about funding affecting the effectiveness of all the factors that relate to sports development, and ultimately the medals or results. 
In particular, the findings on funding, outcomes, and effectiveness show that many associations are in the stage of organisational development where government funding is still the main source of income. Associations and their stakeholders lay claim to being funded from the public purse despite board members acknowledging the need to find supplementary income sources. The heavy dependence on public funding for dayto-day operations and sport development show similarities to the 'rights and entitlements stage' that is characterised by government-funded programmes according to Rosenbaum's (1984:3-4) findings on non profit organisations in America.

This study shows that the respondents feel that outcomes achieved are greater than the funding that is received due to three factors. The first is that board members and secretariat staff raised funds from sponsorships and fundraising activities for sports development and event organisation. The second is that athletes achieved performance results that have exceeded funding expectations. The third is coaches have athletes that have performed well despite the constraints of funding.

Conversely, when constituent groups perceive that the outcomes are commensurate with funding, there are suggestions that athletes' achievements match the funding level; that coaches feel that they have done well despite budget cuts; and that secretariat staff have achieved the targets as planned and delivered the results with the funding given. Very few think that they could have done more with the funding.

It has been observed from the literature that non profit organisations that are heavily dependent on public funds take on a form of state orientation and lose some of their self-governance and independence from government (Anheier, Toepler and Sokolowski 1977; Kawashima 1998). Transposing the findings to this study, it can be hypothesised that associations will become more bureaucratic when they have to comply with the policies, accounting and reporting procedures stipulated by the SSC and the COG. This is evidenced, in part, from the amount of paperwork required by the funding body. Most secretariat staff feel that the mandatory administrative work is not commensurate with the funding requested or received. They are also of the opinion that the over 
emphasis on paperwork will take time and human resources away from sport development, a key mission of associations. For lean secretariats that do not have the manpower to do everything, complying with the administrative minutiae of the SSC and COG may induce a cycle of non-performance.

The findings on personnel management, the second determinant of effectiveness affected by funding, show how funding affects the human resource management of key personnel (coaches, technical personnel, professional administrative staff). The study shows that a better distribution of capital resources for developing human capital, and complementing sports science and management knowledge with passion and volunteerism across levels, can help associations reach their goals quicker.

To athletes, funding affects the recruitment of the right coaches and full-time professional secretariat staff who will be able to help them perform better on and off the field. Coaches perceive that with better funding, more can be done for coaching development across levels. Foreign coaches in particular, wish for more autonomy, trust, and empowerment to do the job they have been recruited to do rather than having too much interference. Secretariat staff feel that while the funding body expects the associations to facilitate and produce athletes that can compete at the highest levels, the resources provided by SSC are not commensurate with expectations, thus resulting in many associations not paying competitive salaries and facing high staff attrition rates.

Concomitantly, on issues of professional staff being employed by voluntary boards of associations, the study shows that, volunteer board members must recognise their roles, responsibilities, and expertise in recruiting and managing professional staff who may be better trained, educated, and have more current experience and/or new knowledge in sports management and sports science than themselves. It also shows that professional staff who are managing complex internal and external environments (because of multiple sports development and accountability objectives), must be given autonomy and trust in decision making but held responsible for them. Further, while funding is important and necessary, it is not the only thing that counts towards effectiveness. 
Many board members cite having the right people in the right roles as being more critical than funding alone. This is because professional personnel with experience and expertise will be able to put most things in place and fulfil multiple objectives quicker, including sourcing for funding.

This section has presented conclusions to the third research question on how the determinants are affected by funding and whether the outcomes are commensurate with the funding received. The next section will summarise contributions that the research has made.

\subsection{Conclusions about the research problem}

This qualitative study sets out to explore organisational effectiveness in Singapore national sports associations paying special attention to four constituent groups - board or executive committee members, secretariat staff, athletes, and coaches - to draw out their perceptions and determinants of effectiveness and the connection to outcomes desired of the associations. The constituent groups construct their perceptions of effectiveness differently leading to multi-dimensional interpretations of effectiveness depending very much on their roles and responsibilities.

Though the study is on non profit sporting organisations, some of the areas explored are no different from those that are apparent in other organisations. Perceptions of effectiveness stated as showing results, good financial management practices, organisational processes and procedures, are similar across profit and non profit organisations as already discussed. Criteria of effectiveness defined as participation and performance are examples of univariate measures that have been highlighted in previous sport studies literature.

However, the qualitative study is a departure from past research where quantitative methods are applied consistently. It is also set in the context of Singapore where there is sparse sports association management literature. This section provides a conclusion 
to the research effort with a summary of the key contributions to sport management knowledge derived from the perceptions of the four constituent groups.

The main contributions are:

1. The study confirms multi-dimensional perceptions of effectiveness and uncovers new themes not discussed in previous literature. The four constituent groups discuss multi-faceted perceptions of effectiveness by providing varying interpretations, meanings, inferences, and relational issues depending on the roles they hold.

a. Of the six themes of effectiveness, three - showing results, good financial management practices, and organisational processes and procedures - were covered in the literature review and are in line with the research done by Price (1968), Steers (1977), Kanter and Brinkerhoff (1981), and Frisby (1986).

b. In particular, three determinants of effectiveness were not cited directly as definitions of effectiveness in previous research - communication, athlete management, and commitment and organisation of the management committee.

i. Both communication and athlete management relate to the broader concept of the ability to manage athletes professionally, and refer to leadership from quality management committee members as the catalyst. Another related consilience is these two themes are cited predominantly by one constituent group athletes.

ii. However, all four constituent groups agree on the importance of commitment and organisation of the management committee and this relates to the broader concept of twinning technical knowledge and management experience with the right motivations to achieve goals faster. 
c. Several significant paradoxes surfaced when constituent groups discussed relational issues on funding along with their perceptions of effectiveness:

i. The paradox of funding emerged when the question of whether funding should be provided first for sport development and sports excellence rather than handing out financial rewards after the achievement of medals. The analogy was whether one provided fuel for the journey or after arrival at the destination. The findings on good financial management practices where coaches, secretariat staff, and board members state that the funding from SSC and supplementary self-generating income are pre-requisites for strategic planning, implementation of plans and achievement of goals, are also in agreement with Frisby's (1986) research that showed that one of the goal model indicators, the effectiveness ranking, was positively and significantly correlated with one of the system model indicators, the total operating budget. However, the SSC would prefer to have tangible signs of performance before releasing funds. This paradox of whether results should come before more substantial government funding, or funding for the achievement of results, is also significant in the findings on the theme of athlete management and the theme of performance (under the section on criteria to determine effectiveness).

ii. The paradox of efficiency surfaced when the question of whether associations should be concentrating the majority of their resources on improving their services to internal stakeholders (internal responsibility) or should they be directing their operations based on their accountability to the external funding body (external accountability). While a good balance is ideal, the reality is that governance compliance does take time and resources away from the associations' main objectives of 
developing the sport especially when associations operate with already lean secretariats and less than adequate technical and coaching personnel. The findings on organisational processes and procedures reveal effectiveness perceived in relation to organisational structure and processes and show convergence with the research by Steers (1977), Kanter and Brinkerhoff (1981), and Salamon (1994). Constituent groups view their associations as effective when there are efficient processes and standard operating procedures in place, with the right people in the right roles and clear job responsibilities. These are seen as antecedents to achieving goals and results within the associations (Steers 1977; Kanter and Brinkerhoff 1981). Coaches see organisational processes, procedures, and structure as effective when they allow them to do their job 'without encumbrances of any issue'. Board members concur with secretariat staff on 'minimum red tape' for effecting quicker decision making. Athletes prefer processes that are more dynamic to allow for 'adjustment of plans'. However, the findings show secretariat staff in particular discussing bureaucracy and time-consuming mandatory paper work required by the funding body as obstacles to effectiveness. Thus, like the research done by Salamon (1994: 118-121), the findings reveal proneness to bureaucracy especially when the major source of financial support is government funding. There are tensions between grassroots control and administrative accountability, especially when objectives in associations have to be prioritised towards securing government funding as key constituent groups think that the limited human resources should be channelled towards the association's sport development and sports excellence objectives rather than priority put on submission of paper work to the funding body. 
d. Communication is the first theme not cited in previous literature as a determinant of effectiveness, and is a major theme for athletes who are emphasising the human component of managing for effectiveness. In non profit sports associations, athletes who are in pursuit of sports excellence do so knowing the inadequate financial support. As such, they do expect to have a voice, and that their opinions on their sports career and welfare are considered more seriously by firstly, their management committee, and secondly, the SSC. Without an improvement in two-way, formal, and timely communication, athleteboard/association conflict is inevitable, impacting association and athlete management effectiveness.

i. A relational issue of professionalism versus voluntarism was raised by secretariat staff in particular, when discussing communication. The findings on this are in line with previous work done on the relationship between professionals and volunteer boards (Auld 1994; Auld and Godbey 1998; Watt 2003). Secretariat staff prefer volunteer boards to be quicker in their decision making and to respect their professional expertise and experience by being more conscious of time and human resources. On the other hand, board members are trying to balance empowerment and expectations of being kept informed of the important day-to-day operational decisions made by the secretariat. These findings on decision making being a source of conflict between volunteers and paid employees call for mutual recognition of both parties' needs and a climate of cooperation and reciprocity for organisations to succeed in serving sport (Auld and Godbey 1998:20; Watt 2003:47, 48). In addition, there is some evidence presented in Auld and Godbey's quantitative research (1998:20) that showed paid professional staff wishing for a more equal relationship in policy development and 
implementation for improved organisational decision making and effectiveness.

e. The second theme not cited as a definition of effectiveness previously is athlete management and is again discussed predominantly by athletes. They are consistent in viewing effective sports associations as facilitating sports excellence objectives with high performance athlete management being the desired outcome (not necessarily medals).

i. The study shows that there is a difference in perceptions of effectiveness between mature athletes and school-going or nonworking athletes. Mature athletes who generally think their associations are ineffective, are particularly concerned about athlete management that looks into other areas of their lives holistically such as personal welfare and employment aside from training. The metaphor of 'a barren fruit tree being axed' is used by an athlete to signify the perceived low importance given to personal well-being and welfare of the athletes during and after their sports careers. Mature athletes feel they are being seen and judged by their associations as instruments for short-term gains.

ii. For the athletes who are still in school or not working, the disbursement of grants, training and competition management, and having the right facilities and coaches for training, are the basic issues that shape their perceptions of effectiveness. Most say they do expect these basic needs to be met but it is not always the case.

iii. Athletes believe that the solution to managing them professionally and effectively stems from quality management committee leadership that starts with the understanding that associations, the board and the various sub-committees exist because of the athletes, and not the other way around.

f. Commitment and organisation of the management committee is the third theme not cited in previous literature as a definition of effectiveness and 
it is a major theme for all four constituent groups. However, only board members perceive their own cohesiveness and effectiveness in a positive light when telling about getting things done and they refer to their roles in policy making, organisational structure, and fund raising. Other constituent groups point out that the conflict of voluntarism versus paid work among board members inevitably interfered with their commitment, a fact some board members agreed with but provided no solutions to. All constituent groups perceive a diverse (with technical and management knowledge) and committed board as an antecedent to effectiveness and results - 'a core of very dedicated volunteers, who can work, read from the same page'. In particular, athletes stress the importance of the boards' motivations for serving as they see a relation between the ideology of the board, and their own performances and careers. Coaches and board members strongly emphasise the importance of the President in keeping associations in the black and achieving the targets set.

g. Finally, the SSC had hoped to professionalise the national sports associations and increase their effectiveness by advocating compliance to the Code of Governance and tying funding to it. However, it is unclear from the study if the constituent groups perceive compliance to the COG as contributing to greater association effectiveness. While governance was referred to most by board members among the constituent groups, Steane (2001:15) found divergent practices, rather than convergent expectations, manifesting in non profit governance in non profit boards for two reasons: the diversity of the board that allows skills to be tapped for funding, lobbying and management; and an ideological foundation where commitment underlies strategic decision making at board and senior management levels.

2. The study shows criteria of effectiveness discussed in terms of two quantitative and univariate indicators - participation, and performance - but two key 
tensions surfaced during the discussions - balancing outcomes with continual process indicators, and development of athletes' potential.

a. The findings on participation, the first quantitative criterion of effectiveness, was mentioned most by secretariat staff, followed by board members and coaches, establish that increasing the participation base is considered as leading to effectiveness. The findings reinforce the goal attainment approach (Price 1968) that numbers are easy to measure and can be used as yardsticks to warrant SSC funding and sponsorship monies. Thus, associations see a need for funding to grow the sport and for extensive outreach efforts. However, beyond sport initiation, associations want to reach out to individuals and organizations that will also support them not only in terms of funding for sport development but also by long term voluntary involvement. But these individuals and organisations would like to see associations with strategic and governance frameworks in place first. Thus, associations will have to professionalise quickly to respond to the tougher challenges and new demands in the current voluntary giving landscape. In addition, associations are also competing with other sports associations (and even other forms of entertainment, arts, or lifestyle interests) for the same pool of people and resources.

b. The findings on performance, the second quantitative criterion of effectiveness, concur with previous research where achieving outcome goals such as competitive results and performance targets are seen as organisational effectiveness. This is covered in the research by Price (1968), Steers (1977), and Kanter and Brinkerhoff (1981). However, the findings show a paradox.

i. The Paradox of influence - The athletes who are most directly responsible for producing the results and getting the medals, have the weakest influence on policy or decision making among the four constituent groups. This is despite funding being a priority in associations, and athletes directly or indirectly 
determining the level of funding through their performances. The evidence is also drawn from the study's findings on the themes of communication and athlete management.

c. The findings on the first key tension balancing outcomes with continual process indicators show that associations would like to be allowed to use continual operating or process objectives with varying emphasis, as indicators of effectiveness, aside from medals or outcome goal indicators. While these findings are a contribution to knowledge as this concept of defining criteria of effectiveness is not found in previous literature, they can relate in part to Herman and Renz's (1999) concept of responsiveness in non profit organisational effectiveness where measuring responsiveness may offer a solution to the problem of differing judgments of effectiveness by different stakeholder groups.

d. The findings on the second key tension development of athletes' potential relate to the ability to satisfy two key internal stakeholders, athletes and coaches, and the issues involved. It follows that athletes and coaches are most vocal about this issue.

i. Athletes stress both management (organisational structure) and programme/sport development (training, coaching, and technical) effectiveness, both of which are critical to maximise their potential, but are lacking in the associations. They see the need for organisational and technical excellence to be in place first before sports excellence. Stressing professionalism, 'doing things in a business-like manner', in all areas of association management, they place special emphasis on formal communication on selection guidelines and criteria to prevent tripartite conflict among athletes, coaches, and associations.

ii. Coaches wish for more realistic target setting amidst Singapore's social, cultural, and funding environment which has a rather high attrition rate of athletes. The findings stress the importance of being recognised for continual performance improvement 
indicators on the field in spite of the challenges in Singapore's social and cultural landscape, which range from an emphasis on winning to educational and national service priorities that limit the pursuit of sports excellence.

iii. The two aforementioned tensions, expressed during discussions on criteria of effectiveness by both athletes and coaches, throw scepticism on Singapore's goal to be among the top ten sporting nations in Asia by 2010. As athletes focus on the management and programme/sport development factors that are internal to the association, and coaches refer to perceptions and assumptions of the external funding body, and the less than conducive macro environment to nurture athletes, both stress a need for continual and periodic assessments of effectiveness for equity.

3. The study unveils programme and management determinants of effectiveness that are most affected by funding - sports development, and personnel management.

a. All the four constituent groups are unanimous about how funding affects all elements that relate to sports development, and ultimately effectiveness and medals or results. The elements are initiation sessions for the introduction of the sport in schools, training allowances/salaries for athletes, competitive exposure, and coaching/technical/planning expertise.

b. Funding affects the effectiveness of human resource management of key personnel - coaches, technical personnel, professional administrative staff.

i. Athletes, in particular, perceive a better distribution of capital resources for building capabilities and human capital, and complementing passion and volunteerism with sports science and sports management knowledge across levels, can help 
associations reach their goals quicker and them to perform better on and off the field.

ii. Coaches perceive that with funding, more can be done for coaching development across levels to raise coaching effectiveness. A relational issue uncovered that affects the effectiveness of foreign coaches in particular is autonomy versus interference. Foreign coaches are open in their wish for more autonomy, trust, and empowerment to do the job they have been recruited to do and prefer minimum interference from the board on selection and technical matters.

iii. Secretariat staff feel that while the funding body expects the associations to facilitate and produce athletes that can compete at the highest levels, the resources (funding, facilities, and administrative support) provided by SSC hardly commensurate. This results in many associations not paying competitive salaries and having to face high attrition leading to ineffectiveness. The lack of manpower and 'coping with what the association can afford' result in the sub-optimal functioning of the organisation.

iv. In addition, the issues related to professional staff being employed by voluntary boards give rise to two key points necessary for a healthy co-existence. One, board members must recognise professional staff for their sports management and sports science knowledge and expertise. Two, professional staff who manage complex internal and external environments due to multiple sports development and accountability objectives, must be given autonomy and trust in decision making but held responsible for them.

v. While funding is important and necessary, one of the most significant findings among board members is that many consider having the right people in the right roles as being more critical than funding - 'People before funding - to put things in place'. 
This is because professional personnel with their experience and expertise will be able to put most things in place and fulfil multiple objectives quicker, including sourcing for funding.

c. When the perception of outcomes achieved is more than the funding received, it is due to one, board members and secretariat staff having raised funds from sponsorships and fundraising activities for sports development and event organisation; two, athletes having achieved performance results that have exceeded funding expectations; and three, coaches having athletes that have performed well despite the constraints of funding.

d. Conversely, when constituent groups perceive that the outcomes commensurate with funding, it is due to: (i) athletes' achievements matching the funding level, (ii) coaches reflecting that they have done well despite budget cuts; and (iii), secretariat staff having achieved the targets as planned and delivered the results with the funding given. Very few think that they could have done more with the funding.

e. The Paradox of efficiency also surfaces here as it has been shown that non profit organisations that are heavily dependent on public funds would take on a form of state orientation and lose some of their selfgovernance and independence from government (Anheier, Toepler and Sokolowski 1977; Kawashima 1998). It can be hypothesised that associations will become more bureaucratic when they have to comply with public sector policies, accounting and reporting procedures as stipulated by SSC and the COG.

The above section has presented a conclusion to the research questions and findings developed during the research, including insights not found in the literature review.

\subsection{Implications for theory}

This section examines the implications of this study for the wider body of sport management knowledge. By investigating the perceptions of four key internal 
constituent groups in Singapore national sports associations, this exploratory study provides an understanding of the construct of effectiveness from their views and how they perceive effectiveness as a function of the roles they hold. The examination of the four groups of internal stakeholders is a strength of the study for a number of reasons.

Firstly, external stakeholders do not have close working relationships with the associations and will not be able to provide value-added data and contribute materially (the reason why episodic volunteers were removed after the pilot testing in the initial stage of the study). Secondly, most associations serve their own members in sports administration and development. Thirdly, athletes, as an internal stakeholder group, are both members and customers of the association and thus a good reference point for both perceptions of effectiveness and assessment of programme effectiveness, an important outcome of associations. Fourthly, coaches and secretariat staff are professional paid staff who are in good positions to provide prima facie evidence of the effectiveness of organisational processes, association management, and board decision making. Lastly, while board members are not remunerated for their services and do not add to manpower costs, they do influence the income expenditure statement of associations by their decisions on most aspects of association management.

The study is perceptual and does not have objective measures of effectiveness. The aims are to view perceptions and criteria of effectiveness from the perspectives of the four internal constituent groups. Thus, the study distinguishes between viewing the stakeholders' perceptions of effectiveness and the actual assessment of effectiveness on association management, programming and operations.

The findings of quality versus quantitative determinants of effectiveness (from the first research question on perceptions of effectiveness), efficiency versus effectiveness measures (from the second research question on criteria used to determine effectiveness) and stakeholder versus SSC accountability (from the final research question on funding impact on effectiveness and outcomes), are important because they show how the constituent groups construct their perceptions of effectiveness and who 
they think they are accountable to. They question whether associations should be accountable to the SSC, the funding body alone or to the greater public who provides the funds.

While non profit sports associations and business organisations may be different legal entities driven by distinct causes and motives for their existence, both face internal organisational and external macro environmental factors that challenge their management of operations and stakeholders. Early research by Warriner and Prather (1965:148) on the four types of voluntary associations (performance, sociable, symbolic or ideological, and productive) had shown that voluntary associations and formal organisations were related to each other in terms of the expression of interests and rewards, and theories of human organisation.

The Singapore national sports associations fare badly in terms of effectiveness from the perceptions of athletes, the stakeholders who are most important in getting the results for further funding, as well as from professional staff. As Papadimitriou (1998: 169180) states: 'Just understanding that sending a team out for a competition is not sending staff out on a conference.' Despite the $\mathbf{S} \$ 1$ million incentive for athletes who win an Olympic gold medal, and the Code of Governance for associations, conflict between athletes and their associations are rife. The $\mathbf{S} \$ 1$ million incentive for athletes is a reminder of the 'Paradox of funding - fuel for the journey or after arrival at destination?' outlined earlier. In addition, the Code of Governance, with the intention to professionalise associations, may just be compliance jargon if the contracts of professional staff are short-term and their salaries uncompetitive.

Effectiveness is context-specific and relates to both macro and micro environment issues. The Singapore government in the best of sports excellence interests has put in the money. However, not all the money has gone into the national sports associations. A large part of the money has gone into the building and the operations of the Singapore Sports School. Even where money does go to select associations, not all have the basic facilities to optimise the use of those funds. More can be done in the areas of 
athlete management, communication, cutting down red tape, and simplifying processes. Having to incur expenses, and then having to claim and justify for those expenses, takes up much time and resources especially when excessive submission of paperwork is required. So, despite the government pumping in a total of S\$800 million over time to realise a sporting nation blueprint, the increase in funding may not have improved or changed the sport delivery system.

\subsection{Implications for policy and sports management practice}

This section covers practical implications for stakeholders, sports administrators, and policy makers. It begins with implications for the four constituent groups followed by implications for the SSC.

\subsubsection{Implications for constituent groups}

The study has shown that members of constituent groups across associations have a host of perceptions on effectiveness and its criteria ranging from univariate measures (medals, participation, processes to name a few) to multiple or continual measures. It can be inferred from the study that effectiveness, depending on the role/s of the person, can be perceived rather differently. Also there is a general consensus that there can be more engagement with the funding body on how an association can be evaluated on effectiveness besides a one size that fits all model. Internal to the association, as expressed strongly in this study, communication with the stakeholders is very important for the board and management to understand athletes, coaches and secretariat and viceversa. This will help to inform, engage, and lead to a better understanding of effectiveness and how stakeholders' criteria of effectiveness may be change over time.

Athletes definitely see a direct impact of the board on their roles and performances. They are able to state concretely how the board's knowledge, expertise and values impacts decision-making and how the board can improve on their own effectiveness and the association's. The athletes-board relationship is of significance as athletes tend to rate their associations as ineffective while board members may think that they themselves and their associations are generally effective. 
Should there be conflict between athletes and boards, the conflict stems from an overarching issue of what athletes consider is professionalism (despite board members being volunteers), and issues concerning open communication, objective leadership and better distribution of funds. They hope to experience less influence from personal agendas and undue interference in technical decision-making, but seek more high performance athlete management expertise, organisational excellence, and long-term planning.

Some athletes do not think that their NSA is effective in any significant way and would like to change almost everything in it from youth development to coaching, welfare, and leadership. They indicate that Singapore NSAs are not organised as systematically or professionally as other non profit sports organisations in other Asia/Australasian countries. This is due to poor management, weak administration, and public funding dependency.

Board members engage primarily with three groups of stakeholders. The two internal constituent groups most engaged are other board members and secretariat staff. The third is the external funding body, SSC. Athletes are hardly referred to their responses. In this respect, the study shows the dichotomy between athletes and board, a matter elaborated on under the theme of communication. Board members cite formal communication channels such as meetings, emails, reporting, and documentation, as evidence of effectiveness, and do not see that there are communication gaps in their associations. This is contrary to the athletes who view communication as a major theme and the lack of it a bane preventing effectiveness. Thus, to be effective, board members may need to engage with athletes at the grass roots.

While coaches are concerned with efficiency indicators such as output and utilisation of resources, they discuss tensions such as balancing outcomes with continual indicators development of athletes' potential stemming from macro environmental issues. From the perspective of job satisfaction, the study finds a clear difference between the views 
of the foreign and local coaches. For foreign coaches, empowerment and trust from the board or management committee is important to enable them to do their jobs. The foreign coaches are particularly aggrieved by the mistrust and lack of empowerment, particularly when they feel that they have already taken a step back in their careers by coaching in Singapore.

On the other hand, local coaches are more concerned with organisation processes and financial management, though they do agree with the foreign coaches that limited interference from the board on selection and technical matters is preferred and more effective in the long run. Thus, both groups of coaches think that effectiveness can be greatly enhanced by an internal environment of trust and empowerment balanced by objectivism, and an external environment of realism balanced by recognition for continual progress.

Secretariat staff find that they have to balance fulfilling objectives in both the internal and external environments leading to sufficing or coping mechanisms which may not be effective nor beneficial for sports development in the long run. Handling sports excellence objectives and mass participation goals can be quite different and when there is pressure to secure a higher level of funding through results, short term gains can be at the expense of development plans. They see a need for formal means of evaluating effectiveness beyond quantitative measures and a better understanding of their roles and responsibilities.

\subsubsection{Implications for the SSC}

While the SSC's funding and KPIs have a tremendous impact on athletes, athletes do not appear to have a direct relationship or access to the funding body. What the SSC's role means to athletes, aside from funding, seems nebulous. Thus athletes offer no clear solution on how associations ought to be managing the SSC, the most important agency in the external macro environment. The athletes-SSC relationship appears more distant than the athletes-board relationship. While some athletes are grateful for the medical 
support provided by the SSC, they think gaps in funding levels and disbursement efficiency need attention.

At the macro environmental level, coaches hope to see effectiveness from a change in how the funding body evaluates them and views success. Developing athletes is a long process comprising multiple factors working together at the individual and organisational levels. However, when the funding body looks only at medals and not continual improvement indicators, coaches are discouraged. The SSC gives the impression that they are impervious and insensitive to the fact that there can be substantial improvement without results defined by medals. Coaches also complain that administrators in the SSC do not have adequate knowledge of the sport to make good decisions, and flex power by the use of funding. They would like to see more access to opportunities to do the sport recreationally at all levels with less emphasis on winning. It follows that coaching at the grassroots level will need to change, as currently earning a living takes precedence over the ability to impart skills and transfer knowledge in the sport.

On the board-SSC relationship, the study shows board members speak of the SSC with reverence and deference. They take care to state that they are grateful for the financial support even though the funding may not always be adequate. The inference is that board members know that their associations have to comply with the requirements set by the SSC if they want the funding, and in this respect, the funding body does influence and shape the behaviour of national sports associations affecting effectiveness at all levels (though the nature and extent is not within the scope of this study).

Secretariat staff want a clearer definition of the SSC's role. They are confused if the SSC were to 'support or control' them and are certain that the SSC cannot be doing both. While they understand that quantitative targets set to meet objectives are necessary in any organisational environment, they also see the need for more room for qualitative measures of effectiveness to be taken into account. 


\subsection{Limitations}

The first limitation is generalisability. It will be difficult to infer the findings in this study to another country with a different socio-economic background. The context of the study is the non profit sports sector in Singapore, a city state of above 4 million people. The country has a small population of 59 national sports associations, of which the better managed receive the most funding from the government. These associations number not more than thirty, and are staffed by larger secretariats with professional staff as compared to the others, some of which are only staffed by volunteers.

The second limitation is purposive sampling. The population from the non profit sports sector is small to start with, and the informants are further segmented into the four constituent groups for their multiple perspectives. Purposive sampling becomes even more challenging when data collection is spread over three distinct research stages. In ascending order, the population of national coaches is the smallest number, followed by secretariat staff, board members and athletes. The researcher had foreseen problems with getting the required number of informants from the four constituent groups for data saturation, especially board members and coaches. A contingency plan to consider potential informants who had held the positions previously was conceived but fortunately there was no need to execute the plan.

The third limitation is access to other data besides the primary data collected in the study. While the research uncovered perceptions of the strong relation between medals and funding, there was little secondary research on this in the context of Singapore. In addition, the researcher is well aware that discussing organisational effectiveness can be particularly sensitive, especially when informants may be speaking of their paymasters, either the associations themselves or the Singapore Sports Council. Anticipating this, the qualitative research methodology of utilising personal interviewing was proposed to build trust in the researcher-informant relationship before going on to solicit the views of the informants for rich and dense data. 
The fourth limitation is the operationalisation of the effectiveness-funding relationship. While respondents provided personal comments on how effectiveness is affected by funding and justified whether the outcomes commensurate with the funding received, there was no specificity on the measures to be used to operationalise the relationship. There are also few literature references concerning the efficiency and effectiveness of (elite) sports policies and investments ... in part due to the difficulty of measuring these effects objectively (De Bosscher et al. 2006:186), adding to the difficulty in even speculating on its operationalisation.

One variable the the researcher could not quite control was time. Some interviews took about 40 minutes while others went on for an hour and a half. The longer interviews were not an issue but the shorter interviews were the result of time pressure from the respondents who had to go back to work, training, or class. Needless to say, as probing had to be highly selective in such circumstances, the data for the shorter interviews was not as in-depth as the longer interviews.

\subsection{Implications for further research}

Firstly, since this is the first exploratory research done on national sports associations in Singapore, it paves the way for future quantitative studies with larger sample sizes and across more constituent groups. As the qualitative study has confirmed the multiconstituent and multi-dimensional nature of the construct effectiveness, additional potential respondents can come from public bodies such as the Singapore Sports Council and Ministry of Community Development Youth and Sports. These funding agencies are the most important in the external institutional environment and have a tremendous influence on the behaviour of associations and their stakeholders. Assuming there is access to these groups of respondents, there can be more light shed on the external institutional environment of associations that may offer either more confluence or incongruence in the perceptions and criteria of effectiveness. 
Secondly, the study assumes that sports excellence is of utmost priority for associations and thus the sample comprised national athletes and national coaches as respondents. If mass participation was more important to associations than sports excellence, then the selection of the research participants would be targeted to that end and may change the perceptions and criteria of effectiveness.

Thirdly, following from the second point above, the study covered 25 associations with the majority from the previously classified 'core' and 'merit' categories. Fifteen associations were from the 'core' and 'merit' categories (out of a total of 16 for the two categories) while 10 were classified under 'other' associations (out of a total of 42). In the past, when the national sports associations were categorised as 'Core', 'Merit' and 'Other', the Core sports could receive up to $\mathrm{S} \$ 3$ million each while Merit sports could receive up to $S \$ 2$ million each and Other sports up to $S \$ 500,000$. For more views or different interpretations on perceptions and criteria of effectiveness, perhaps the sample for future studies could include more respondents from 'other' sports that tend to be smaller associations staffed by few paid staff or some none at all.

Fourthly, if a mixed or multi methodological approach was going to be used in future research, the sample size for each constituent group and/or sport/association should be increased so that there can be triangulation and reduction of subjectivity. This is particularly important if inferences are going to be made from the individual level to the organisational level.

\subsection{Conclusion}

The study sets out to explore perceptions of effectiveness in Singapore national sports associations. The four constituent groups from 25 associations - athletes, board or executive committee members, coaches, and secretariat staff - were sampled through a focus group and semi-structured interviews to draw out their perceptions and determinants of effectiveness, and the relation to outcomes desired of the associations. The qualitative data was analysed using NVivo software to organise the data into general themes and sub-themes. 
The researcher has made a contribution to knowledge by:

a) using qualitative methodology in the field of effectiveness in non profit organisations where previously quantitatively methods were used rather consistently;

b) using the qualitative methodology in Singapore where it does not appear to have been used before in relation to sports association management; and

c) adding to the sparse sports association management research and literature in Singapore by making a synthesis that has not been done before through the adaptation of Papadimitriou's (1994) semi-structured questionnaire.

The four constituent groups discuss multi-faceted perceptions of effectiveness by providing varying interpretations, meanings, inferences, and relational issues depending on the roles they hold. While confirming multi-dimensional perceptions of effectiveness, the study uncovered three determinants of effectiveness that were not cited directly as definitions of effectiveness in previous research and they are communication, athlete management, and commitment and organisation of the management committee.

The results from the study also show criteria of effectiveness discussed in terms of quantitative and univariate indicators and further delivers two key tensions, that of balancing outcomes with continual process indicators, and development of athletes' potential. In addition, the study unveils sports development, and personnel management as programme and management determinants of effectiveness that are most affected by funding..

On the external environment, the findings reveal that, in particular, the constituent groups' perceptions of the Singapore Sports Council influence their perceptions of effectiveness within their associations. In turn, the SSC's policy making and organisational behaviour are perceived to affect how the constituent groups are being 
evaluated, how they perform, and what they can reasonably do within their associations.

The implications for sports administrators and policy makers are calls for transactional communication, quality leadership (with decisions based on sports management and sports science knowledge), a more equitable distribution of funds, an internal environment of trust and empowerment balanced by objectivism, and finally, an external environment of realism balanced by recognition for continual progress, to enhance association effectiveness.

\section{END OF CHAPTER FIVE DISCUSSION AND CONCLUSION.}




\section{Bibliography}

Anheier, H., K., S. Toepler, et al. 1997, 'The implications of government funding for non profit organizations: three propositions', International Journal of Public Sector Management, 103:190-213.

Auld, C. 1994, 'Changes in professional and volunteer administrator relationships: Implications for managers in the leisure industry', Australian Journal of Leisure and Recreation, 42:14-22.

Auld, C., J. and G. Godbey 1998, 'Influence in Canadian National Sport Organizations: Perceptions of Professionals and Volunteers', Journal of Sport Management, 12: $20-38$.

Baruch, Y. and N. Ramalho 2006, 'Communalities and distinctionsin the measurement of organizational performance and effectiveness across for-profit and nonprofit sectors', Nonprofit and Voluntary Sector Quarterly, 351:39-65.

Bazeley, P. 2007, 'Analysing qualitative data: more than identifying themes', Qualitative Research Convention 2007, Selangor, Malaysia, Qualitative Research Association of Malaysia.

Bazeley, P. and Richards, L. 2005, The NVivo Qualitative Project Book, London, Sage Publications Ltd.

Beamish, R. 1985, 'Sport executives and voluntary associations: A review of literature and introduction to some theoretical issues', Sociology of Sport Journal, 2:218232.

Bird, F. 2001, 'Good governance: A philosophical discussion of the responsibilities and practices of organizational governors', Canadian Journal of Administrative Sciences, 184: 298 - 312.

Booth, A., N. Babchuk, et al. 1968, 'Social stratification and membership in instrumental-expressive voluntary associations', Sociological Quarterly, 9:427439.

De Bosscher, Verle et. al. 2006, 'A conceptual framework for analyzing sports policy factors leading to international sporting success', European Sport Management Quarterly, $6(2): 185-215$. 
Bradish, C., L. 2003, An examination of the relationship between regional sport commissions and organizational structure, $\mathrm{PhD}$ thesis, Department of Sport Management, Recreation Management and Physical Education, Florida State University, College of Education:180.

Bratton, R. 1971, 'Demographic characteristics of executive members of two Canadian sports associations', CAHPER Journal, 37:26-28, 45.

Brower, R., S., M. Abolafia, Y., et al. 2000, 'On improving qualitative methods in public administration research', Administration and Society, 32(4):363-397.

Cameron, K. 1978, 'Measuring effectiveness in institutions of higher education', Administrative Science Quarterly, 23.

Cameron, K., S. 1986, 'Effectiveness as a paradox: consensus and conflict in conceptions of organizational effectiveness', Management Science, 32:539-553.

Cameron, Kim, S. and Whetten, David, A. (ed) 1983, Organizational effectiveness: a comparison of multiple models, New York, New York: Academic Press.

CCH Asia Ltd. 2005, Singapore Master Tax Guide $-22^{\text {nd }}$ Edition, Singapore.

Chapin, F. S. and J. Tsouderos, E. 1955, 'Formalization observed in ten voluntary associations: concepts, morphology, process', Social Forces, 33(4):306-309.

Chelladurai, P. 1985, Sport Management - Macro Perspectives, England, Sports Dynamics.

Chelladurai, P. 1987, 'Multidimensionality and multiple perspectives of organizational effectiveness', Journal of Sport Management, 1:37-47.

Chelladurai, P. 1999, Human Resource Management in Sport and Recreation, USA, Human Kinetics.

Chelladurai, P. and T. R. Haggerty 1991, 'Measures of organizational effectiveness in Canadian national sport organizations', Canadian Journal of Sport Science, 16:126-133.

Chelladurai, P., M. Szyszlo, et al. 1987, 'Systems-based dimensions of effectiveness: the case of national sport organizations', Canadian Journal of Sport Science, 12:111-119.

Chia, V. 2008 'Third-time lucky Remy bags his first European title', The Straits Times, 23 July 2008. 
Ch'ng, Alan and Koh-Tan, Angela 2006, Managing Sport: Concepts and Issues of Non profit Organisations, Pearson Prentice Hall, Singapore.

Chow, P. N. 2008, 'Social entrepreneurs leading new wave of philanthropy', Business Times, 28 July 2008.

Connelly, M., D. 2004, 'The sea change in nonprofit governance: a new universe of opportunities and responsibilities', Inquiry - Excellus Health Plan, 41(1):6-20.

Connolly, T., Conlon, E. M., and Deutsch, S. J. 1980, 'Organizational effectiveness: a multiple constituency approach', Academy of Management Review, 5(2):211217.

Cote, Jean and Sedgwick, Whitney, A. 2003, 'Effective behaviours of expert rowing coaches; a qualitative investigation of Canadian athletes and coaches', International Sports Journal 7(1):62-78.

Covell, D., Walker, s., Siciliano, J. and Hess, P. W. 2003, Managing sports organizations: responsibility for performance, Thomson South Western, Canada.

Curtis, James. 1971. 'Voluntary association joining: a cross-national note', American Sociological Review, 36(5):872-880.

Cuskelly, Graham. 1995, 'Organizational commitment: The retention of volunteers in sport', in The Second Conference of the Australian and New Zealand Association for Leisure Studies, Lincoln University, New Zealand, pp.361-366.

Dauriac, Chantal, Malenfant 1980, 'Sport and the voluntary nonprofit sector of the economy: a Franco-American comparison', in The Second International Seminar on Comparative Physical Education and Sport, Halifax, ed. Pooley, J and Pooley, C., Dalhousie Printing Centre, pp.57-58.

Davis, J. (n.d.), Organizational Effectiveness Literature Review, [Online], Available from:

http://64.233.179.104/search?q=cache:RRHZUQqiHKQJ:www.packard.org/pdf loe_lit_review.pdf $+\% 22 \mathrm{Herman} \% 22+\% 22$ Nonprofit+Organizational+Effective ness $\% 22 \& \mathrm{hl}=\mathrm{en} \& \mathrm{ct}=\mathrm{clnk} \& \mathrm{~cd}=6$ [4 February 2006].

De Vaus, D. A. 1995, Surveys in Social Research, Allen and Unwin, Australia. 
Denzin, N. K. and Lincoln Y. S., (eds) 1994, Handbook of qualitative research, Sage Publications, London.

Directory of non profit organisations NPOs, (13 August 2006), [Online], Available from: http://www.nvpc.org.sg/npo/ [13 August 2006].

Donalek, Julie, G. and Soldwisch, Sandie 2004, 'An introduction to qualitative research methods', Urologic Nursing, 24(4).

Dotson, Floyd 1953, 'A note on participation in voluntary associations in a Mexican City', American Sociological Review, 18(4):380-386.

Drucker, Peter 1973, 'Managing the public service institution', The Public Interest, 33(Fall): 43-60.

Edwards, A., Elwyn, G. et al. 2001, 'Consumers' views of quality in the consultation and their relevance to 'shared decision-making' approaches', Health Expectations, 4:151-161.

Fang, Nicholas 2005, 'NSAs' cash to depend on homework', The Straits Times.

Fang, Nicholas and Wang, Jeanette 2006, 'More money when we deliver, please: SBF', The Straits Times.

Frisby, W. 1986, 'Measuring the organizational effectiveness of national sport governing bodies', Journal of Applied Sport Science, 11:94-99.

Gallagher, Orvoell, R. 1957, 'Voluntary Associations in France', Social Forces, 36(2): 153-160.

Gibbs, Graham, R. 2002, 'Qualitative data analysis: explorations with NVivo', in Understanding Social Research ed. Bryman, Alan, Open University Press, Buckingham and Philadelphia.

Given, Lisa, M. 2004, 'Mini-disc recorders: A new approach for qualitative interviewing', International Journal of Qualitative Methods, 3(2).

Gordon, C. Wayne and Babchuck, Nicholas 1959, 'A typology of voluntary associations.' American Sociological Review, 24(1):22-29.

Gratton, Chris and Jones, Ian. 2004, Research methods for sport studies, Routledge, London and New York.

Green, Christine and Chalip, Laurence 1998, 'Sport volunteers: research agenda and application', Sport Marketing Quarterly, 7(2):14-23. 
Hall, P. D. 1998, 'Philanthropy, public welfare, and the politics of knowledge: acquiring knowledge by taking risks', in Vision and values: rethinking the nonprofit sector in America, ed. Deborah S. Gardner, New York: The Nathan Cummings Foundation, 1998, 11-27.

Hannabuss, S. 1996,'Research interviews', New Library World, 97(1129):22-31. Haywood, L., Kew, F. et al. 1995, Understanding leisure - Second Edition, Stanley Thornes (Publishers) Ltd, Cheltenham.

Heath, Helen and Cowley, Sarah 2004, 'Developing a grounded theory approach: a comparison of Glaser and Strauss', International Journal of Nursing Studies, 41: 141-150.

Henderson, K. 1984, 'Volunteerism as leisure', Journal of Voluntary Action Research, 13: 55-63.

Herman, R. D. and Renz, D. O. 1999, 'Theses on non profit organizational effectiveness', Nonprofit and Voluntary Sector Quarterly, 28(2):107-126.

Herman, R. D. and Renz, D. O. 2004, 'Doing things right: effectiveness in local nonprofit organizations, a panel study', Public Administration Review, 64(6):694-704.

Hernández, R. A. 2002, Managing Sport Organisations, Human Kinetics, Champaign. Hoye, Russell 2004, 'Leader-member exchanges and board performance of voluntary sports organisations', Nonprofit Management and Leadership, 15(1):55-70.

Hoye, Russell 2006, 'Leadership within Australian voluntary sport organisation boards', Nonprofit Management and Leadership, 16(3):297-313.

Jeavons, Thomas, H. 1992, 'When the management is the message: relating values to management practice in nonprofit organisations', Nonprofit Management and Leadership, 2(4).

Kanter, R. M. and Brinkerhoff, D. 1981, 'Organizational performance: recent developments in measurement', Annual Review of Sociology, 7:321-349.

Kawashima, Nobuko 1998, 'The emerging voluntary sector in Japan: issues and prospects', International working paper, 7:1-48. 
Kearns, Kevin, P. 1994, 'The strategic management of accountability in nonprofit organizations: an analytical framework', Public Administration Review, 54(2): 185-192.

Komarovsky, Mirra 1946, 'The voluntary associations of urban dwellers', American Sociological Review, 11:686-698.

Langford, Joe and McDonagh, Deana 2003, Focus groups - supporting effective product development, Taylor Francis, London and New York.

Lau, Teng Chuan 1978, 'Origin and Development of Sports For All in Singapore', in The International Conference on the History of Sport and Physical Education in the Pacific Region 20-24 November 1978, University of Otago, Dunedin, New Zealand.

Leong, Cubby 2006, 'Cuesports president on the rack; Thursday meeting could see fireworks as NSA struggles with huge debts', Today, 6 March 2006, Singapore.

Leung, Wai Leng 2006, 'Cybergaming gets official nod of approval as a national sport', The Straits Times, 24 April 2006, Singapore.

Lewis, D. S., French, E. et. al. 1997, 'A culture of conflict', Leadership and Organization Development Journal, 18(6):275.

Lim, L. 2007, 'They took the money and ran', The Straits Times, 15 April 2007, Singapore.

Lim, M. 2006a, 'Panel to put Singapore sports on world map', The Straits Times, 29 September 2006, H24, Singapore.

Lim, M. 2006b, ‘\$7m kitty to develop Olympic champions', The Straits Times, 15 November 2006, Singapore.

Lin, Xinyi 2006, 'Subhas to clean up Cuesports', The Straits Times, 30 July 2006, Singapore.

Litosseliti, Lisa 2003, Using focus groups in research, Continuum, London.

Lius, Ernest 2006, 'The Sports Wall', The New Paper, 9 October 2006, Singapore. Low, Jeffrey 2003a, 'Sports 'bible'? An Everest still lies ahead', The Straits Times, 15 February 2003, Singapore.

Low, Jeffrey 2003b, 'Not all happy with the Code', The Straits Times, 16 February 2003, Singapore. 
Low, Lin Fhoong 2007, 'All hands on deck; With so many major sporting events on the horizon, SSC aims to bolster sports industry workforce', Today, 2 November 2007, Singapore.

Luis, Ernest 2005, 'The Sporty Sports Boss', The New Paper, 4 April 2005, Singapore. Malenfant, Chantal 1987, 'Sociabilities and volunteering in sports associations in France', International Review for the Sociology of Sport, 22:281-293.

May, Tim 1997, Social research issues, methods and process - Second Edition, Open University Press, UK.

Mergenhagen, Paula 1991, 'A new breed of volunteer', American Demographics, June 1991, 72-73.

Miles, M. B. and Huberman, A. M. 1994, An Expanded Sourcebook: Qualitative Data Analysis - Second Edition, Sage Publications, California, USA.

Ministry of Community Development and Singapore Sports Council 1993, Sports Excellence 2000 - Winning for Singapore, Singapore.

Ministry of Community Development and Singapore Sports Council. 2003, Code of Governance for National Sports Associations, Singapore.

Ministry of Community Development and Sports. 2001, Report of the Committee on Sporting Singapore, Singapore.

Ministry of National Development. 1989, Report of the Advisory Council on Sport and Recreation, Singapore.

Morris, Susannah 2000, 'Defining the nonprofit sector: some lessons from history', Voluntas: International Journal of Voluntary and Nonprofit Organizations, 11(1): 25-43.

National Volunteer Centre. (2003), National Volunteer Centre's 2002 Survey on Volunteerism in Singapore, [Online], Available from: http://www.nvc.org.sg/resources/Survey2002/highlights.html and http://www.nvc.org.sg/resources/Survey2002/pptpresentation_files/frame.htm [6 May, 2003].

Newman, W. H. and Wallender, H. W. 1978, 'Managing Not-for-Profit Enterprises', The Academy of Management Review, 3(000001):24-31. 
Norton, M. J. 1998, 'Volunteer and business organizations: Similar issues for collaboration', The 1998 American Society for Information Science Midyear Meeting 16-20 May 1998, Orlando, FL, 78-83.

Papadimitriou, D. A. 1994, The organisational effectiveness of Greek National Sports Organisations: an empirical application of the multiple constituency approach, PhD Thesis, Leisure Management Unit, University of Sheffield.

Papadimitriou, D. 1998, 'The impact of institutionalized resources, rules and practices on the performance of non profit sport organizations', Managing Leisure 3(4):169 - 180.

Parker, Stanley, R. 1992, 'Volunteering as serious leisure', Journal of Applied Recreation Research, 17:1-11.

Parkhouse, Bonnie, L. (ed.) 2001, The management of sport - its foundation and application, McGraw Hill, New York.

Parks, Janet, B., Zanger, Beverly, R. K. and Quarterman, Jerome (eds.) 1998, Contemporary sport management, Human Kinetics, Champaign.

Patton, Michael, Quinn 1999, 'Enhancing the quality and credibility of qualitative analysis', HSR: Health Services Research, December 1999, 34(5 Part 11):11891208.

Peh, S. H. 2004, SSC axes takraw from list of merit sports, [Online], The Straits Times Interactive, Available from http://straitstimes.asia1.com.sg/storyprintfriendly/0,1887,259573,00.html? [3 July 2004].

Peregrine, Michael, W. 2004, 'Best practices: non profit corporate governance' University Healthsystem Consortium (ed.), September, McDermott, Will and Emery:1-15.

Perry, Chad 1994, 'A Structured Approach to Presenting PhD Theses: Notes for Candidates and Their Supervisors', in ANZ Doctoral Consortium, University of Sydney.

Phan, Matthew 2006, 'Sports industry eyes doubling in GDP output', Business Times, 3 October, Singapore. 
Plumptre, Tim and Graham, John 2000, Governance in the new millenium: challenges for Canada, Institute On Governance (ed.), January, Ottawa, Ontario, Canada:127.

Pohl, Sarah, L., Borrie, William, T., et al. 2000, 'Women, wilderness, and everyday life: a documentation of the connection between wilderness recreation and women's everyday lives', Journal of Leisure Research, 32(4):415-434.

Prentice, Noel 2006, 'Blueprint for a sporting Mecca It's bold, it's ambitious and it's happening in tiny Singapore - the Lion City's plans for its Sports Hub will be the envy of Asia', South China Morning Post, 7 May.

Price, James, L. 1968, Organisational effectiveness: an inventory of propositions, Homewood: Irwin.

Price, James, L. 1972, 'The study of organizational effectiveness', Sociological Quarterly 13 (Winter):3-15.

Quah, T. H. 2008, SSA should have left changes till after the Olympics, [Online], The Straits Times, Available from http://global.factiva.com.ezproxy.library.uwa.edu.au/ga/default.aspx?imt=2 [24 July 2008].

Ramchandani, Nisha 2008, 'Olympic-sized exposure for home-grown brands', Business Times 23 February 2008.

Renz, David, O. and Herman, Robert, D. (n.d.), More theses on nonprofit organizational effectiveness, [Online], Available from: http://www.arnova.org/org_eff.php, [4 February 2006]

Richards, Lyn 1999, Using NVivo in qualitative research, Sage, London.

Robbins, S. P. and Coulter, M. 2002, Management - Seventh Edition, Prentice Hall, USA.

Roberts-Du Bord, Rhonda 1989, 'Volunteers: Motivation for involvement', NIRSA Journal, 13(2):39-40.

Rose, Arnold, M. 1955, 'Voluntary Associations under Conditions of Competition and Conflict', Social Forces, December, 34(2):159-163.

Rosenbaum, Nelson 1984, 'The competitive market model: emerging strategy for nonprofits', The Nonprofit Executive, July, pp. 4-5. 
Ross, J. 1972, 'Towards a reconstruction of voluntary association theory', British Journal of Sociology, 23:20-32.

Rothwell, J. Dan 2004, In the company of others - An introduction to communication, Second Edition, McGraw Hill, New York.

Ryan, Gery, W. and Bernard, H. Russel 2003, 'Techniques to identify themes', Field Methods, February, 15(1):85-109.

Salamon, Lester, M. and Anheier, Helmut, K. 1992, 'In search of the nonprofit sector: The question of definitions', Voluntas, 3:125-151.

Salamon, Lester, M. 1994, 'The rise of the nonprofit sector', Foreign Affairs, July/August, 73(4): 109-122.

Salamon, Lester, M. and Anheier, Helmut, K. 1998, 'On developing comparative nonprofit-sector theory: a reply to Steinberg and Young, and Ragin', Voluntas, September, 9(3):271- 281.

Salamon, Lester, M. and Dewees, Sarah 2002, 'In search of the nonprofit sector', The American Behavioral Scientist, July, 45(11):1716-1617.

Salamon, Lester, M. and Sokolwoski, Wojciech 2001, 'Volunteering in cross-national perspective: evidence from 26 countries', Working Paper, The Johns Hopkins Comparative Nonprofit Sector Project.

Scott, Jr. John C. 1957, 'Membership and participation in voluntary associations', American Sociological Review, June, 22(3):315-326.

Seale, Clive (ed.) 2004, Social research methods - A Reader, Routledge, London.

Seippel, Ornulf 2002, 'Volunteers and professionals in Norwegian Sport Organizations', Voluntas: International Journal of Voluntary and Nonprofit Organizations, September, 13(3):253-270.

Shenton, Andrew, K. 2004, 'Strategies for ensuring trustworthiness in qualitative research projects', Education for Information, IOS Press, 22:63-75.

Shenton, Andrew, K. and Hayter, Susan 2004, 'Strategies for gaining access to organisations and informants in qualitative studies', Education for Information, IOS Press, 22:223-231. 
Shilbury, David and Moore, Kathleen, A. 2006, 'A study of organizational effectiveness for national Olympic sporting organizations', Nonprofit and Voluntary Sector Quarterly, 35(1):5-38.

Singapore Service Class. (15 September 2008), [Online], Available from: http://www.spring.gov.sg/Content/WebPage.aspx?id=d1fc54a6-ad3b-47b4a455-b654ed5deefc [15 September 2008].

Singapore Sports Council. (25 July 2006). Financial statements 2005. [Online], Available from: http://www.ssc.gov.sg/SportsWeb/finance/906.pdf [25 July 2006].

Singapore Sports Council. (25 July 2006). Singapore Sports Council launches new funding model for national sports associations, [Online], Available from: http://www.ssc.gov.sg/SportsWeb/media_release.jsp?artid=5891 [25 July 2006].

Singapore Sports Council. (19 August 2008). Athlete Assistance Handbook. [Online], Available from: http://www.ssc.gov.sg/publish/etc/medialib/sports_web_uploads/high_performa nce/athletes.Par.0001.File.tmp/AthleteAssistanceSchemesOverviewFY2007.pdf [19 August 2008].

Skadian, Carl 2008, 'It's Singapore 2010', The Straits Times, 23 February.

Slack, T., 1981, 'Volunteers in amateur sport organizations: biographic and demographic characteristics and patterns of involvement' in The First Regional Symposium, International Committee for the Sociology of Sport, Vancouver.

Societies Act. [Online], Available from: http://statutes.agc.gov.sg/ [1 June 2004]. Sport England 2002, Sports volunteering in England in 2002 - a summary report, Sport England, London.

Staats, Elmer, B. 1988, 'Public service and the public interest', Public Administration Review, March/April, 48(2):601-605.

Standeven, Joy and De Knop, Paul 1999, Sport tourism, Human Kinetics, USA. Steane, Peter 2001, 'Governance: convergent expectations, divergent practices', Corporate Governance, 1(3):15-19.

Stebbins, R. A. 1996, 'Volunteering: A serious leisure perspective', Nonprofit and Voluntary Sector Quarterly, 25:211-224. 
Steers, Richard, M. 1977, 'Organisational effectiveness: a behaviorial view', in The Goodyear Series in Management and Organisations, ed. Lyman, W. Porter, Goodyear, Santa Monica, CA.

Stoker, Gerry 1998, 'Governance as theory: five propositions', International Social Science Journal, March, 50(155):17-28.

Strauss, Anselm and Corbin, Juliet 1994, 'Grounded theory methodology - An Overview', in Handbook of qualitative research, eds., N. K. Denzin and Y. S. Lincoln, Sage Publications, London.

Strigas, Athanassios, D. and Jackson, E. Newton 2003, 'Motivating volunteers to serve and succeed: design and results of a pilot study that explores demographics and motivational factors in sport volunteerism', International Sports Journal, Winter, 7(1):111-122.

Sutton, R. I. and Hargadon, A. 1996, 'Brainstorming groups in context: effectiveness in a product design firm', Administrative Science Quarterly, 41: 685-718.

Tan, Yo-Hinn 2006a, 'Tougher money rules; SSC will unveil new regulations for sports associations to ensure accountability', Today, 23 March.

Tan, Yo-Hinn 2006b, 'Athletes get their chance to be heard: MCYS' Teo will raise issues affecting sportsmen and women in Parliament', Today, 27 October.

Tan, Yo-Hinn 2006c, 'Wanted: Mindset change, sports heroes', Today, 11 November.

Tan, Yo-Hinn 2006d, 'Multi-million dollar boost for sports in schools', Today, 20 December.

Tay, Cheng Khoon 2006, 'Sports has no place for cronyism', The Straits Times, 30 July.

Teng, Sharon 2002. (18 August 2008), Tan Howe Liang, [Online], National Library Board Singapore, Available from: http://infopedia.nlb.gov.sg/articles/SIP_635_2005-01-10.html [ 18 August 2008].

The Straits Times. 16 February 2003a, Most welcome new sports hub, Singapore.

The Straits Times. 19 February 2003b, Go big-time in sport, Singapore.

The Straits Times. 13 November 2005, Rugby sixes and sevens, Singapore.

The Straits Times. 15 April 2007, Singapore sports' most wanted, Singapore. 
The Straits Times. (18 August 2008). China just too hard to beat, [Online], Available from:

http://global.factiva.com.ezproxy.library.uwa.edu.au/ga/default.aspx ?imt=2 [18 August 2008].

Thibault, Lucie, Slack, Trevor and Hinings, Bob 1991, 'Professionalism, structures and systems: the impact of professional staff on voluntary sport organizations', International Review for the Sociology of Sport, 26(2):83-99.

Tng, Peggy P. K. 2008, Transformational Leadership: A preliminary investigation for Singapore NSA, Masters of Science in Sport Management thesis, Faculty of Health and Wellbeing, Sheffield Hallam University.

Tomeh, Aida, K. 1973, 'Formal voluntary organizations: participation correlates and interrelationsips', Sociological Inquiry, 43:89-123.

Voon, Terrence 2007, 'Ex-Cuesports chief demands \$65,000 refund', The Straits Times, 19 October.

Voon, Terrence 2008, 'Kelong K.O.', The Straits Times, 24 May.

Wang, Meng, Meng 2007, 'Singapore keen on hosting 2018 Asiad', The Straits Times, 2 November.

Warriner, Charles, K. and Prather, Jane, Emery 1965, 'Four types of voluntary associations', Sociological Inquiry, 35:138-148.

Watt, David, C 2003, Sports management and administration - Second Edition, Routledge, London.

Wee, Vincent 2007, 'Private sector support needed in bid for Youth Olympics: Ser Luck', Business Times, 9 November.

Whitson, David and Macintosh, Donald 1988, 'The professionalization of power and purpose', Arena Review, 12(2):81-96.

Whittemore, Robin, Chase, Susan, K., et al. 2001, 'Validity in qualitative research', Qualitative Health Research, July, 11(4):522-537.

Williams, Trevor and Jackson, John, J. 1981, 'Involvement in a voluntary sport organization', Journal of Sport Behavior, 4:45-53. 
Wood, Barbara, Joan 1989, A structural taxonomy of national sport organizations, Master of Arts thesis, Department of Physical Education and Sports Studies, University of Alberta.

Wright, C. and Hyman, H. 1958, 'Voluntary association membership of American adults: evidence form national sample surveys', American Sociological Review, 23:284-294.

Yin, Robert, K. 1989, 'Case study research - Design and methods', in Applied Social Research Methods Series, Sage Publications, Newbury Park.

Yuchtman, E. and Seashore, E. S. 1967, 'A comparison of multiple constituency models of organizational effectiveness', Academy of Management Review, 9:606-616. 


\section{Appendices}

\section{Appendix 1 - E-Letter of invitation to focus group}

The Graduate School of Management

University of Western Australia

35 Stirling Highway

CRAWLEY WA 6009

Australia

4 May 2006

$\mathrm{Mr} / \mathrm{Ms}$

Designation

Name of national sports association

Dear Mr/Ms

\section{Invitation to participate in a focus group discussion on Tuesday 9 May 2006, 6.00pm $-7.00 p m$}

You are invited to participate in a focus group discussion on Tuesday 9 May, 6.00pm $7.00 \mathrm{pm}$, at Singapore Athletic Association Conference Room, National Stadium, Kallang. The focus group is part of a research study conducted by Angela Koh-Tan, a doctoral student from the University of Western Australia, Graduate School of Management. The aim of the study is to learn the determinants of effectiveness in Singapore sporting associations. The results of the study will contribute to her doctoral thesis. You have been selected as a participant in this study because you are either a board member, coach, elite athlete, secretariat staff, or volunteer in a national sports association.

The benefits of the study are to explore how the different groups of stakeholders perceive and interprete the effectiveness of national sports associations and to contribute to the sparse sports association management literature in Singapore. The benefit to humanity is for an improved understanding of how national sports associations can balance serving the needs of the various constituents - athletes, governing councils, management committees, secretariat staff, members, coaches and volunteers.

Your participation is voluntary and if you kindly consent, you will be asked for your views on perceptions of organisational effectiveness at the focus group session. You are free to withdraw at any time or to decline to answer any particular question. The information provided by you will be confidential and only aggregate data will be analysed. Your consent will be sought for audio-taping of the discussion. 
Any information that is obtained in connection with this study and that can be identified with you will remain confidential and will be disclosed only with your permission or as required by law. Data will be used in amalgation and personal information will be kept confidential. Data security will be ensured with notes, transcripts, computer files, and drives password protected. Only the researcher and the supervisor will be privy to the information and all records will be destroyed after five years. To maintain the confidentiality of respondents, no information or responses will be given to other person/s or organisation/s.

Your decision whether or not to participate will not affect your relationship with Angela Koh-Tan or University of Western Australia. If you decide to participate, you are free to withdraw your consent and discontinue participation at any time.

I will be happy to make known the results to you upon successful completion of the study. If you have any questions, please contact me on email: angelakohtan@gmail.com or mobile: (65) 81255762, or my supervisor, Professor David Plowman, on email: dplowman@gsm.uwa.edu.au or office telephone: (619) 64883984, or at The Graduate School of Management, University of Western Australia, 35 Stirling Highway, CRAWLEY WA 6009, Australia.

I look forward to your consent and your invaluable contribution to the focus group discussion and this research study.

Yours sincerely

Angela Koh-Tan

Doctoral student

Graduate School of Management

University of Western Australia 


\section{Appendix 2 - Transcript of focus group discussion}

Focus group discussion on Tuesday 9 May, 6.00pm -7.00pm, at Singapore Athletic Association Conference Room, National Stadium, Kallang

\begin{tabular}{|l|l|l|}
\hline Participant & National sports association & Constituent group \\
\hline S_FG & Singapore Athletic Association & Secretariat \\
\hline A_FG & Singapore Shooting Association & Athlete \\
\hline C_FG & Singapore Silat Federation & Coach \\
\hline V_FG & Triathlon Association of Singapore & Volunteer \\
\hline
\end{tabular}

\section{As a secretariat staff, coach, volunteer, and elite athlete in your national sports association, how would you define the term organisational effectiveness in the context of your NSA?}

A_FG - It can be complicated. If the NSA has good and responsible management committee members and leaders, a team that is dedicated, and a plan of short and long term goals and moving towards a target. With a core group of committee members, everything will fall in place. Quality of management is crucial. Having these group of people, elected members, see the importance of quality coaching, trials and selection process, transparency, high performance objectives, a system that works for athletes.

V_FG - What leads to effectiveness is communication. There are a lot of assumptions made about what the inter-departments are doing. There needs to be effective communication horizontally, or vertically between top and lower staff level, and is something I seldom see. That's why misunderstanding occurs. As a result, time is spent clearing the air and fire-fighting.

C_FG - Main role is to come out with an effective programme for athletes as we have been talking about growth and development and for my sport, and we have yet to reach Asian Games or Commonwealth Games levels. Effectiveness of the training programme and athlete commitment. Coach also faces a lot of problems as most of the athletes are students and we have only three full-time coaches and the rest are part-time.

S_FG - First thing is getting things done in sports and the decision-making process from the secretariat's point of view, and how fast things get done constitute effectiveness. Whether to compete, or have a plan and to implement it, who to decide to go for the competition. Sometimes, decision may take a year. So speed is important. It 
has to be prompt and on-time. It has to be fast, prompt and on time, for in sports if too slow will be over, as sport is dynamic.

\section{Based on your experience, which specific characteristics would affect sports organisations most today?}

S_FG - Today is to move towards a business-like entity with professional management and people. Committee members who are knowledgeable, clients who are athletes and coaches, with the right attitude to sports. More on athlete and coaches as business like.

V_FG - Is a culture within the NSA, where the association has a vision. Sports is inspiring and a driving force for people, not money or something tangible, but a culture. People are inspired by being in NSA if the association has a culture and with vision where staff are willing to work. It needs to have a driving force to work towards what the organisation has set. Boils down to culture that educates and inspires. It is amazing to see volunteers working hard and contributing their part. It is why the driving force is important in Singapore. For some volunteers, you may need to have tangible rewards and if an organisation is as such, they keep coming back.

S_FG - I can identify with the family-like culture that works with the old. Many of them, if not paid, they still come down. After a meet or meeting, people get together for dinners, family-like, part of it and belong, but seem to be the older generation, not the young ones. But may work if we do it differently.

V_FG - For younger ones interested to be in the scene, they want to know 'how can I get involved' and they have no idea. Need to reach out to the masses.

C_FG - Usually parents get involved as volunteers and when they come, they mingle around and join as volunteers, and do everything for the group. They bring the food and willing to help the group to organize. They are fathers, mothers and grandparents.

A_FG - What is mentioned is very relevant. From the athlete's perspective, it is about professionalism and doing things in a business-like manner. Singapore is not moving fast enough as compared to other countries. We are moving behind. Good training programmes, competition, transparent selection process, other countries are way ahead, including, adjustment to family and career, to manage athletes' sports and personal life. I am in the midst of adjusting to my career and family and I can put some time to train but they expect the athlete to have one life and that is sports. Nobody has sat with me to discuss my problem, a goal to win a medal, and all they do is say that you have not been training recently. The high performance manager does not ask about my personal life and work but concerned only about training. Having a conducive enviornment and like LY said about communication. Many just train as they are interested in sports. It is tough as they may not have an understanding spouse. To me, effectiveness is professionalism. We are like fruit trees left on our own to bear fruit and when there are no fruits, the tree will be cut. 


\section{Could you please discuss any organisational aspects or characteristics that satisfy you and you do not wish to change?}

(AT qualified that the question referred to NSA as a whole and experience relevant to the participant's position.)

A_FG - To be fair to the NSA, I do know that it is tough for them to deal with SINGAPORE SPORTS COUNCIL, prima donnas, SNOC, and coaches, when they are volunteers having a family and career with many doing out of passion. However, passion is not enough in today's world. Not in today's life as things happen so fast. The day we never get this sorted out, we will not move ahead fast. There are a lot of basics that should be in place. At least having a two-way communication, discussing about plans, goals, open and transparent selection process. Can't say we are having a trial soon as people need to train for it. There are organisations that are better.

C_FG - My workload is always increasing. As a coach, usually my athletes are students and we will ask for their school timetables. If they cannot make it, we will arrange for extra training. Usually observe what is lacking and volunteer to give them extra training. Ask them to choose between education and commitment in competition, so that their interest will not be lost. And if they have financial problems, try to help from carding and sourcing for part-time jobs. That is the best we can offer. Sometimes they train good but they need a counsellor to talk to. Sometimes they are not comfortable. (AT/researcher - what you saying is that coaches give extra training as your athletes are students and you want to have the retention objective and thus find ways to help them.) Qualified counselor in sports or personal life. Both areas are covered and don't want them changed. Sometimes because of coaches as ex-athletes and we know how they feel and what they want but they too have to understand our roles. We have to make them understand but sometimes the athlete has a special attitude and very difficult to say.

S_FG - Don't change means don't take away. Structures in core sports. Secretariat, don't take it away. Structure like secretariat of a professional association regardless of size, but change to improve the structure of the secretariat. Personal counseling is essential and NSA should have. We are currently looking for a high performance manager to help athletes manage the other aspects of athletes' lives outside sports. First is to have a plan and their commitment to the sport and if they are committed, we can see how they can achieve it. Our relay girls are doing A levels but if they are committed, we help them to stay in hostel and train to save on transportation costs. For national service boys, if they are interested, we write to Mindef to help them qualify for the Asian Games. We also get athletes into tertiary institutions. Write to SMU. A lot of athletes get into university education with poor results, talk to them about what they want in life and what they want to do in sports and what they can do. Share with them and guide them on the career. Get them to think through about what they want to do and tell them how to get there. It is a career coach role. 
A_FG - Athlete's life is complicated in Singapore. As athletes are part-time, it is important to customize a programme for them to maximize their lives. NSAs expect everyone to put in same time and effort.

S_FG- And it is tough for individual sports.

A_FG- Especially if athlete is working. For students may be easier as they have free time and less commitments as compared to one with family and financial commitments.

V_FG- The magic about being in an NSA is that everybody thinks that things can be better but everyone still goes on despite, continue to cooperate, do for the sport and keep going.

4. Would you please think of another sport governing body within or outside the country that you perceive as more effective than the one you work or deal with. Now could you identify some factors or characteristics that you think make the organisation more effective?

V_FG-Do I have to compare?

AT/researcher - There must be a base for comparison.

V_FG - Commonwealth Games, 15,000 volunteers, and based on age, many are old as they are chairman and directors of organisations, yet they give road directions. They call the shots in their working lives and now they take instructions and take part in these events, waving flags to be part of the action. It is part of the culture and how the people generally perceive sports and how they want to participate.

C_FG-My parents will say 'got money or allowance otherwise wasting my time'.

AT/researcher (probe) - Why are they proud to be part of the event?

S_FG- It is Australia. It is national pride.

V_FG- It could be that they are proud to be part of the event. To be selected to be a volunteer, they have to be interviewed. Their children are represented even.

S_FG- In the Arafura Games in Darwin though smaller scale, they have volunteers and are well-organized. People go all out to make others good.

V_FG- In Australia, being laid back where work is concerned, but they do it fast (in sports). 
C_FG- In some cases I had to wait for two hours for transport and schedule in Asian competitions. In Asia, we faced this problem where our boys and girls have to wait for transport and were told not to expect things tip top. Changes not informed.

V_FG- When I went to Singapore Sailing for a one and a half hour interview, Andrew Sanders, now Executive Director, brought me through the vision of where the association wanted to be and shared the plans. I was impressed that he got everything all planned out. The plans were concrete, something of what you are looking for, 3 to 5 years. He convinced me such that I wanted to be part of Singapore Sailing.

A_FG-Some sports flourish in other countries because of long history. When I was in Italy, for a shooting competition, we could go to a farm and in the farm there was a range that allowed people to shoot for competition and win medals here. You could shoot for fun in Sunday competitions. It is fun and shooting become the second national sport in Italy. They have the culture but we can't do it here as we can't bring a gun. Different restrictions. And Singapore government control is tight and that restricts the sport development. In sailing, towing a small boat to another place, have to sail over. In Singapore we are effective in some way but there are controls which prevent sports to promote itself.

S_FG-From what I know, if I could say, badminton seems a little more systematic and lately, is in a stage that is quite well organized. The secretariat structure is adequate and they have plans. They are knowledgeable and can articulate vision and because of that they are able to get results. Through planning, they get the right people in the right places. In some roles, they have people with money, and that is one thing they do well. .The President, being a minister, has a lot to do with it. Politics still have a large part to play. Some associations move a lot faster because of this In politics, among ministers, they get ministers to help out but some may not take up. Minister Lim Swee Say chose badminton. Football is the only association that has board members appointed by government while the rest is left to the ministers to make their own decisions. Back to question 3, on the characteristics that I don't want to change, is the international network capacities and the old generation in SAA should continue. They have a lot of clout. Loh Lin Kok can get things done through calls. Something that is essential in the NSA is to get things done. Loh Lin Kok calls his Asean counterparts and at the national level, he can get our athletes into international competitions or gets other countries to send officials to help in our competitions, supporting one and another in open championships. For example, right now through good relations with China, there are goodwill exchange programmes.

\section{Would you discuss some major problems that your sports organisation has encountered that inhibited its effective functioning?}

AT/researcher: Two or three problems. 
S_FG- Need knowledgeable people not idiots even if they have the passion. Knowledgeable people in management capacity. If they can't think, they can't contribute effectively especially in selection decision making. Don't go to the ground and don't know what is happening and they make decisions about selection.

C_FG- Committee members are idiotic. Committee members are from clubs. For example, there was an athlete who was involved in training at the ground and volunteered to be a part-time coach but the Master don't allow giving the excuse that they are not ready. The Master not happy with them volunteering as part-time coaches. The Master will take them out from club and this affects their active national level representation. Committee members are against the athlete but not sure what are the reasons are, be it personal or others. Not sure of the real reason.

S_FG- could be personal or selfish reason.

\section{Is there something specifically associated with the organisation's way of functioning that inhibits you carrying out your own responsibilities within the sport organisation?}

V_FG- No consensus among management. About the main thing that holds athlete back, if the boss don't communicate, the small fry will not know. Professionalism has to come in place for sports.

A_FG- I want to see better qualified and professional full time staff. Some NSA could have GM and have aspiration for sports but high performance managers who are not qualified in high performance, may not know the basic requirements, and in turn give a lot of frustration to the rest. NSA may have dedicated Exco members but if they have no professional administrative staff that is core and important, and Exco members do not have the time, they would not be able to implement. Also, the admin group has to know what they are doing.

S_FG- Sometimes they know. It is the decision making process. I am stifled by the decision making process. That must be a point where someone must be able to call the shots for critical decisions. Process must be prompt, not too long. Also whether management and board understand the GM role, and my function is administrative. I want to get the directions, not directives and move from there. Should not expect the CEO to just take instructions. Should not limit the capacity of the person.

C_FG- Management committee just want title but not the work.

S_FG-Some are not happy when you do the work. 
7. If you were asked to make some changes towards the organisational effectiveness of the sport organisation, what would these be?

C_FG- Change sincerity from athlete to board members. Work together and stop fighting and quarrelling. We want the sport to grow.

S_FG- Knowledgeable board members who know their roles and sport well. Second would be the capacity and ability and resources to equip the secretariat with more professional people. Pay peanuts, you get monkeys.

A_FG- Professionalism is the way for athletes to have good results. In the midst of your commitments, one needs to come down for training, instead of complaining. Attitude of athletes. Every stakeholder has a role to play and things will work out much better.

\section{Can you mention some organisational objectives that your sport organisation is pursuing or trying to achieve?}

S_FG- We have plans. Not sure whether to share with the committee members. Sincerity, everyone in the committee is sincere but they see things differently. They have different perceptions. Objectives of high performance, getting people in sports, raise money, revenues streams. High performing, self-sufficiency.

A_FG- My NSA has a strategic plan and they are reviewing the plans but not done so. They want to build up a bigger base of shooters in Singapore, want to win 2 medals in 2010 Asian Games, bring in Asian Clay Championships and events into Singapore. But they have not done enough communication to the community. Need to tell people and not keep it in the cupboard.

V_FG- Want to raise awareness for the sport and increase participation. As for high performance, all talk and no action.

C_FG- To bring silat into Commonwealth and Asian Games levels.

9. From your own perspective, what criteria would you use to evaluate the overall effectiveness of this organisation?

A_FG- depends on the types of goals, KPIs to see NSA has been doing their work or not.

C_FG- goals and KPIs are criteria.

S_FG- goals and KPIs are criteria, but there are other indicators such as whether sports is successful or not for example climate within the fraternity, response from clients, 
participants and the public, most direct feedback will be from staff and volunteer coaches. While goals and KPIs are clear cut, they must be balanced by the feedback. Can get carried away for attaining a goal.

V_FG- climate of the NSA. Volunteers reports to NSA. Each OIC supposed to know their scope of work and they may have problem with what they have to do. As a volunteer, you may have time to observe. When committee argues in public, that is not good. This may give impression that the NSA is not effective.

C_FG- As coach, feedback is important.

AT/researcher - feedback is formal or informal?

C_FG-Survey form is good. As name is asked, no one will give honest feedback.

AT/researcher - open or structured?

C_FG-Open questionnaire.

S_FG- I used to do up a document to evaluate NSA. This has to be used correctly such as validity and reliability.

A_FG- there may have degree of subjectivity.

S_FG- Five areas are used. High performance, sports development, climate, management and administration, and achievement. The are not ranked. Each has a questionnaire on a Likert scale of 1 to 7 . No qualitative data is sought. Instrument can be used by different groups of people. Difficult part is the validity and reliability. For example, people have to be clear of the scale as they may interpret the scale differently. Normally, we will discuss the scale. Assessment is done by different group of people. Six groups including NSA.

\section{What sort of mechanisms of monitoring organisational effectiveness would be appropriate for the sports organisation?}

AT/researcher - Are surveys, open questionnaires, KPIs enough?

A_FG- KPIs determine the different objectives and sub-objectives for each area of concern to achieve. These objectives could be long or short term.

V_FG- implement all the various mechanisms and to see consistency across the instruments.

AT/researcher - how to use some of these to check reliability? 
A_FG- The SQA model is used to assess the NSA, Singapore Sailing, as an evaluation tool. It is in progress but not sure if it is relevant.

S_FG- Besides all these, the informal feedback is a good yardstick as a monitoring tool, such as coaches are fighting. The informal feedback is like a thermometer. Can meet goals but athletes can be unhappy. What is a perfect NSA? That has to be health.

A_FG- NSA is an organic organisation, not product, hardware but software. NSA is so dynamic, people relationship, politics. There are so many things and it is difficult to find a tool for that. Difficult to determine perfect mechanism. Different mechanisms for different NSA. Can use a system that is customised to the NSA. Possible to use it as a guide.

S_FG- look at overall or specific, for example, effectiveness of leadership.

A_FG-Different style for different organisations.

S_FG- May need different leadership. For example, FAS high on management but may not translate into results. FAS is well-oiled but no results so does it mean that they are not effective? What do you want out of effectiveness?

A_FG-FAS have brought teams to Singapore and contributed to the sport industry but not there in terms of high performance.

S_FG-FAS is good in bringing up sports but not high performing results.

\section{END OF TRANSCRIPT.}




\section{Appendix 3 - Assurance of confidentiality and anonymity}

\section{Dear Respondent}

Thank you for providing me with your email address. I am a doctoral student with the Graduate School of Management in University of Western Australia and have attached a letter which will give you an idea of the research that I am undertaking.

The aim of the study is to explore the determinants of effectiveness in Singapore sporting associations. I have been seeing athletes, coaches, secretariat staff and board members and hearing their views on perceptions of effectiveness in their respective associations.

This is a private study and self-sponsored. No government body or any other agency is involved in this research. If you agree to let me hear your views, please be assured that your name will not be used at all and only aggregate data will be reported.

To give you some background on myself, I have been involved in sport and wellness management education for about a decade and am co-author of a book entitled 'Managing Sport: Concepts and Issues of Non profit Organisations.' I have taught in two polytechnics, and part-time in two universities. My research interest is in non profit sport management and I hope to contribute to the sparse sport management literature in Singapore hence the undertaking.

I shall call you to see if you are agreeable to see me for about 30 minutes if you would be so kind as to respond to this email. I shall be asking you about your perceptions and there is no right or wrong answer.

If you have any questions about the contents in this email or the letter attached please do clarify with me directly. You can reach me on my mobile shown below or via this email address.

Looking forward to a positive reply and your views.

Have a good day

Angela Koh-Tan

81255762 (m) 


\title{
Appendix 4 - Reminder email
}

\author{
Dear Respondent \\ I am resending the email once again to you in case you missed it the first time. I wonder if you would be \\ so kind as to give me 30 minutes of your time for an interview that will contribute to my doctoral \\ research which aims to uncover perceptions of effectiveness in national sports associations. \\ I can see you at any time of your convenience so as not to impose on you. Would really appreciate if I \\ could have your important views on the subject. \\ Have a good weekend \\ Angela Koh-Tan \\ 81255762
}




\title{
Appendix 5 - Clarification of private endeavour
}

\author{
Dear Respondent \\ Thank you for your kind consideration. While disappointed that you will not be able to spare 30 minutes \\ of your time for me to get a chance to hear your views, I would like to take this opportunity to wish you \\ success in your helmsmanship of the association. \\ Should you change your mind, I can be contacted via the same email and mobile listed below. My last \\ phase of primary data collection will possibly end in February 2007. \\ May I also clarify that this study is a private research endeavour and self-sponsored. The work will only \\ be seen by the researcher, the researcher's supervisor Professor David Plowman and the University of \\ Western Australia who will be assessing the researcher. No names will be quoted or used in the \\ dissertation. For reporting purposes, all respondents will be assigned a code to ensure confidentiality. \\ Lastly, I shall not be interviewing anyone from the Singapore Sports Council as the constituent groups \\ for the research are athletes, coaches, secretariat and board members. Thank you anyway for your kind \\ suggestion. \\ Have a good weekend and a wonderful year ahead \\ Angela Koh-Tan \\ 81255762
}




\title{
Appendix 6 - Email of thanks
}

\author{
Dear Respondent \\ Thank you very much for your time and invaluable information rendered. I am indeed grateful for your \\ help and the other referrals provided. \\ In all my dealings with your association over the years, I must say that the secretariat staff and coaches \\ have always been accommodating to all and sundry. This certainly speaks well of the organisational \\ culture. While the financial control issue may be a slight setback, your association can only bounce back \\ wiser and stronger. \\ May I also take this opportunity to congratulate you on the excellent work that you have done at the \\ association for the past eight years and may you have more fruitful and successful years ahead in both \\ your personal and public endeavours. \\ Have a good week \\ Angela Koh-Tan \\ 81255762
}




\section{Appendix 7 - E-Invitation and consent forms for interview}

The Graduate School of Management

University of Western Australia

35 Stirling Highway

CRAWLEY WA 6009

Australia

28 December 2006

$\mathrm{Ms} / \mathrm{Mr}$

National athlete, national coach, secretariat staff, or board member

Singapore National Sports Association

Dear Ms/Mr

\section{Request for a personal interview}

You are invited to be part of a research study conducted by Angela Koh-Tan, a doctoral student from the University of Western Australia, Graduate School of Management. The aim of the study is to explore the determinants of effectiveness in sporting associations in the Singapore context. The results of the study will contribute to Angela's doctoral thesis. You have been selected as a participant in this study because you are a national athlete, coach, secretariat staff, or board member, in a national sports association. The interview will be for 30 to 45 minutes.

The benefits of the study are to explore how the different groups of stakeholders perceive and interpret the effectiveness of national sports associations. The study will contribute to the sparse sports association management literature in Singapore. The benefit to humanity is for an improved understanding of how national sports associations can balance serving the needs of the various constituents - athletes, governing councils, management committees, secretariat staff, members, coaches and volunteers.

Your participation is voluntary and if you kindly consent, you will be asked for your views on perceptions of organisational effectiveness at the interview session. You are free to withdraw at any time or to decline to answer any particular question. The information provided by you will be confidential and only aggregate data will be analysed. Your consent will be sought for audio- recording of the interview.

Any information that is obtained in connection with this study and that can be identified with you will remain confidential and will be disclosed only with your permission. Data will only be used in aggregated form and any and personal information will be kept 
confidential. Data security will be ensured. All notes, transcripts, computer files, and drives are password protected.

This self-sponsored study is a private endeavour. Only the researcher and the supervisor will be privy to the information and all records will be destroyed after five years. To maintain the confidentiality of respondents, no information or responses will be given to other person/s or organisation/s.

Your decision whether or not to participate will not affect your relationship with Angela Koh-Tan or University of Western Australia. If you decide to participate, you are free to withdraw your consent and discontinue participation at any time.

I will be happy to make known the results to you upon successful completion of the study. If you have any questions, please contact me on email: angelakohtan@gmail.com or mobile: (65) 81255762, or my supervisor, Professor David Plowman, on email: dplowman@gsm.uwa.edu.au or office telephone: (618) 64883984, or at The Graduate School of Management, University of Western Australia, 35 Stirling Highway, CRAWLEY WA 6009, Australia.

I look forward to your consent and your invaluable contribution to the interview and this research study.

Yours sincerely

Angela Koh-Tan

Doctoral student

Graduate School of Management

University of Western Australia 


\section{CONSENT AGREEMENT TO BE A PARTICIPANT IN THE STUDY}

Your signature indicates that you have read and understood the information provided above, that you agree to participate willingly, that you may withdraw your consent at any time and discontinue participation without penalty, that you will receive a copy of this form, and that you are not waiving any legal claims, rights or remedies.

Name of participant:

Signature:

Date:

\section{CONSENT AGREEMENT FOR AUDIO RECORDING}

I have received an adequate description of the purpose and procedures for audio recording sessions during the course of the proposed research study. I give my consent to allow the interview to be audio recorded during participation in the study, and for those audio recording to be heard by persons involved in the study, as well as for other professional purposes as described to me. I understand that all information will be kept confidential and will be reported in an anonymous fashion, and that the audio recording will be erased after an appropriate period of time after the completion of the study. I further understand that I may withdraw my consent at any time.

Name of participant:

Signature:

Date: 